Daniel Manzi

\title{
DETERMINAÇÃO DE PARÂMETROS DO MODELO PRESSÃO- VAZAMENTO PARA SETOR DE DISTRIBUIÇÃO DE ÁGUA DA CIDADE DE PIRACICABA, SP
}

Dissertação apresentada à Escola de Engenharia de São Carlos da Universidade de São Paulo, como parte dos requisitos para a obtenção do título de Mestre em Hidráulica e Saneamento

Orientador: Prof. Dr. Rodrigo de Melo Porto

São Carlos 


\section{AGRADECIMENTOS}

- A Deus, pelo dom da vida e pelo prazer de poder vivê-la;

- Aos meus pais, Mário e Ermelinda, pelo exemplo de vida, humildade, persistência e sabedoria;

- Aos meus irmãos, Gerson e Rosângela, pelo companheirismo e presença;

- A Emanuela pelo amor, cumplicidade e paciência;

- Ao Prof. Rodrigo pela atenção e orientação no trabalho e a Profa. Luiza Fernanda, pelos auxílios e conselhos;

- Ao presidente do SEMAE Piracicaba, Eng. José Augusto R. B. Seydell e ao Diretor de Operação e Manutenção, Eng. Renato Takami, pelo incentivo e apoio ao trabalho desde sua concepção;

- A todos os amigos do SEMAE: Hidrometria (Ronaldo, Tuta, Cida, Giba, Dal, Lube, Bilú e Maé), Pitometria (Zé, André e Mauro), Cadastro (Tião, Paulo, Zé Carlos e Maria), Pedro Caes, Sérgio Abreu e muitos outros que, embora não constem aqui, mereçam um muito obrigado;

- Aos amigos do LABSIN (Tinil, Peter, Alexandre, Kleber, Zé, Hugo, Carlão);

- Aos amigos de São Carlos (Ana Rosa, Dani, Quaresma, Sá, Pavi, Denise, Wesley, Luciana, Miriam e Gisele Saab);

- Aos Degustadores, pelo apoio implícito em cada brinde;

- A CAPES, pela bolsa concedida. 


\section{SUMÁRIO}

LISTA DE FIGURAS i

LISTA DE TABELAS iii

LISTA DE ABREVIATURAS iv

LISTA DE SÍMBOLOS v v

RESUMO vii

ABSTRACT viii

1. INTRODUÇÃO E JUSTIFICATIVA 1

2. OBJETIVOS 4

3. REVISÃO DA BIBLIOGRAFIA PERTINENTE 5

3.1 Técnicas físicas de quantificação das perdas em sistemas de abastecimento 5

3.2 Conceito de modelagem matemática e calibração de redes 12

3.3 Pesquisa operacional na redução de vazamentos com redução de pressão 14

$\begin{array}{lll}3.4 & \text { Estatística e amostragem } & 17\end{array}$

3.5 Métodos de otimização 19

3.6 Modelagem de demandas de consumo 21

4. MATERIAIS E MÉTODOS 25

4.1 Setor estudado 26

4.2 Equipamentos envolvidos 29

4.3 Estudo da vazão mínima noturna 34

4.3.1 Determinação dos parâmetros de vazamento através da VMN 34

4.3.2 Emprego de descargas de rede 35

4.3.3 Monitoramento da VMN - CEP 37

4.4 Balanço hídrico mensal corrigido 39

4.4.1 Estimativa dos erros de indicação 40

4.5 Modelo de GERMANOPOULOS \& JOWITT (1989) 41

4.6 EPANET 42

4.7 Modelo hidráulico do setor 45

4.8 Busca Direta Univariada 47

4.9 Simulador Hidráulico $\quad 50$

4.9.1 Simulador hidráulico sob consumo noturno nulo 50

4.9.2 Simulador hidráulico sob demanda de consumo dirigida pela pressão 51 
5. RESULTADOS E DISCUSSÕES 56

5.1 Coleta de dados 56

5.2 Controle Estatístico do Processo - CEP 60

5.3 Estimativa dos erros de micromedição 61

5.3.1 Avaliação do tempo de permanência em vazões limites de medição 67

5.4 Índices globais $\quad 71$

5.5 Simulações sob consumo noturno nulo 72

5.5.1 Simulações sob patamares de redução de pressão 72

5.5.2 Simulações sem vazamento pontual 75

5.5.3 Simulações com vazamento pontual 76

5.6 Simulações sob consumo diurno e vazamento dirigidos pela pressão $\quad 78$

5.6.1 Simulações com Modelo I de demanda de referência de consumo 78

5.6.2 Simulações com Modelo II de demanda de referência de consumo 79

5.7 Avaliação das rugosidades adotadas no modelo hidráulico do setor 81

6. CONCLUSÕES 84

7. REFERÊNCIAS BIBLIOGRÁFICAS 86

$\begin{array}{ll}\text { ANEXOS } & 91\end{array}$

I Setor Alvorada: malha hidráulica, arruamentos e referências.Escala 1:2000 91 


\section{LISTA DE FIGURAS}

$\begin{array}{lll}\text { Figura 3.1 Relação entre pressão e vazamentos } & 15\end{array}$

$\begin{array}{llr}\text { Figura 3.2 } & \text { Teste de hipótese } & 19\end{array}$

Figura 4.1 Materiais componentes do setor Alvorada 26

Figura 4.2 Aspecto da caixa de proteção da VRP na entrada do setor 28

Figura 4.3 Curva de desvios dos medidores de vazão tipo Woltman horizontais 29 de 100 mm de diâmetro nominal

Figura 4.4 Descarga D22 (Sol Nascente) com medidor e coletor de dados 30

Figura 4.5 Descarga D96 (Alvorada) com medidor e coletor de dados 31

Figura 4.6 Aferição dos sensores de pressão em bancada de testes da 31 Hidrometria

Figura 4.7 Curva de aferição dos sensores de pressão 32

Figura 4.8 Tela do software CDLWin de programação e leitura dos coletores 33 de dados

Figura 4.9 Componentes da VMN 34

Figura 4.10 Acionamento de descarga de rede (D96 - Alvorada) 36

Figura 4.11 Análise preliminar do acionamento das descargas 36

Figura 4.12 Propagação das descargas no software EPANET 37

Figura 4.13 Curva característica de erros de hidrômetros taquimétricos 40

Figura 4.14 Caminhamento do método de busca direta univariada 48

Figura 4.15 Fluxograma do método de busca direta univariada 49

Figura 4.16 Fluxograma do simulador hidráulico com consumo noturno nulo 51

Figura 4.17 Curva de FUJIWARA \& LI (1998) 53

Figura 4.18 Curva de TABESH \& KARIMZADEH (2000) com $n=2 \quad 53$

Figura 4.19 Curva EXPONENCIAL (2003) 53

$\begin{array}{lll}\text { Figura 4.20 } & \text { Curva SENOIDAL (2003) } & 53\end{array}$

Figura 4.21 Fluxograma do simulador hidráulico com vazamentos e consumos 55 dirigidos pela pressão

Figura 5.1 Instalação típica de sensor de pressão 56

Figura 5.2 Localização dos pontos monitorados 57

$\begin{array}{lll}\text { Figura 5.3 Dados coletados no setor Alvorada } & 58\end{array}$ 
Figura 5.4 Detalhe dos dados coletados durante descargas e patamares de 59 redução de pressão

Figura 5.5 Monitoramento da VMN do setor Alvorada 60

Figura 5.6 Curvas de erros de indicação por estrato 64

Figura 5.7 Erros de indicação por faixa de totalização (gráfico de barras) 65

Figura 5.8 Curva de erros de indicação por faixa de totalização 65

Figura 5.9 Curvas dos erros de indicação em função do tipo de acionamento, 67 idade e fabricante

Figura 5.10 Instalação típica de medidor com coletor de dados 68

Figura 5.11 Curvas coletadas de vazão de entrada em ligações residenciais 71

Figura 5.12 Variação do coeficiente C1 em função da redução de pressão 74

Figura 5.13 Variação do expoente N1 em função da redução de pressão

Figura 5.14 Sobreposição das curvas de consumo dirigido pela pressão $\quad 81$ 


\section{LISTA DE TABELAS}

Tabela 4.1 Materiais componentes do setor Alvorada 26

Tabela 4.1 Características dos medidores de vazão tipo Woltman utilizados 29

Tabela 4.3 População do parque de medidores do setor Alvorada 40

Tabela 4.4 Rugosidades absolutas empregadas no modelo do setor Alvorada 46

Tabela 4.5 Equações empregadas de demanda de consumo dirigido pela 52 pressão

$\begin{array}{lll}\text { Tabela 5.1 } & \text { Pontos monitorados no setor Alvorada } & 57\end{array}$

Tabela 5.2 População e amostragens dos hidrômetros dos setor Alvorada 62

Tabela 5.3 Erros de indicação observados e esperados por estrato e vazão 63

Tabela 5.4 Erros de indicação por faixa de totalização 65

Tabela 5.5 Erros de indicação em função do tipo de acionamento, idade e 66 fabricante

Tabela 5.6 Índices globais do setor Alvorada 71

Tabela 5.7 Resultados com simulação simultânea dos quatro patamares $\quad 73$

$\begin{array}{lll}\text { Tabela 5.8 } & \text { Resultados com simulação individual de cada patamar } & 73\end{array}$

Tabela 5.9 Resultados com calibração sem vazamento pontual 76

Tabela 5.10 Resultados com calibração com vazamento pontual 77

Tabela 5.11 Resultados das calibrações com Modelo I 79

Tabela 5.12 Resultados das calibrações com Modelo II 80

Tabela 5.13 Resultados obtidos com variação dos valores das rugosidades 82 iniciais 


\section{LISTA DE ABREVIATURAS}

ABNT Associação Brasileira de Normas Técnicas

ASCII American Standard Code for Information Interchange

AWWA American Water Works Association

BABE Bursts and Backgroung Estimates

BBL Bureau Brasileiro Ltda, empresa de consultoria

C++ $\quad$ Linguagem computacional

CA Tubo em Cimento Amianto (Fibrocimento)

CDLWin Cosmos Data Logger, dispositivo eletrônico de coleta de dados

CEP Controle Estatístico do Processo

DEFoFo Tubo em PVC, com diâmetro externo igual aos tubos em FoFo

EPANET Simulador hidráulico da Environmental Protection Agency, agência norte-americana

FoFo Ferro Fundido

INMETRO Instituto Nacional de Metrologia

IPEM Instituto de Pesos e Medidas

LABSIN Laboratório de Simulação Numérica, SHS/EESC/USP

NBR Norma Brasileira Registrada

OPTO Dispositivo óptico de saída de dados para coletores eletrônicos

PVC Tubo em Cloreto de Polivinila

REED Dispositivo magnético de saída de dados para coletores eletrônicos

RS Estado do Rio Grande do Sul

SANASA Sociedade de Abastecimento de Água e Saneamento S/A (Campinas, $\mathrm{SP})$

SEMAE Serviço Municipal de Água e Esgoto de Piracicaba, SP

SHS Departamento de Hidráulica e Saneamento

SP Estado de São Paulo

USP Universidade de São Paulo

VMN Vazão Mínima Noturna

VRP Válvula Redutora de Pressão 


\section{LISTA DE SÍMBOLOS}

$\bar{X}$

A

C1

$c_{l}$

$\boldsymbol{D}$

DR

DTotal

$f$

FO

FT

H

$\boldsymbol{H}^{\text {des }}$

$\boldsymbol{H}^{\text {min }}$

$i$

ind

LC

LIC

$L_{i j}$

LSC

M

n

$N$

N1

NN

$n p$

NT

obs

$\mathbf{P}$

$\boldsymbol{P}_{i j}{ }^{A V}$
Média amostral

Área

Coeficiente de vazamento, em L/s.m

Coeficiente de vazamento no modelo de GERMANOPOULOS \& JOWITT (1989)

Diâmetro, descarga ou demanda

Demanda de consumo de referência

Demanda total (consumo + vazamento)

Fator de atrito na Fórmula Universal de perda de carga

Função Objetivo

Fator temporal de consumo

Pressão

Carga de pressão desejada ou de saturação

Carga de pressão mínima de abastecimento

Iterações

Indicadores de parada do processo de otimização

Limite central de controle

Limite inferior de controle

Comprimento do trecho entre os nós $i$ e $j$

Limite superior de controle

Número de pontos de vazão monitorados

Número de elementos amostrais, número de nós, variável do modelo de TABESH \& KARIMZADEH (2000)

Número de pontos de pressão monitorados

Expoente de vazamento

Número de nós

Número de padrões hidráulicos considerados

Número de trechos

Símbolo que denota valores observados

Pressão

Pressão média entre os nós $i$ e $j$ 


\begin{tabular}{|c|c|}
\hline Q & Vazão \\
\hline Qmáx & Vazão máxima \\
\hline Qmin & Vazão mínima \\
\hline$Q n$ & Vazão nominal \\
\hline$Q t$ & Vazão de transição \\
\hline $\operatorname{Re}$ & Número de Reynolds \\
\hline$R m$ & Amplitude média \\
\hline$s^{2} X$ & Variância populacional \\
\hline$S_{i j}$ & Vazamento entre os nós $i$ e $j$ \\
\hline sim & Símbolo que denota valores simulados \\
\hline$t$ & $\begin{array}{l}\text { Limites estatísticos tabelados de t-Student, tamanho do passo no } \\
\text { método de busca direta univariada }\end{array}$ \\
\hline$V$ & Vazamento \\
\hline$w \boldsymbol{H}$ & Peso atribuído aos desvios de pressão \\
\hline$w Q$ & Peso atribuído aos desvios de vazão \\
\hline$X_{q}, X_{q+1}$ & Vetor de variáveis otimizadas no método de busca direta univariada \\
\hline$\Delta$ & Tolerâncias do modelo de calibração \\
\hline$\alpha_{q}$ & Tamanho do passo no método de busca direta univariada \\
\hline$\delta m$ & Desvio sistemático de micromedição \\
\hline$\varepsilon$ & $\begin{array}{l}\text { Rugosidade absoluta, parcela do passo } t \text { a ser testado no método de } \\
\text { busca direta univariada }\end{array}$ \\
\hline$\theta_{i j}$ & $\begin{array}{l}\text { Área de vazamento por unidade de área de tubulação em trecho entre } \\
\text { os nós } i \text { e } j\end{array}$ \\
\hline 0 & Adimensional de consumo dirigido pela pressão \\
\hline
\end{tabular}




\section{RESUMO}

MANZI, D. (2004). Determinação de parâmetros do modelo pressão-vazamento para setor de distribuição de água da cidade de Piracicaba, SP. São Carlos, 2004, 92p. Dissertação de mestrado, Escola de Engenharia de São Carlos, Universidade de São Paulo.

A redução das perdas em sistemas de distribuição de água tem se tornado, além de uma questão ética, um determinante da eficiência e mesmo da sobrevivência das concessionárias destes serviços. A quantificação e determinação da natureza das vazões perdidas, que possuem relação íntima com as pressões de operação, são aspectos que ainda merecem análises mais profundas e práticas. Os parâmetros do modelo pressãovazamento permitem o detalhamento das perdas físicas e foram obtidos por meio de calibrações para um setor de distribuição de água da cidade de Piracicaba, SP, em padrões hidráulicos distintos - sob hipótese de consumo noturno nulo (vazão mínima noturna), descargas de rede, patamares de pressão e sob consumo diurno dirigido pela pressão através de curvas encontradas na literatura e propostas. Os resultados obtidos indicaram que os valores dos parâmetros do modelo pressão-vazamento não são fixos, mas variam conforme o padrão hidráulico de operação da rede. Estudos acerca do parque de hidrômetros e seus desvios de indicação também foram realizados, em conjunto com uma análise das vazões típicas de abastecimento residencial, e apontaram para fortes erros de medição em razão do uso de reservatórios domiciliares.

Palavras-chave: redes de distribuição de água, modelo pressão-vazamento, perdas físicas e não-físicas, hidrometria, consumo dirigido pela pressão, vazões típicas domiciliares. 


\begin{abstract}
MANZI, D. (2004). Determination of parameters of the pressure-leakage model for a water supply network of Piracicaba city, SP. São Carlos, 2004, 92p. Master's dissertation, São Carlos School of Engineering, University of São Paulo, Brazil.
\end{abstract}

Losses reduction on water supply networks came to be, beyond the ethical question, a condition for efficiency and even survival of enterprises which develop those services. Quantification and determination of the nature of leakage, which are closely related to operational pressure, are aspects which still claim for deeper and more practical analysis. Parameters to the pressure-leakage model allows to detail physical losses at one given system, and they were obtained throughout employment of distinct hydraulic patterns - minimal night flow (no usage), network flush situations, pressure levels and day usage driven by pressure from curves found on lectures and author's propositions when proceeding calibration at a water supply section at the Piracicaba city, SP. Achieved results have shown that pressure-leakage model parameters values are not constant, but really change according to network's operational hydraulic pattern. Studies concerning section's water flow meters and its measuring deviation were also done, and joined to an analysis of typical patterns of home usage flows; they have pointed to huge metering errors because of employment of home reservoirs.

Keywords: water supply networks, pressure-leakage model, unaccounted-for-water, water metering, usage driven by pressure, typical usage flows. 


\section{INTRODUÇÃO E JUSTIFICATIVA}

Diante do custo crescente da água potabilizável e seu tratamento, bem como da atual escassez dos recursos hídricos, a necessidade de redução das perdas em sistemas de distribuição de água tem se estendido além da questão ética, tornando-se também uma estratégia de sobrevivência das companhias de saneamento.

Em face de percentuais perdidos inadmissíveis de água captada e quimicamente tratada, os serviços vêm realizando auditorias em seus sistemas a fim de identificar e sanar as origens das perdas. As perdas não-físicas são abordadas através de atualização de medidores e revisão do cadastro comercial e de receita. As perdas físicas são tratadas através de pesquisas sistemáticas de vazamentos, substituição e reabilitação de redes, emprego de novos materiais e tecnologias, bem como redução de pressão; esta última medida se destaca pelo caráter mais efetivo e custo acessível.

Tais estratégias de redução de vazamentos são relativamente bem conhecidas e viáveis, e vêm sendo aplicadas em parcela crescente dos sistemas de distribuição.

Técnicas efetivas que permitam a quantificação e determinação da natureza dos volumes perdidos por vazamentos são necessárias, uma vez que parte considerável dos sistemas de distribuição de água apresenta entre 30 e 50 anos de idade e intervenções devem ser feitas antes do final da vida útil dos sistemas implantados, para viabilizar boas práticas de manutenção.

Os parâmetros do modelo matemático pressão-vazamento, por traduzirem diretamente características hidráulicas e operacionais do sistema, revelam-se índices mais eficientes do que as relações percentuais obtidas por balanço hídrico em determinados meses e sob dadas circunstâncias. Índices absurdos são encontrados, por 
vezes, devido a problemas no isolamento hidráulico de setores e erros sistemáticos de macro e micromedição, principalmente.

As propriedades das técnicas físicas de quantificação de vazamentos são ilustradas por diversos autores (SILVA et al., 1998; TUCCIARELLI et al., 1999; LAMBERT et al., 2000; LAMBERT \& HIRNER, 2000). O uso da vazão mínima noturna (VMN) através de testes noturnos de campo é defendido e incentivado como alternativa acessível às companhias de saneamento (LAMBERT \& HIRNER, 2000; KUROKAWA \& BORNIA, 2002). Também balanços hídricos mensais, sistematicamente corrigidos pelos erros de medição e cadastro comercial, permitem a obtenção de índices e parâmetros seguros e confiáveis (CARVALHO FILHO et al., 2000; RECH, 1999). Ainda assim, os métodos encontrados na literatura merecem tratamento estatístico mais robusto no processamento dos erros de medição em hidrômetros, aferidos em laboratório.

A simulação hidráulica que considera demandas de consumo dirigidas pela pressão é aplicada a estudos de confiabilidade de sistemas de distribuição de água e vêm sendo desenvolvida e empregada em modelos de simulação e operação por diversos autores (WAGNER et al., 1988; CHANDAPILLAI, 1991; GUPTA \& BHAVE, 1996; FUJIWARA \& LI, 1998; MARTINEZ et al., 1999; TABESH \& KARIMZADEH, 2000; OBRADOVIC, 2000; SOARES, 2003).

O conjunto de medidores de um sistema de distribuição, além de ser determinante da entrada de receita aos cofres da concessionária dos serviços, é também a principal fonte de conhecimento e monitoramento de dados de consumo e faturamento dos sistemas implantados. Produzidos ao longo dos anos, com vários modelos, tipos e características, os hidrômetros são instrumentos de medida relativamente frágeis e imprecisos, mas com características metrológicas definidas e previsíveis. 
Assim, a boa hidrometria suporta a entrada justa e previsível de receita e permite a avaliação segura de dados do sistema de distribuição com base em valores consumidos e faturados.

Entretanto, são raros os trabalhos que aplicam diretamente os métodos de determinação dos parâmetros de vazamento a sistemas reais, e ainda mais raros aqueles que consideram várias técnicas ao mesmo tempo, para fins de comparação e validação, como testes sob diferentes padrões hidráulicos e com análise sistemática da hidrometria. Não se foi longe o suficiente no emprego dos recursos metodológicos no processo de avaliação das perdas em campo, tanto do ponto de vista científico e de pesquisa quanto pelas próprias companhias de abastecimento.

Segue-se que os parâmetros de vazamento e outros índices a que este trabalho se dedica merecem atenção, eis que são características hidráulicas próprias para simulação matemática, para operação de estratégias de controle de perdas e, principalmente, para indicação da eficiência de sistemas de distribuição de água. 


\section{OBJETIVOS}

O trabalho, de caráter numérico-experimental, tem os seguintes objetivos:

- Determinar parâmetros do modelo pressão-vazamento através de técnicas físicas em testes sistemáticos de campo e emprego de rotinas de simulação matemática e calibração;

- Avaliar o comportamento dos parâmetros sob condições particulares de operação, como abertura de descargas de rede, patamares de redução de pressão e sob consumo diurno dirigido pela pressão;

- Estudar o comportamento dos desvios do conjunto de micromedidores em função de seus fatores de operação;

- Confrontar os valores encontrados com a literatura existente; e

- Consolidar ferramental para pesquisas de campo. 


\section{REVISÃO DA BIBLIOGRAFIA PERTINENTE}

\subsection{Técnicas físicas de quantificação das perdas em sistemas de abastecimento}

SILVA et al. (1998) apresentam metodologia para levantamento de dados e produção de indicadores aplicáveis às companhias de saneamento, levando a parâmetros básicos de controle de eficiência do serviço.

O índice de perda na distribuição ou água não contabilizada, que relaciona volumes distribuídos e não utilizados, é dado por:

$$
I P D(\%)=\frac{V D-V U}{V D} * 100
$$

onde: $V D=$ volume disponibilizado; e $V U=$ volume utilizado .

O índice de perda de faturamento ou água não faturada é uma relação entre volumes que incorpora perdas físicas e não-físicas em função da água faturada, dado por:

$$
\operatorname{IPF}(\%)=\frac{V D-V F}{V D} * 100
$$

onde: $V F=$ volume faturado.

O índice de perda física na distribuição é uma relação entre a água distribuída e a que efetivamente chega até o usuário, sendo:

$$
P F D(\%)=\frac{V D-V F U}{V D} * 100
$$

onde: $\quad V F U=$ volume fisicamente utilizado $=V U-\delta m-\delta M-\delta E ; \quad \delta m=$ erros sistemáticos de micromedição; $\delta M=$ erros sistemáticos de macromedição; e $\delta E=$ desvios estatisticamente fixados de consumos estimados (não-medidos).

O índice linear de perda física representa o volume que não é disponibilizado diretamente ao consumidor, dividido pela extensão da rede e tempo de análise, sendo:

$$
I L F=\frac{V D-V F U}{E T^{*} N D} \quad\left[m^{3} / \mathrm{km} \cdot \mathrm{dia}\right]
$$


onde: $E T=$ extensão total da rede analisada; e $N D=$ número de dias analisado.

Nas áreas de captação e produção são apresentados outros tantos índices, além de parâmetros de confiabilidade de operação do sistema.

LAMBERT et al. (2000) trazem a técnica BABE como aproximação aos cálculos das perdas ditas "inevitáveis" do sistema de distribuição através de parâmetros que envolvem o comprimento das redes, suas pressões e vazões médias e freqüências de reparos - além do número de ligações e suas distâncias à rede conectada.

Para as perdas físicas e não-físicas de água, LAMBERT \& HIRNER (2000) propõem uma terminologia e trazem recomendações de cálculo. Considerando que não há tubulação totalmente estanque, são definidas as perdas inevitáveis e classificadas aquelas que possuem caráter físico ou não.

Segundo os autores, o uso de volumes hidrometrados em trabalhos científicos, embora factível, é visto com reservas; o artigo valoriza a importância de um bom esquema de macro e micromedição e trata como funções da boa hidrometria controlar o dimensionamento, instalação e manutenção dos hidrômetros, sua deterioração com idade e uso, calibração, substituição e fixação de rotas de leitura.

Para quantificação das perdas é proposto um método na forma de balanço hídrico anual do sistema, embora os autores sugiram testes de vazão mínima noturna com controle de rompimentos e manutenção, além da modelagem matemática dos parâmetros do modelo pressão-vazamento.

Os autores recomendam ainda que índices de performance do sistema analisado sejam expressos não em relação ao comprimento das redes, mas em função do número de ligações, dada a sensibilidade alcançada pelo tratamento, principalmente em áreas com baixos índices de ocupação. 
CARVALHO FILHO et al. (2000) desenvolveram uma metodologia para determinação de perdas físicas através do índice de submedição encontrado na micromedição da SANASA em Campinas, SP. O grupo de hidrômetros de um setor isolado de abastecimento foi dividido em extratos em função da idade dos hidrômetros e consumo das respectivas ligações. Para determinação dos erros de submedição dos hidrômetros dos diversos extratos, amostras foram coletadas e analisadas em bancadas de aferição. O índice de perdas físicas foi determinado pela diferença entre o volume macromedido na entrada do setor e o volume micromedido, corrigido pelo erro de submedição. Nas condições do trabalho, foi obtido um índice de submedição de 13,45\%; as perdas físicas ficaram em 7,99\% e as totais em 21,44\%. Em suma, dos $21,44 \%$, foram verificados $63 \%$ de perdas não-físicas (faturamento), e 37\%, físicas.

RECH (1999) realizou análise semelhante em amostra do parque de hidrômetros de Porto Alegre, RS, e obteve índice de submedição igual a 1,28\%.

Uma eficiente abordagem do problema das perdas físicas em setores de abastecimento, através do estudo das vazões mínimas noturnas (VMN) com Controle Estatístico do Processo (CEP) pela "carta X”, é apresentada por KUROKAWA \& BORNIA (2002). Analisadas as VMN de dado setor é possível estimar os principais componentes das perdas noturnas, tais como consumos excepcionais e perdas nas redes e ramais. A variável física - vazão - é analisada através de limites de controle estatísticos, que permitem identificar perdas por vazamentos e avaliar a eficácia das ações corretivas - como redução de pressão ou localização de vazamentos.

A AWWA (1990) apresenta procedimentos para análise de perdas em setores de distribuição e detecção de vazamentos, por ações de verificação cadastral das redes, macromedição na produção e distribuição, análise de micromedição e consumos estimados e condições de operação. São também sugeridas ações nas áreas de 
manutenção de hidrômetros, ligações clandestinas, manutenção de equipamentos acessórios, verificação de reservatórios e pesquisa de vazamentos visíveis e não visíveis.

LAMBERT (2001) apresenta referências a estudos de laboratório e de campo que não permitem que a equação de orifício seja empregada na quantificação de vazamentos em redes de distribuição. Dada a equação para vazão em orifício

$$
Q=c_{d} A(2 g P)^{0,5}\left[\mathrm{~m}^{3} / \mathrm{s}\right]
$$

onde: $Q=$ vazão de vazamento, em $\mathrm{m}^{3} / \mathrm{s} ; c_{d}$ é o coeficiente de descarga do orifício considerado; $A$ = área do orifício, em $\mathrm{m}^{2} \mathrm{e} ; P=$ carga de pressão no trecho, em $\mathrm{mH}_{2} \mathrm{O}$; e considerados o regime de escoamento do vazamento e a viscosidade cinemática da água, que é função da temperatura, comprova-se rápido crescimento do coeficiente $c_{d}$ com o aumento do número de Reynolds no regime laminar, o que indica que pequenos vazamentos são muito sensíveis às variações de pressão. No regime turbulento, mais que no de transição, o coeficiente de orifício $c_{d}$ apresenta bom comportamento, ao oscilar entre 0,7 e 0,8 .

Testes de laboratório indicam, ainda, que a área do orifício varia com a pressão, principalmente em tubos plásticos. Como alternativa ao ajuste exponencial dado ao problema de vazamento-pressão, é sugerida a relação

$$
\frac{L_{1}}{L_{0}}=\left(\frac{P_{1}}{P_{0}}\right)^{N 1}
$$

onde $L_{l}$ é o vazamento após redução de pressão; $L_{0}$ é o vazamento antes da redução; $P_{1}$ é a pressão final; $P_{0}$ é a pressão de referência, antes da redução; e N1 é um expoente que depende do material da tubulação e níveis de vazamento e oscila entre 0,50 e 2,50.

O isolamento de condutos de uma rede, através do fechamento de válvulas, permite que testes de vazamento sejam executados ao variar gradualmente a carga de pressão 
entre 5 e $40 \mathrm{mH}_{2} \mathrm{O}$, por 45 minutos. Resultados práticos indicaram valores para o expoente $\mathrm{N} 1$ entre 0,65 a 2,12, com média 1,15 .

LAMBERT \& HIRNER (2000), com base nos mesmos índices afirmam que, para grandes sistemas, a adoção de uma relação linear entre pressão e vazamento é aceitável. A variação dos expoentes é justificada pela dependência do material das tubulações e quantidade e qualidade das juntas e conexões.

A análise de dados revela que alterações bruscas e freqüentes das pressões de operação reduzem, drasticamente, a vida útil do sistema, e em casos extremos atinge frequiência de colapsos até 10 vezes maior do que as observadas em sistemas bem operados.

Se vazamentos visíveis forem localizados e reparados antes do teste e consumos noturnos forem bem estimados ou medidos, podem ser obtidos expoentes N1 mais consistentes.

KHADAM et al. (1991) apresentam resultados do emprego de técnicas práticas de avaliação das perdas no sistema de distribuição de água da cidade de Ar-Riyadh, capital da Arábia Saudita. Diante de perdas físicas brutais, a ponto de elevar o nível das águas subterrâneas da cidade, foram detectados e quantificados vazamentos em redes de distribuição de água, coleta de esgotos e drenagem urbana em uma área de 25 hectares. Cada sub-área estudada recebeu um índice de vazamentos e uma pesquisa demográfica completa. As curvas obtidas de vazamento-pressão não revelaram variações exponenciais, como era esperado, segundo os autores, possivelmente, devido à variação dos orifícios nos tubos em PVC com a pressão de operação - além de fadiga térmica e péssimas práticas de construção.

Com as auditorias foram observadas grandes variações nos índices de vazamentos entre diferentes áreas e, direta e indiretamente, grandes economias de capital. A 
manutenção preventiva mostrou ser forte aliada no combate às perdas através de procedimentos de controle de pressão, investigações sônicas periódicas e controle da micromedição.

ARREGUÍN \& OCHOA (1997) propõem método para quantificação das perdas de água e apresentam exemplo de aplicação em quinze cidades mexicanas. O método baseia-se na análise de amostras aleatoriamente selecionadas em ligações prediais de distritos hidrométricos. Com estimativas dos volumes distribuídos, consumidos e perdidos, podem ser determinados índices de perdas físicas e não-físicas.

O setor de distribuição é dividido em zonas de pressão e, em seguida, cada extrato de pressão é subdividido em faixas de vazamentos.

Os vazamentos são investigados através de amostras selecionadas aleatoriamente em cada extrato, com tamanho dado por:

$$
n_{o}=\left(\frac{Z_{c}^{2}}{N d^{2}}\right)\left[\sum N_{i} P_{i}\left(100-P_{i}\right)\right]
$$

onde: $Z_{c}$ é a abscissa da curva de distribuição normal, para dado grau de confiança; $N$ é o número total de ligações do sistema; $d$ é o erro de estimativa, em porcentagem; $N_{i}$ é o número de ligações em cada extrato $i$; e $P_{i}$ é a porcentagem da ocorrência de vazamento em cada extrato $i$.

Caso o tamanho da amostra resulte maior que 5\% da população, deve ser corrigido por:

$$
n=\frac{n_{o}}{1+\frac{n_{o}}{N}}
$$

O volume perdido pelas ligações prediais é estimado a partir das ligações que apresentaram vazamentos, com tamanho de amostra: 


$$
n_{a}=\left(\frac{Z_{c}^{2}}{d_{q}{ }^{2} N}\right) \sum S_{q i}^{2} N_{i}
$$

onde: $S_{q i}$ é o desvio-padrão da perda média das ligações do extrato $i$, em $\mathrm{mL} / \mathrm{s}$; e $d_{q}$ é o erro desta estimativa, em $\mathrm{mL} / \mathrm{s}$.

O desvio-padrão é dado por:

$$
S_{q i}=\sqrt{\frac{\sum\left(q_{l}-q_{\text {average }}\right)}{N_{l}-1}}
$$

onde: $q_{l}$ é o $l$-ésimo vazamento medido no extrato $i$, em $\mathrm{mL} / \mathrm{s} ; q_{\text {average }}$ é a média dos vazamentos medidos no extrato $i$, em $\mathrm{mL} / \mathrm{s}$; e $N_{l}$ é o total de vazamentos medidos no extrato $i$.

Muitos métodos podem ser empregados na medida dos vazamentos, como equações de orifício, técnicas de "cronômetro e balde" ou "mangueira e hidrômetro", para vazamentos maiores.

As perdas nas tubulações de distribuição são estimadas em distritos hidrométricos, devidamente divididos em função do nível socioeconômico, densidade de urbanização e ocupação.

A dimensão do distrito hidrométrico a analisar é dada por:

$$
k_{o}=\left(\frac{Z_{c}^{2}}{K d_{k}^{2}}\right)\left[\sum K_{j} P_{j}\left(100-P_{j}\right)\right]
$$

onde: $k$ é a dimensão do distrito, em número de trechos; $d_{k}$ é o erro na estimativa, em porcentagem; $K_{j}$ é o número de trechos em cada sub-extrato $j$; e $P_{j}$ é a porcentagem de perdas anuais nas tubulações, em cada sub-extrato $j$.

O tamanho da amostra será:

$$
n_{c}=\frac{Z_{c}^{2} S_{c}^{2}}{d_{c}^{2}}
$$


onde: $S_{c}$ é o desvio-padrão da média dos consumos, em L/hab.dia; e $d_{c}$ é o erro da estimativa, em L/hab.dia.

Aplicado a quinze cidades mexicanas o método produziu bons resultados, com grau de confiança de 95\%. As principais dificuldades encontradas foram na medição de pequenas vazões nas ligações prediais e aquelas geradas na formação dos extratos, problema contornado pela seleção aleatória.

Ainda que os dados obtidos no estudo não possam ser extrapolados para outros sistemas, índices de perdas físicas e não-físicas bem definidos constituem importante referência: $24,5 \%$ de perdas nos ramais, $10,6 \%$ nas redes e $1,3 \%$ na micromedição, com total de $36,4 \%$.

\subsection{Conceito de modelagem matemática e calibração de redes}

A modelagem matemática de sistemas de distribuição de água é ferramenta eficiente no desenvolvimento de estratégias de planejamento e operação, manutenções, combate a incêndios e reabilitações. O modelo computacional de uma rede hidráulica é a representação matemática de um sistema real e sua validade depende, diretamente, da segurança sobre os dados de entrada e calibração (ORMSBEE \& LINGIREDDY, 1997 e AWWA, 1999).

Calibração de redes é o processo de ajuste das características hidráulicas de um modelo para melhor refletir as condições do sistema real. Devem ser ajustados aqueles parâmetros cuja obtenção seja difícil ou imprecisa, como rugosidades de tubulações, demandas e parâmetros de vazamentos.

EGGENER \& POLKOWSKI (1976) relatam que se houver um cadastro fiel do sistema estudado, os dados de entrada e os elementos de controle podem ser 
devidamente modelados - e as variáveis podem ser reduzidas às condições de demanda, à escolha da equação de resistência e aos coeficientes de rugosidade.

Com testes conduzidos sob boas condições, a demanda pode ser satisfatoriamente estimada.

Para uma previsão inicial das rugosidades, podem ser executados testes de campo a partir de escoamentos programados, como descargas em hidrantes, por exemplo, e respectivas medições das cargas hidráulicas e elevações das extremidades do trecho estudado (WALSKI, 1984). O mesmo parece ser possível na calibração de parâmetros do modelo pressão-vazamento.

Diversas equações de resistência são comparadas por LAMONT (1981), em função de idade, diâmetro e rugosidade das tubulações. Os ensaios empreendidos pelo autor mostraram que a fórmula de Hazen-Williams gera resultados satisfatórios para usos práticos e a de Colebrook é a mais confiável do ponto de vista acadêmico. São apresentados em tabela - para diversas idades, diâmetros e equações de perda de carga valores esperados para os coeficientes de resistência.

BAPTISTA \& COELHO (2002) trazem valores usuais das rugosidades absolutas de redes em função do tipo de material, além de valores máximos e mínimos.

A AWWA (1999) recomenda que valores de rugosidade de tubulações obtidos em determinadas cidades sejam usados com reservas em estudos conduzidos para outras localidades, dada a influência direta de fatores como qualidade da água e características dos trechos na variação dos coeficientes com o tempo.

CESARIO (1980) propõe uso de rotinas computacionais, de simulação e calibração, para a solução de problemas de modelagem de redes sob várias condições de operação.

ORMSBEE \& LINGIREDDY (1997) afirmam que a validade do modelo depende dos dados de entrada e das simplificações que forem feitas durante a modelagem, como 
divisão das demandas em nós e sob áreas de influência, além da aceitação que somente as demandas e rugosidades sejam variáveis. O emprego a que se destina o modelo deve orientar os critérios de precisão da calibração.

As principais fontes de erro na modelagem de redes hidráulicas residem nos dados de entrada, rugosidades estimadas, demandas, mapas, elevações dos nós, detalhes dos modelos, anomalias geométricas das tubulações e instrumentos de medição. Mapas com escalas impróprias, materiais de redes desconhecidos, diferenças entre demandas espaciais e temporais, tubos desconectados, diferenças entre cotas, simplificação do sistema em tubos e nós e manômetros e medidores de vazão imprecisos ou de baixa precisão, segundo a AWWA (1999), são fatores que devem ser controlados.

Há diversos métodos disponíveis para calibração de redes hidráulicas, com predomínio dos de tentativa e erro (trial-and-error) nos quais os parâmetros variáveis são ajustados até o melhor encaixe. O problema da compensação de erros ainda permeia os métodos, inclusive os de otimização. Em métodos de cálculo direto de parâmetros, usam-se restrições que impedem que valores fora da realidade permaneçam no modelo, enquanto técnicas de otimização incluem constantes nas variáveis de decisão para minimizar os efeitos da compensação de erros (AWWA, 1999).

\subsection{Pesquisa operacional na redução de vazamentos com redução de pressão}

GERMANOPOULOS \& JOWITT (1989) apresentam técnica para redução de vazamentos em redes de abastecimento, através de redução de pressões até um limite que atenda as demandas mínimas em cada nó, com o ajuste da abertura de válvulas redutoras de pressão (VRPs). Tal procedimento também sugere que os consumos ditos “desnecessários" podem ser minimizados, pois as demandas de consumo - assim como os vazamentos - são variáveis com a pressão. 
O modelo é formulado com uma Função Objetivo linear e um conjunto de restrições não lineares, a partir da aplicação da equação da continuidade em cada nó (balanço hídrico nodal). O melhor ajuste das VRPs instaladas observa as restrições operacionais do sistema, como pressões e demandas mínimas.

Para quantificação do índice de vazamentos em função da pressão, é adotada uma relação explícita não linear, através do expoente fixo 1,18, conforme Figura 3.1 e equação (3.13).

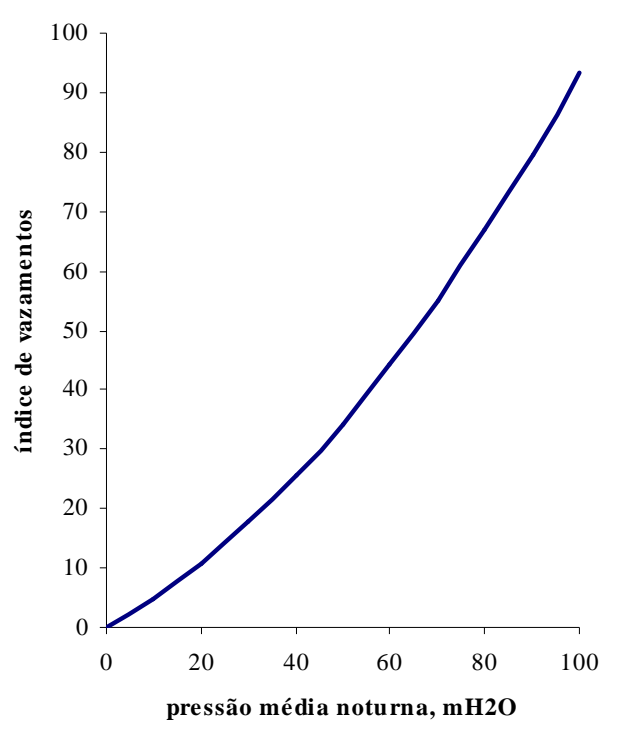

Figura 3.1 - relação entre pressão e vazamentos Fonte: GERMANOPOULOS \& JOWITT, 1989

$$
S_{i j}=c_{l} L_{i j}\left(P_{i j}{ }^{A V}\right)^{1,18}
$$

onde $S_{i j}=$ vazão de vazamento no tubo conectado aos nós $i$ e $j ; c_{l}$ é uma constante; $L_{i j}$ é o comprimento da tubulação; e $P_{i j}{ }^{A V}$ é a pressão média entre os nós conectados.

Na formulação de minimização, a vazão $S_{i j}$ é assumida igualmente distribuída entre os nós de montante e jusante. Um ajuste de abertura de cada válvula $k, V_{k}$, inserido na equação de continuidade de cada tubulação controlada por válvula, permite que a variável seja otimizada pelo método linear, proposto para solução. 
Como extensão ao método de GERMANOPOULOS \& JOWITT (1989), JOWITT \& XU (1990) apresentam um algoritmo que visa minimizar diretamente os vazamentos, e não só aquelas devidas às sobrepressões. Também a linearização das equações que modelam válvulas de controle difere do trabalho citado, devido ao esforço no sentido de incorporar limites físicos à válvula, como critérios a se somarem ao seu fator de abertura, de forma a ser possível a escolha da melhor válvula para redução de pressão.

O conjunto de equações não lineares, que relaciona pressão nos nós e vazão nas tubulações, recebe a formulação de vazamento, formando um sistema de equações passível de ser solucionado por linearizações sucessivas e programação linear.

REIS \& PORTO (1992), em duas redes teóricas, aplicam o modelo de minimização de vazamentos de JOWITT \& XU (1990) e incorporam também os coeficientes de perda localizada das válvulas. Limites máximos e mínimos para pressões e demandas são analisados em relação às perdas inevitáveis na pressão mínima e às altas demandas em pontos onde, por restrições operacionais, as pressões não podem sofrer reduções ainda maiores. Na segunda parte do trabalho são discutidas a quantidade e disposição das válvulas no sistema, a partir de simulações das perdas e fatores de abertura em função do fator de demanda. Pela formulação do problema, a situação de demanda nula não implica em caso estático, uma vez que há pressão nas tubulações, e os vazamentos, que são sua função, ocorrem; mesmo assim, as perdas por vazamentos continuam maiores no caso onde não houve controle por válvulas.

Para ajuste de válvulas e redução de vazamentos, técnicas tradicionais enfrentam problemas tais como o alto número de variáveis envolvidas e a não linearidade dos modelos hidráulicos. VAIRAVAMOORTHY \& LUMBERS (1998) afirmam que a minimização de vazamentos requer formulação explícita no modelo hidráulico. 
TUCCIARELLI et al. (1999) propõem um modelo estático de simulação hidráulica e calibração através de relações entre as variáveis de decisão, em dois passos: estimativa dos parâmetros de simulação (coeficientes de perda de carga e vazamento) e determinação da abertura ótima de válvulas, sob restrições de pressão mínima nos nós.

A vazão de vazamento é determinada considerando uma área de vazamentos (orifícios) por unidade de área de superfície das tubulações, na forma:

$$
Q_{i}=\left(H_{i}-z_{i}\right)^{a} \sum_{j=1}^{M_{1}} \frac{\pi}{2} D_{i j} \theta_{i j} L_{i j}
$$

onde: $H_{i}=$ carga hidráulica no nó $\mathrm{i} ; z_{i}=$ cota do nó $\mathrm{i} ; a=$ expoente de vazamento; $L_{i j}=$ comprimento da tubulação; $D_{i j}=$ diâmetro da tubulação e; $\theta_{i j}=$ área de vazamento por unidade de área da tubulação entre os nós $i$ e $j$.

A Função Objetivo a ser minimizada adota ponderações (pesos) que garantem a proporção entre os valores somados, de forma que eles não dependam do sistema de unidades. Na verdade, os pesos aplicados aos diferentes termos contemplados garantem que eles possuam a mesma magnitude e que possam ser considerados como se fossem dimensionalmente homogêneos. É recomendado o uso da metodologia do autor em testes de vazão mínima noturna.

\subsection{Estatística e amostragem}

A análise do comportamento de determinadas variáveis de uma dada população pode ser feita através do estudo de uma parcela $n$ de $N$ elementos, denominada amostra.

O processo de amostragem probabilística na qual há sorteio aleatório da amostra dentre a população é denominada amostragem causal simples, onde qualquer dos $n$ elementos sorteados possui a mesma probabilidade de constituir uma amostra, sem reposição. 
De posse dos valores medidos que interessam ao estudo, é necessária a construção de uma inferência, ou seja, o estabelecimento de mecanismos estatísticos que relacionam os valores amostrais com os populacionais, através de estimadores tais como a média amostral e a variância populacional.

A média amostral representa a esperança matemática da variável $x$, observada em um grupo de $n$ elementos (amostra), e é dada por:

$$
\bar{x}=\frac{\sum_{i}^{n} x_{i}}{n}
$$

A variância populacional, por sua vez, pode também ser estimada em função dos valores observados na amostra estudada:

$$
s^{2} X=\frac{\sum_{i}^{n}\left(x_{i}-\bar{x}\right)^{2}}{n-1}
$$

A análise amostral compõe estimativas para a média populacional, de forma ser necessário obter relações dos valores pontuais estimados frente aos erros de amostragem.

Estas relações são conhecidas como intervalos de confiança e são função do estimador adotado, do tamanho da amostra e da distribuição original da variável na população. Conforme cresce o tamanho da amostra, maior será a aproximação da estimativa obtida para a curva Normal, minorando o erro de estimativa.

Entretanto, na maioria dos casos a variância da variável aleatória controlada não é conhecida para toda a população.

Considerando que a variável apresenta distribuição Normal é possível estimar o desvio-padrão através de curvas padronizadas.

A distribuição $t$ de Student permite validar testes de hipótese de parâmetros observados em amostras retiradas, onde: 


$$
T=\frac{\bar{x}-\mu}{\frac{s}{\sqrt{n}}}
$$

Na equação (3.17) $\bar{x}$ é a média amostral; $\mu$ é o valor da média populacional que se deseja validar no teste de hipótese; $s$ é o desvio-padrão observado na amostra e; $n$, o tamanho da amostra.

O teste de hipótese implica no confronto entre valores calculados de $T$ e aqueles obtidos em tabelas padronizadas da distribuição $t$-Student.

Deve-se rejeitar a hipótese se o intervalo dentro da distribuição da média amostral acrescida de $T$ estiver além dos limites tabelados de $t$-Student, conforme figura 3.2.
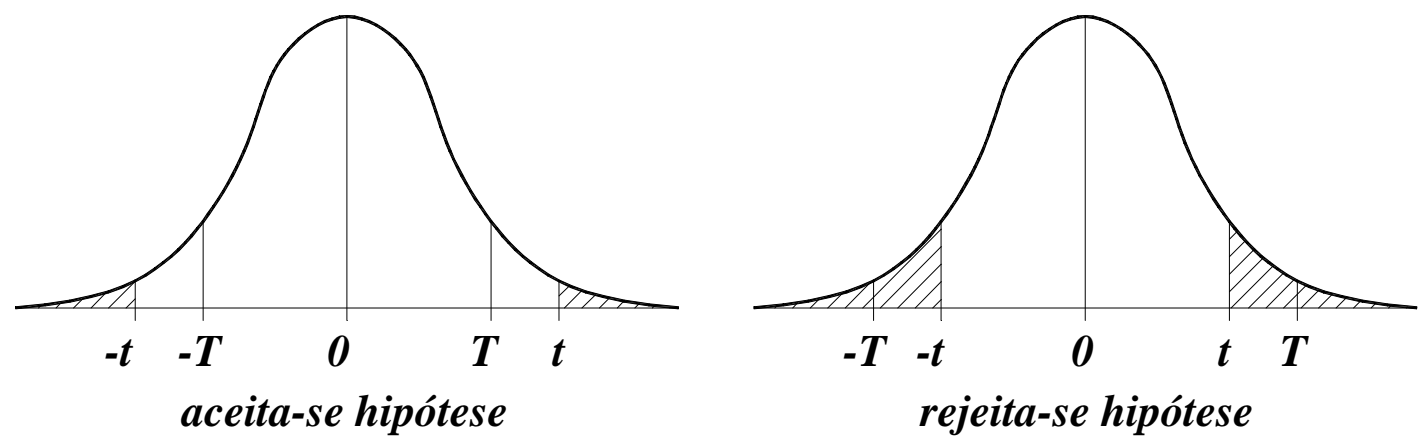

Figura 3.2 - teste de hipótese

A distribuição $t$-Student apresenta as probabilidades em tabelas numéricas, em função do número de graus de liberdade do problema e permite, inclusive, análise de hipóteses unilaterais.

\subsection{Métodos de otimização}

A análise de sistemas propõe várias técnicas de otimização aplicáveis aos problemas de hidráulica. Os métodos de Busca Direta apresentam-se como ferramentas úteis à calibração de modelos hidráulicos, pela capacidade de resolução de problemas não 
lineares. De caráter iterativo e mais numérico que analítico, os métodos de Busca Direta podem utilizar ou não derivadas de primeira e segunda ordens, com critério de convergência na melhora significativa do valor da Função Objetivo. A principal diferença entre os métodos reside na determinação da direção de busca e sua característica irrestrita pode ser contornada com a aplicação de penalidades.

No método de Busca Aleatória, um escalar fixo é multiplicado por um vetor direcional aleatório, consumindo muitas iterações na sua resolução. A Busca Univariada caminha ortogonalmente até o ótimo a partir de direções de busca definidas; ao lado da Busca por Padrões - onde além dos passos univariados caminha-se em uma direção resultante padrão - consistem nas formas mais simples de Busca Direta.

O método de Powell possui início com busca univariada e caminha até o ótimo em uma sucessão de padrões, promovendo convergência mais rápida e robusta. No método SimplexO, de Nelder-Mead, o espaço de soluções é percorrido até o ótimo através de operações de reflexão, contração e expansão, ao avaliar a Função Objetivo sem derivadas.

Os métodos dos Gradientes e de Fletcher-Reeves são exemplos de procedimentos de busca que se valem de derivadas de primeira ordem, enquanto derivadas de ordem dois são necessárias aos métodos de Newton-Raphson e Davidon-Fletcher-Powell (FOX, 1971).

Métodos não convencionais de busca, baseados em fenômenos da natureza, são encontrados e possuem como principais representantes os algoritmos genéticos (AGs), que são processos artificiais de evolução baseados na seleção natural e nos mecanismos de sucessão genética que, ao promover uma "varredura" do problema em busca de candidatos a ótimo - através de processos de seleção, recombinação e mutação - 
permite uma boa resolução de problemas com um grande número de soluções viáveis, sob condições não lineares e espaço discreto de decisão.

\subsection{Modelagem de demandas de consumo}

WAGNER et al. (1988) apresentam método de simulação computacional para estudos de confiabilidade de sistemas de distribuição como complemento aos métodos analíticos. Uma rotina de simulação permite analisar falhas em tubos e bombas através de simulações estocásticas, de forma a permitir a compreensão dos sistemas em "tempo real".

As demandas nos nós são modeladas através da raiz quadrada de adimensional relativo às cargas hidráulicas limites de operação do sistema, na forma:

$$
Q=\left(\frac{H-H_{s}}{H_{m}-H_{s}}\right)^{1 / 2} C
$$

onde $H$ é a pressão atuante no nó de estudo; $H_{s}$ é a pressão de serviço ou desejada para o nó de estudo; $H_{m}$ é a pressão mínima e; $C$ é a demanda total do nó.

A relação permite estimar demandas como variáveis com a pressão, de forma que para cada pressão abastecida há crescimento da demanda no nó até que uma demanda de referência seja atingida. $\mathrm{O}$ modelo prevê ausência de abastecimento sob pressões menores que o limite mínimo de operação do sistema.

CHANDAPILLAI (1991) propõe o desenvolvimento de modelos de demanda dirigida pela pressão para aplicação em países em desenvolvimento, sob condições de insuficiência e intermitência no abastecimento.

Em sistemas abastecidos com volumes aquém dos desejados - nos quais as demandas de consumo não são atingidas integralmente - há a tendência do consumidor em coletar toda água que lhe for possível no período em que houver distribuição. Dessa 
forma, em sistemas não suficientemente abastecidos, a demanda de consumo em dado nó depende, além da pressão, dos consumos efetivos nos outros nós.

O autor considera que em sistemas de fornecimento intermitente há reservação em caixas d'água por parte dos consumidores. Assim, a pressão mínima de abastecimento será aquela que vencer o desnível geométrico e a perda de carga no ramal domiciliar, conforme equação:

$$
H=h_{1}+k Q^{n}
$$

onde $h_{l}$ é desnível geométrico entre rede e reservatório domiciliar ou ponto de abastecimento; $Q$ é demanda de entrada; $k$ é constante que depende da equação de resistência e; $n$ é expoente de perda de carga, também dependente da relação de perda de carga.

O abastecimento deve ser nulo enquanto as pressões forem insuficientes e constantes quando atingirem uma pressão desejada de serviço.

Resultados do autor mostram que, mesmo sem importância prática, a abordagem permite observar que qualquer mudança no sistema provoca efeitos em toda zona abastecida, em termos de pressão e demanda.

A técnica apresentada por CHANDAPILLAI (1991) permite ainda o ajuste de parâmetros de operação como altura de reservatórios e durações ideais de fornecimento em sistemas sujeitos a intermitências.

Mesmo sistemas bem gerenciados podem operar sob condições de insuficiência na distribuição frente à operação de hidrantes, vazamentos pontuais de grande monta ou falhas no bombeamento. GUPTA \& BHAVE (1996) comparam métodos de modelagem de demandas dirigidas pela pressão com vistas à determinação de parâmetros de confiabilidade em sistemas de distribuição de água. 
Dentre técnicas que consideram demandas constantes em função degrau, adaptações da equação de orifício livre e outras relações parabólicas, os autores mostram com aplicações práticas que as melhores relações variam a demanda em dado nó desde nula - para pressões menores que a mínima - até a demanda máxima, quando a condição de pressão desejada é satisfeita, como nos trabalhos de WAGNER (1988) e CHANDAPILLAI (1991).

O comportamento das demandas em situações críticas de abastecimento é analisado pelo modelo proposto por FUJIWARA \& LI (1998).

Um fator de demanda para dado nó $j, \rho\left(H_{j}\right)$, varia entre 0 e 1 para pressões menores que a mínima e maiores que a máxima, respectivamente, conforme equação:

$$
\begin{array}{ll}
\rho\left(H_{j}\right)=0 & \text { se } H_{j} \leq H_{j}{ }^{\text {min }} \\
\rho\left(H_{j}\right)=\frac{\left(H_{j}-H_{j}{ }^{\min }\right)^{2}\left(3 H_{j}{ }^{d e s}-2 H_{j}-H_{j}{ }^{\text {min }}\right)}{\left(H_{j}{ }^{d e s}-H_{j}{ }^{\min }\right)^{3}} & \text { se } H_{j}{ }^{\text {min }} \leq H_{j} \leq H_{j}{ }^{\text {des }} \\
\rho\left(H_{j}\right)=1 & \text { se } H_{j} \geq H_{j}{ }^{\text {des }}
\end{array}
$$

Com o fim de obter parâmetros globais de eficiência em sistemas de distribuição, MARTÍNEZ et al. (1999) apresentam modelo que integra demandas de consumo e vazamento como variáveis com a pressão. A simulação proposta, em período estendido, permite a obtenção de índices mais seguros quanto ao controle de vazamentos, falhas em equipamentos ou restrições operacionais.

Além da caracterização dos consumos e vazamentos a partir de consumos hidrometrados e índices de quebra e perdas, índices globais de demanda conjugada (vazamento e consumo) podem ser obtidos.

TABESH \& KARIMZADEH (2000) apresentam modelo de otimização de projeto de sistemas de distribuição a partir de três submodelos: simulação estática, de confiabilidade e de otimização de custos. 
A confiabilidade é analisada a partir de demandas dirigidas pela pressão, simuladas em situações extremas de projeto, enquanto a configuração de menor custo da rede é obtida pelo modelo de otimização.

O modelo de demanda dirigida pela pressão utilizado é similar ao proposto por WAGNER (1988), permitindo o ajuste do expoente de descarga, na forma:

$$
\begin{aligned}
& Q_{j}^{a v l}=0 \quad \text { se } H_{j} \leq H_{j}^{\min } \\
& Q_{j}{ }^{a v l}=Q_{j}{ }^{r e q}\left(\frac{H_{j}-H_{j}^{\min }}{H_{j}^{\text {des }}-H_{j}^{\min }}\right)^{\left(\frac{1}{n_{j}}\right)} \quad \text { se } H_{j}{ }^{\min } \leq H_{j} \leq H_{j}^{\text {des }} \\
& Q_{j}{ }^{a v l}=Q_{j}{ }^{r e q} \quad \text { se } H_{j} \geq H_{j}{ }^{\text {des }}
\end{aligned}
$$

OBRADOVIC (2000) discute técnicas de obtenção de dados para identificação de demandas de consumo e vazamento através de equipamentos de coleta de dados e telemetria. O problema da indeterminação das relações entre vazamentos e consumos com a pressão é estudado.

SOARES (2003) emprega modelo de estimativa de demanda de consumo, considerando vazamentos, através de fator multiplicativo temporal, estimado inicialmente como proporcional a uma vazão de referência. O processo iterativo empregado promove a calibração da estimativa inicial do fator multiplicativo através do balanço de massa entre o volume aportado e as parcelas referentes à população não atendida e aos vazamentos. Curvas de convergência dos fatores multiplicativos em função do número de iterações mostram boa resposta da técnica para o sistema estudado. 


\section{MATERIAIS E MÉTODOS}

A coleta de dados consistiu no monitoramento de pressões em quatro pontos de referência do Setor Alvorada, além das pressões a montante e jusante da VRP e da vazão de entrada, por um período de onze dias. Duas descargas de rede também receberam medidores de vazão compatíveis com os coletores de dados disponíveis no SEMAE Piracicaba.

Foram executadas manobras em descargas de rede e na VRP para promoção de patamares de redução de pressão, em instantes sempre próximos da vazão mínima noturna.

O procedimento elaborado para calibração consiste em uma rotina que contém método de otimização que solicita, a cada avaliação de melhora da Função Objetivo, uma rotina de simulação hidráulica que aplica os modelos de demanda dirigida pela pressão (consumo e vazamento) e avalia os desvios entre valores observados e simulados.

Como simulador hidráulico foi utilizado o EPANET, cuja biblioteca foi acoplada às rotinas de calibração e simulação desenvolvidas através do código epanet2 na plataforma $\mathrm{C}++$.

A avaliação dos desvios médios dos hidrômetros instalados no setor foi executada a partir da divisão em extratos de informações coletadas no banco de dados do SEMAE Piracicaba. Medidores foram retirados aleatoriamente, aferidos e substituídos. Também de forma aleatória foram instalados coletores eletrônicos de dados de vazão em residências do setor para avaliação das vazões de abastecimento nestas ligações. 


\subsection{Setor estudado}

O setor de abastecimento denominado "Setor Alvorada" integra o sistema de abastecimento da cidade de Piracicaba, SP, ocupando parte dos setores comerciais 17 e 52 - bairros Jardim Alvorada e Sol Nascente. Abastecido através de derivação da subadutora por recalque "Unileste-Dois Córregos", com diâmetro nominal de $250 \mathrm{~mm}$, o setor foi isolado após consultoria da empresa BBL - Bureau Brasileiro Limitada, por solicitação do SEMAE Piracicaba, preocupado com os altos índices de rompimentos e perdas devido às pressões elevadas de operação.

O setor conta com aproximadamente 1631 ligações distribuídas em 11,5 km de tubulações, das quais mais de $90 \%$ em tubos plásticos, conforme Anexo I. Apenas 2,68\% das tubulações são formadas por Cimento Amianto (CA), material reconhecidamente prejudicial pela sua facilidade em abrir fissuras permanentes.

Tabela 4.1 - materiais componentes do setor Alvorada

\begin{tabular}{lrr} 
material & $\mathrm{L}(\mathrm{m})$ & \multicolumn{1}{c}{$\%$} \\
\hline CA & 307.1 & 2.68 \\
DEFoFo & 718.9 & 6.27 \\
FoFo & 696.6 & 6.08 \\
PVC & 9734.1 & 84.96 \\
\hline & 11456.7 & $100 \%$
\end{tabular}

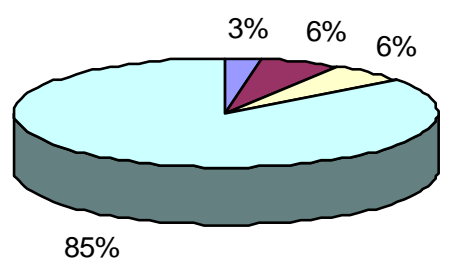

$\square C A$

$\square$ DEFoFo

$\square$ FoFo

$\square$ PVC

Figura 4.1 - materiais componentes do setor Alvorada

As cotas do terreno variam entre $537,958 \mathrm{~m}$, na parte mais baixa, até $581,859 \mathrm{~m}$ no ponto mais elevado. A topografia acidentada garante ao setor uma variação de pressões 
da ordem de 14 a $60 \mathrm{mH}_{2} \mathrm{O}$, mesmo com atuação da VRP instalada. A localização da VRP é questionável e passível de estudos.

A entrada do setor conta com VRP de marca Watts, com $100 \mathrm{~mm}$ de diâmetro nominal, instalada através de by-pass com a tubulação derivada. Dotada de filtro "Y" e macromedidor com turbina horizontal ABB Woltman $100 \mathrm{~mm}$, a entrada do sistema conta com dispositivos de coleta de dados, via data loggers Meinecke.

A região definida inicialmente para instalação de VRP foi posteriormente alterada para solução de problemas de operação de áreas adjacentes. Com a expansão do setor não foi possível a atuação da VRP com a regulagem projetada, mas sim com reduções de pressão muito mais tímidas. Assim, durante o período de estudo a válvula mantevese livre, exceto quando da promoção de patamares de redução de pressão, apresentados em momento oportuno.

O setor abastece economias de uso exclusivamente residencial, por se tratar de conjunto habitacional com idades de, aproximadamente, 10 e 15 anos, nas regiões dos bairros Jardim Alvorada e Sol Nascente, respectivamente.

Durante o ano de 2002 foram empreendidas campanhas no sentido de verificar o isolamento hidráulico do setor e avaliar a eficiência dos dispositivos instalados e equipamentos a utilizar. A VRP foi retirada e verificada, o macromedidor recebeu relojoaria nova e calibrada e os instrumentos de coleta e armazenamento de dados foram aferidos. 


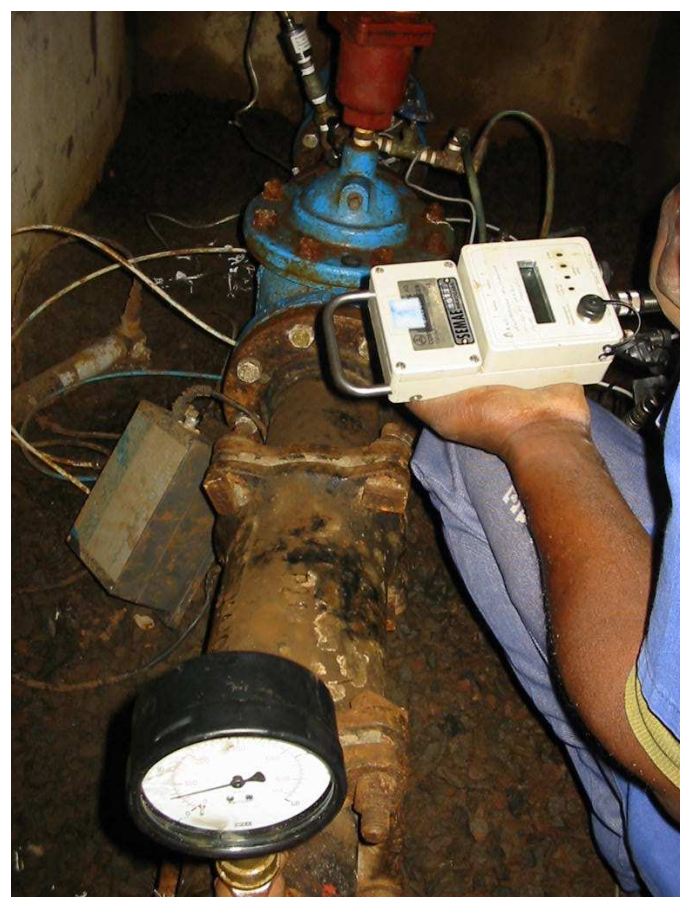

Figura 4.2 - aspecto da caixa de proteção da VRP na entrada do setor

Houve revisão do dimensionamento do macromedidor, que foi confirmado como instrumento seguro para medição e armazenamento das vazões de entrada, inclusive sob baixos valores. 


\subsection{Equipamentos envolvidos}

As vazões na entrada do setor e em descargas foram totalizadas através de medidores de vazão tipo Woltman com dispositivos de saída pulsada de dados tipos OPTO e REED os quais indicam, através de pulsos ópticos ou magnéticos proporcionais à vazão, respectivamente, um determinado volume que atravessa o medidor. Dimensionados para indicar as vazões esperadas em cada ponto com desvios mínimos, os macromedidores instalados apresentam as seguintes características principais:

Tabela 4.2 - características dos medidores de vazão Woltman horizontais utilizados Fonte: ABB Nansen

\begin{tabular}{l|c|c|c|c|c|c|c}
\hline Medidor & $\begin{array}{c}\text { DN, } \\
\mathbf{m m}\end{array}$ & $\begin{array}{c}\text { Vazão de } \\
\text { partida, } \\
\mathbf{m}^{\mathbf{3}} / \mathbf{h}\end{array}$ & $\begin{array}{c}\text { Vazão } \\
\mathbf{m i ́ n i m a ,} \\
\mathbf{m}^{\mathbf{3}} / \mathbf{h}\end{array}$ & $\begin{array}{c}\text { Vazão de } \\
\text { transição, } \\
\mathbf{m}^{\mathbf{3}} / \mathbf{h}\end{array}$ & $\begin{array}{c}\text { Vazão } \\
\text { nominal, } \\
\mathbf{m}^{\mathbf{3}} / \mathbf{h}\end{array}$ & $\begin{array}{c}\text { Vazão de } \\
\text { carregamento } \\
\text { permanente, } \\
\mathbf{m}^{\mathbf{3} / \mathbf{h}}\end{array}$ & $\begin{array}{c}\text { Vazão } \\
\text { máxima, } \\
\mathbf{m}^{\mathbf{3}} / \mathbf{h}\end{array}$ \\
\hline Entrada & 100 & 0,25 & 0,6 & 2,0 & 60 & 180 & 250 \\
\hline $\begin{array}{l}\text { Descarga } \\
\text { Sol Nascente }\end{array}$ & 50 & 0,09 & 0,3 & 1,0 & 15 & 35 & 50 \\
\hline $\begin{array}{l}\text { Descarga } \\
\text { Alvorada }\end{array}$ & 50 & 0,09 & 0,3 & 1,0 & 15 & 35 & 50 \\
\hline
\end{tabular}

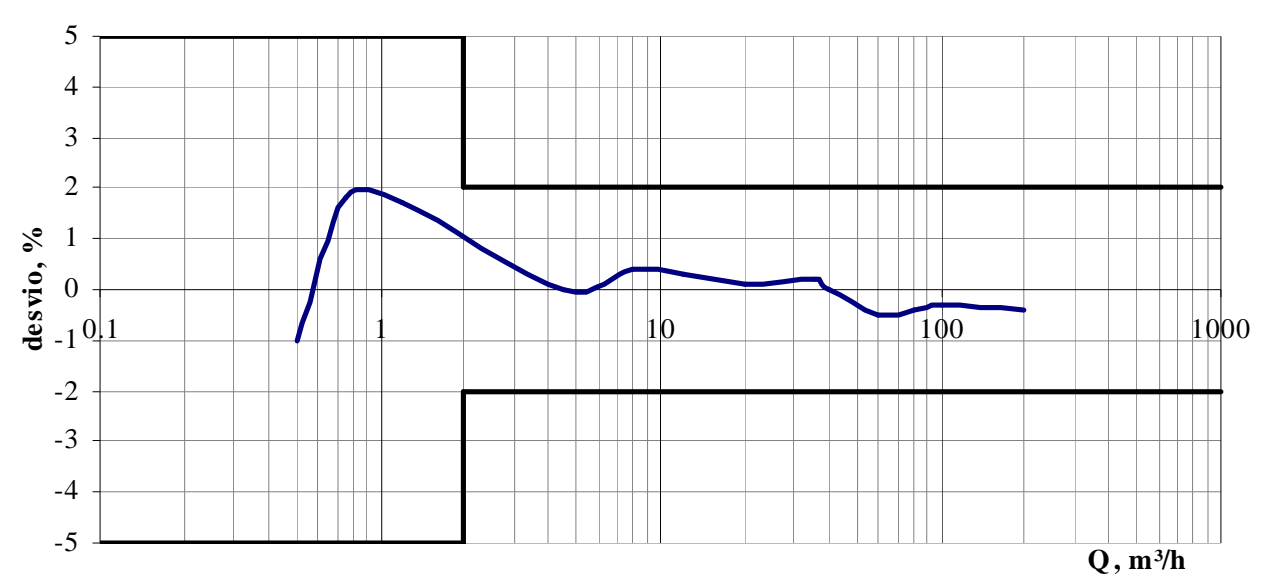

Figura 4.3 - curva de desvios dos medidores de vazão Woltman horizontais de

$100 \mathrm{~mm}$ de diâmetro nominal

Fonte: ABB Nansen 
A vazão mínima de um medidor é aquela que determina seu início de funcionamento, mesmo que com o erro máximo previsto em norma.

A vazão de transição de um hidrômetro taquimétrico é aquela na qual se dá mudança entre regimes laminar e turbulento de escoamento (NBR8009) e separa os limites inferior e superior de medição, ilustrados pela Figura 4.3 com desvios de $\pm 5 \%$ e $\pm 2 \%$, respectivamente.

Hidrômetros taquimétricos, em tempo, são todos aqueles acionados a partir de hélices ou turbinas solicitadas pela velocidade do fluido em escoamento.

Os medidores podem trabalhar ininterruptamente por uma vazão menor ou igual à vazão de carregamento permanente indicada na Tabela 4.2.

Duas descargas de rede do setor receberam caixas de abrigo para instalação de medidores de vazão. Pré-dimensionados para registrar - também com desvios mínimos - vazões da ordem de 5,0 L/s, foram instalados medidores tipo Woltman DN50 nas descargas, com dispositivos REED de saída pulsada.

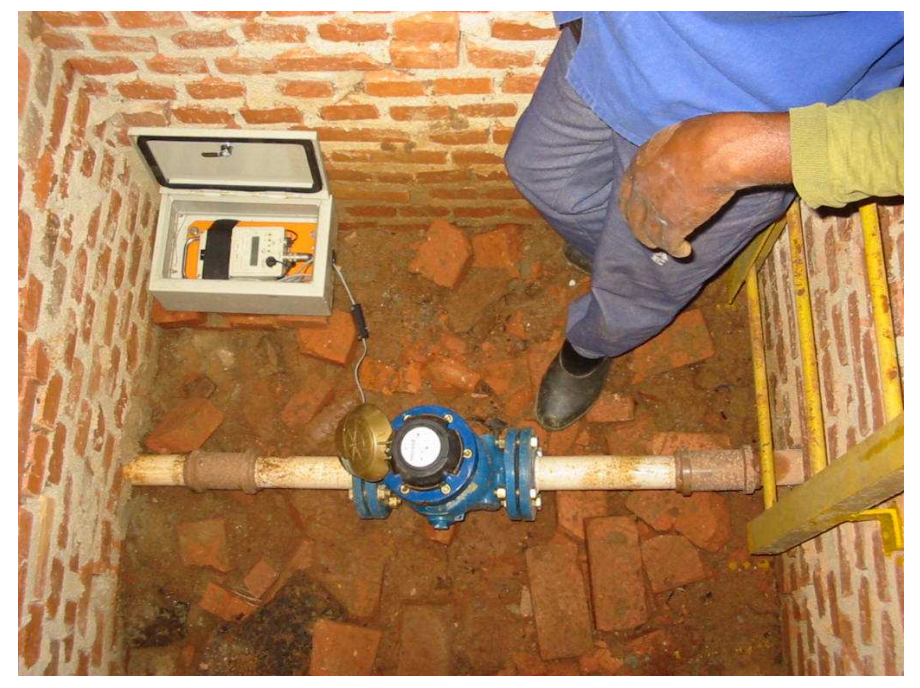

Figura 4.4 - descarga D22 (Sol Nascente) com medidor e coletor de dados 


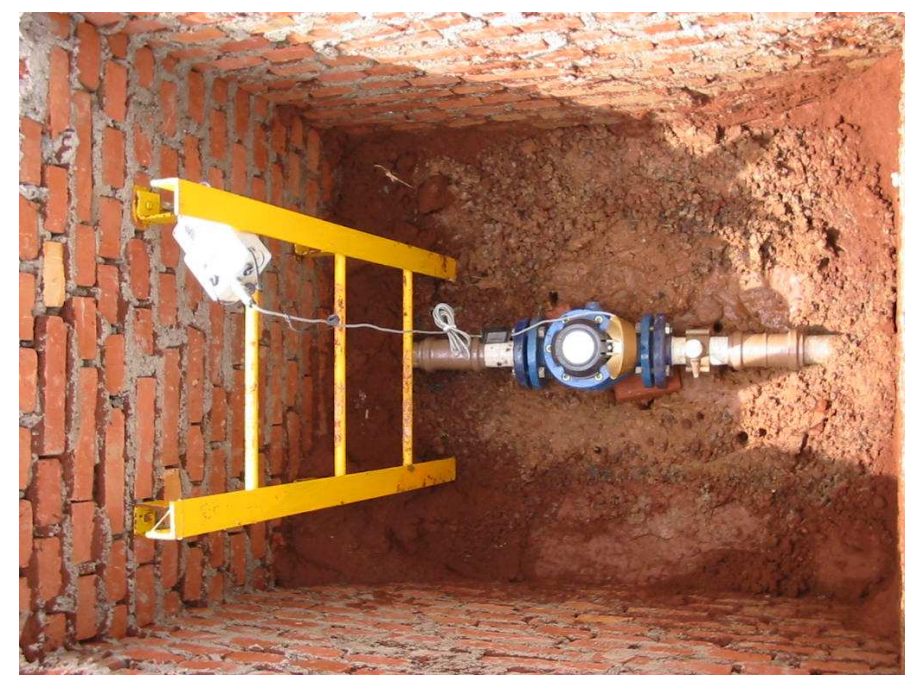

Figura 4.5 - descarga D96 (Alvorada) com medidor e coletor de dados

As pressões de entrada e nos pontos críticos foram registradas através de sensores de pressão Meinecke, com fundo de escala de 10 e 20,7 bar (100 e $207 \mathrm{mH}_{2} \mathrm{O}$, respectivamente). Aferidos antes e após a coleta de dados revelaram curvas de calibração lineares e confiáveis, conforme Figuras 4.6 e 4.7.

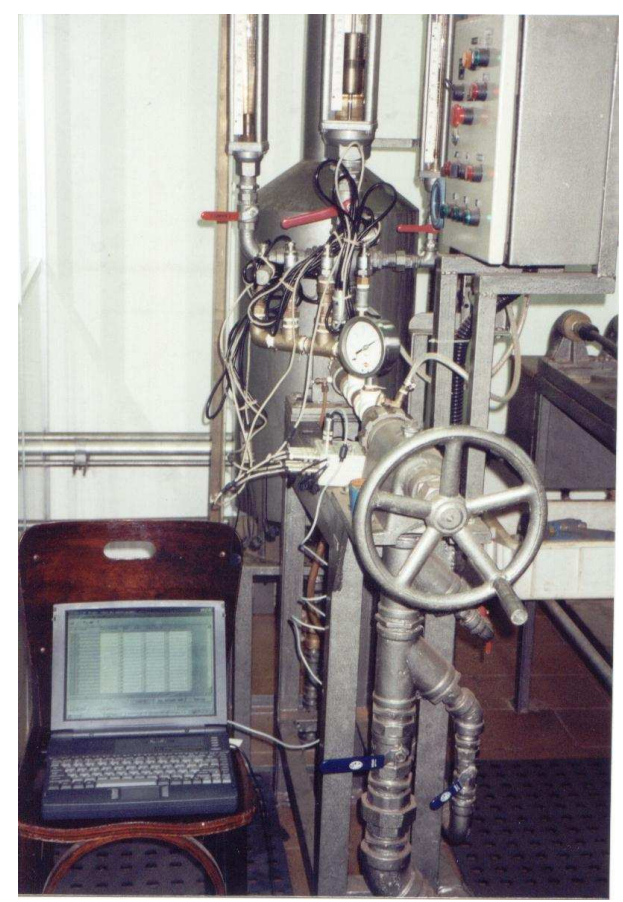

Figura 4.6 - aferição dos sensores de pressão em bancada de testes da Hidrometria 


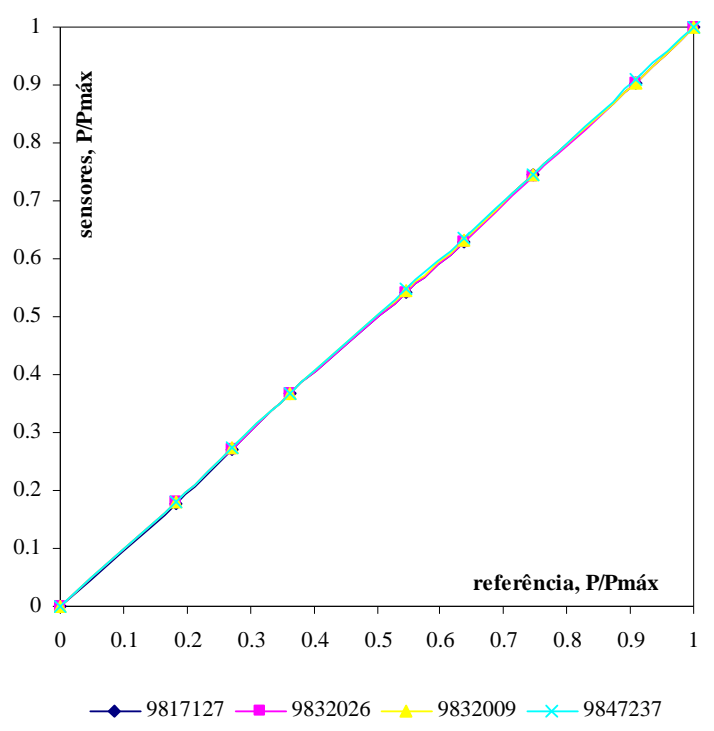

Figura 4.7 - curva de aferição dos sensores de pressão

Os sinais gerados pelos medidores de vazão e sensores de pressão foram coletados e interpretados em coletores eletrônicos de dados - data loggers - Meinecke, de 2 ou 4 canais.

As vazões foram medidas através da programação feita entre o coletor e a porta de saída do sinal (OPTO ou REED), no qual um sinal ótico ou magnético informa ao coletor que um determinado volume atravessou o hidrômetro. Neste instrumento, o coletor indica a vazão "instantânea" através da relação entre volume atravessado e o intervalo de tempo gasto. Os macromedidores instalados permitiram a coleta de pulsos em intervalos a partir de $10 \mathrm{~L}$ - a escolha do volume de referência depende do período de coleta dos dados e o respectivo uso de memória no coletor. A programação utilizada permitiu o cômputo de vazões a cada 100L, indicando boas medidas de vazão sem grandes alocações de memória do coletor.

As etapas de programação e leitura dos coletores foram feitas através de software fornecido pelo fabricante em plataforma Windows. 


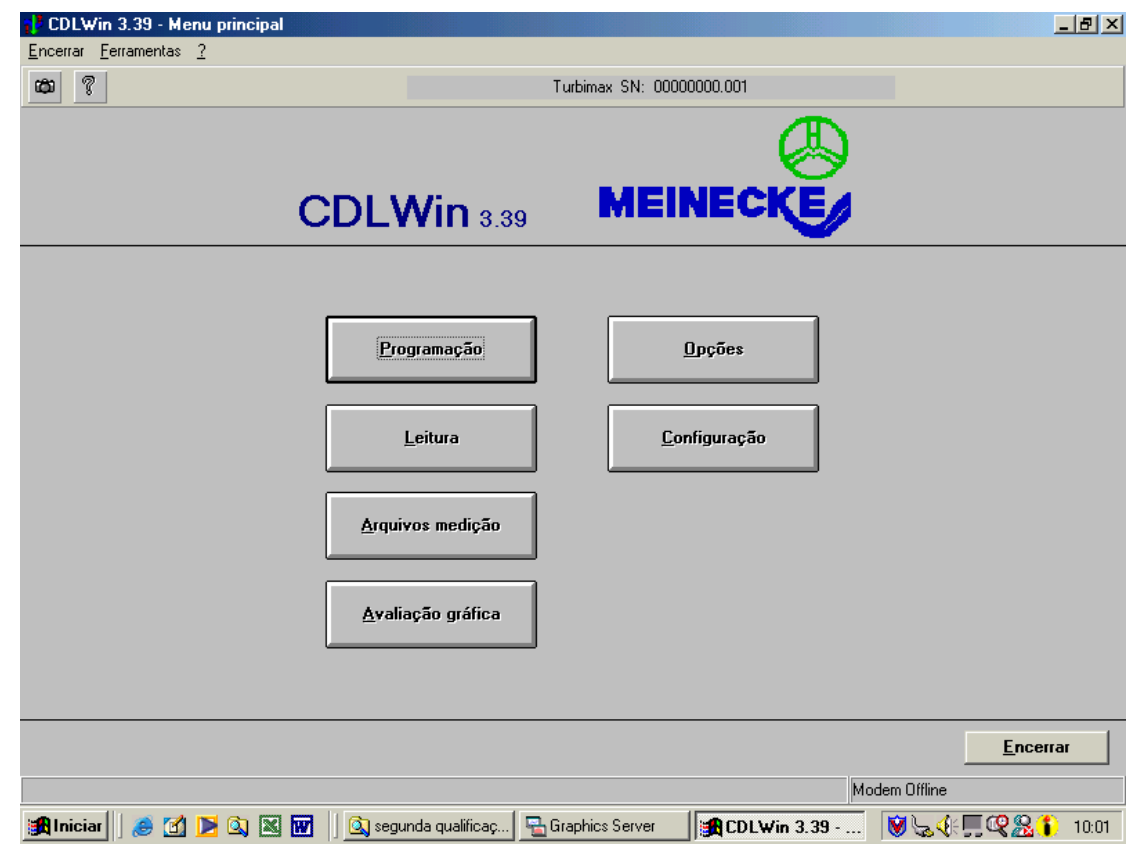

Figura 4.8 - tela do software CDLWin de programação e leitura dos coletores de dados

Os dados coletados foram exportados em formato ASCII e, posteriormente, tratados em planilhas eletrônicas, nas quais foi possível a sobreposição de curvas e sua visualização em escala conveniente.

Os hidrômetros coletados para determinação do erro de micromedição foram ensaiados em bancadas de aferição do SEMAE Piracicaba, dotadas de rotâmetros, manômetros e tanques aferidos e certificados pelo IPEM/INMETRO.

As rotinas de calibração foram programadas em C++ Borland Builder 5.0, linguagem de programação robusta que permite comunicação com o código de simulação hidráulica EPANET. 


\subsection{Estudo da vazão mínima noturna}

\subsubsection{Determinação dos parâmetros de vazamento através da VMN}

A vazão mínima noturna (VMN) é formada pelos consumos noturnos e pelos vazamentos propriamente ditos (GONÇALVES, 1998 apud KUROKAWA \& BORNIA, 2002).

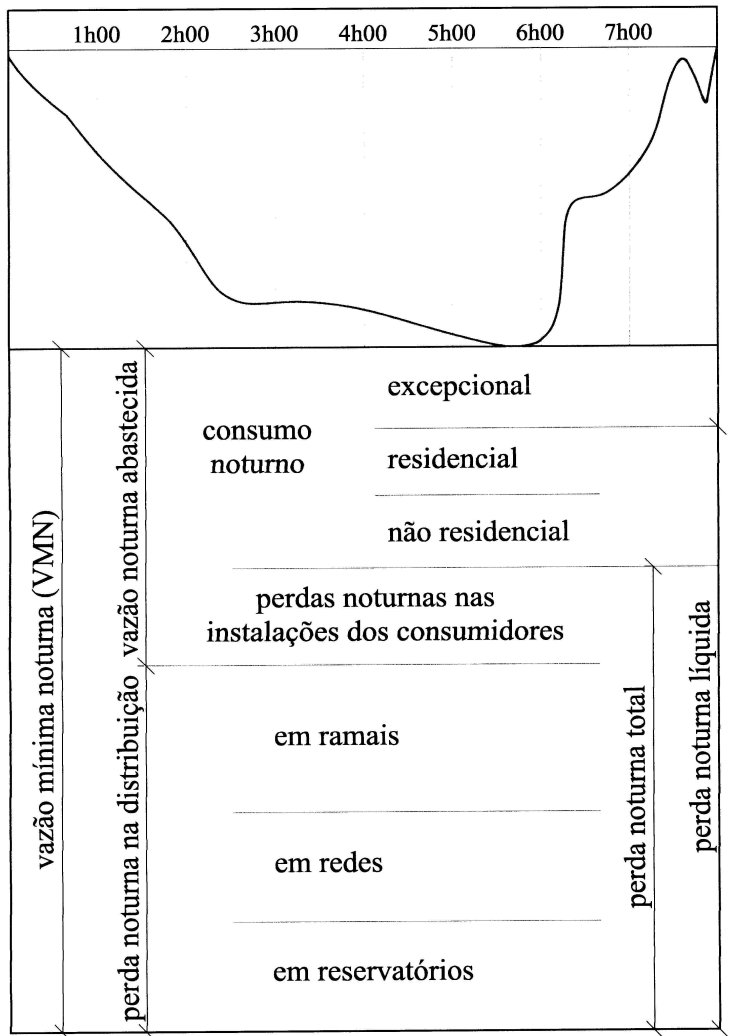

Figura 4.9 - componentes da vazão mínima noturna Adaptado de GONÇALVES (1998) apud KUROKAWA \& BORNIA (2002)

A existência de reservatórios domiciliares, principalmente em residências e pequenos comércios, tende em levar o consumo noturno a valores nulos ou muito pequenos (GERMANOPOULOS \& JOWITT, 1989).

O setor Alvorada, proposto para estudo, é de ocupação exclusivamente residencial de baixa e média renda, o que permite assumir, ao menos inicialmente, consumo noturno nulo. 
Conforme o modelo pressão-vazamento, há acréscimo das perdas conforme cresce a pressão de operação do sistema. Assim, através da avaliação da VMN sob diversos ajustes de VRP - diversas pressões de distribuição - é possível obter a relação entre a variação dos vazamentos com a variação da pressão a partir de uma situação de referência (VRP aberta) conforme LAMBERT (2001).

Os dados coletados durante condição de vazão mínima noturna alimentaram as rotinas de calibração para determinação dos parâmetros de vazamento sob diversas situações de operação (consumo noturno nulo, com descargas de rede e sob patamares de redução de pressão), com o propósito de estudar os parâmetros obtidos sob hipótese de consumo noturno nulo em situações diversas.

\subsubsection{Emprego de descargas de rede}

O uso de descargas em hidrantes como forma de solicitar hidraulicamente o sistema é proposto por WALSKI (1984) para coletas de dados para calibração de rugosidades de tubulações.

Sabe-se que, mesmo que validada a hipótese de consumo noturno nulo, não se tem um sistema estático, pois ainda há vazão de vazamento (REIS \& PORTO, 1992).

Assim, pretendeu-se avaliar o comportamento do sistema sob demandas altas e localizadas, através da abertura de dispositivos de descarga de rede, já que não existem hidrantes no sistema, conforme ilustra a Figura 4.10. 


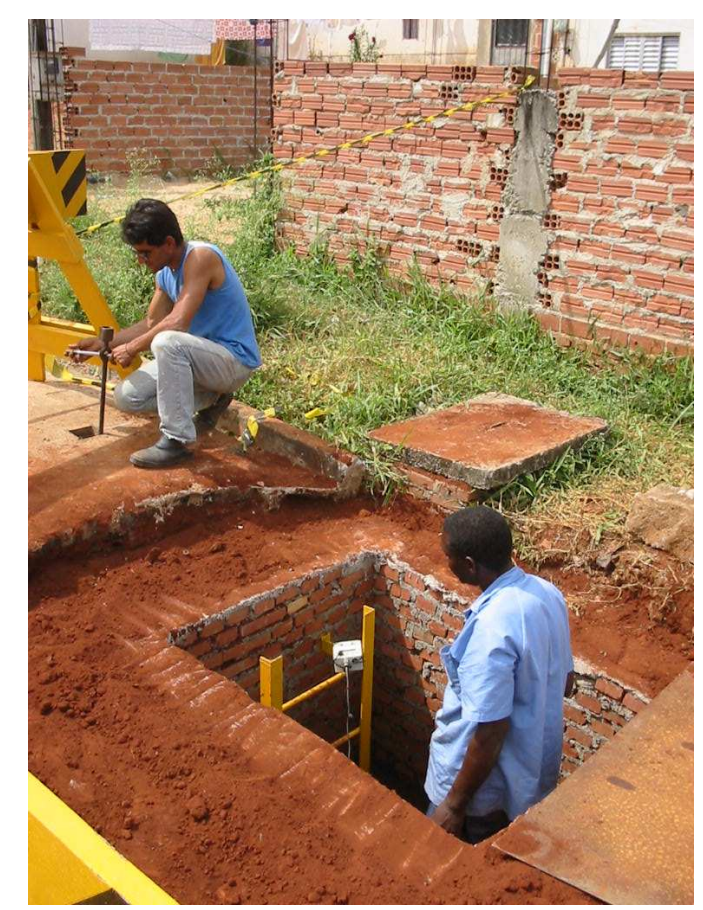

Figura 4.10 - acionamento de descarga de rede (D96 - Alvorada)

As descargas de rede serviram como consumos pontuais conhecidos, em localização e intensidade, capazes de substituir em uma simulação os consumos por parte da população, impossíveis de serem determinadas com precisão.

Uma manobra preliminar de teste das descargas, realizada em abril/2003, indicou haver boa propagação das descargas ao longo do setor sem ocorrência de pressões negativas, inclusive em nós críticos, conforme mostram as figuras 4.11 e 4.12.

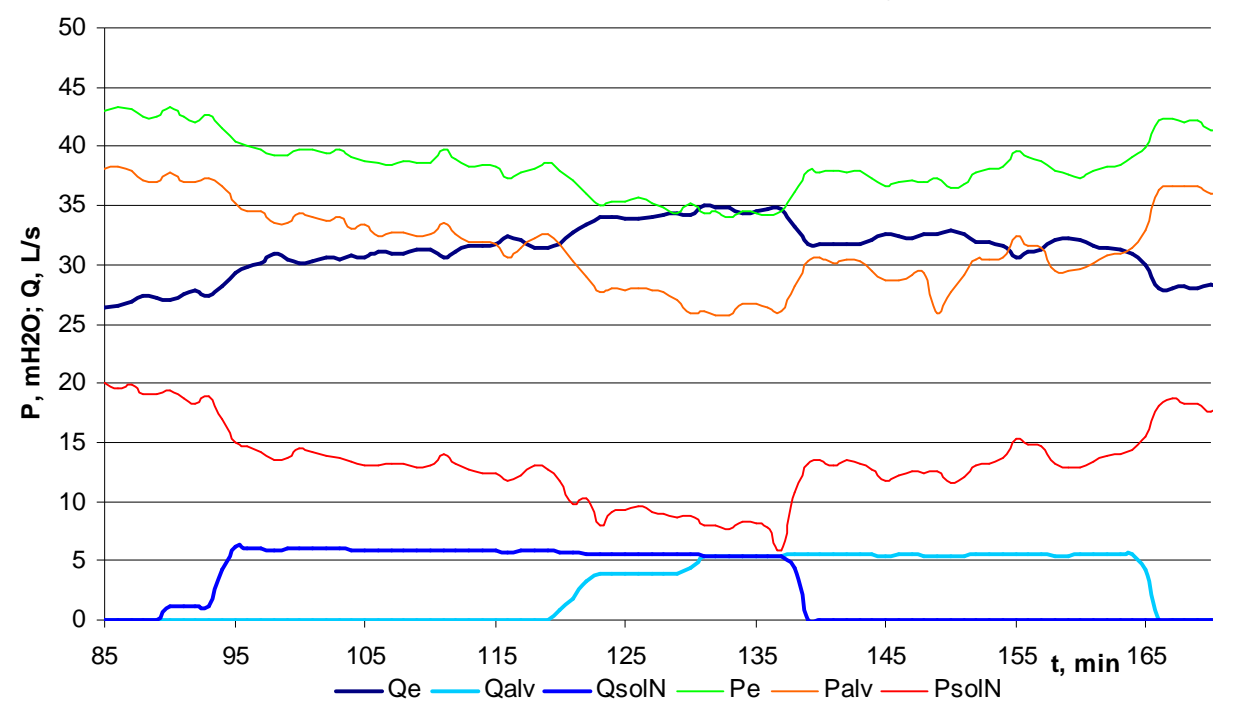

Figura 4.11 - análise preliminar do acionamento das descargas 

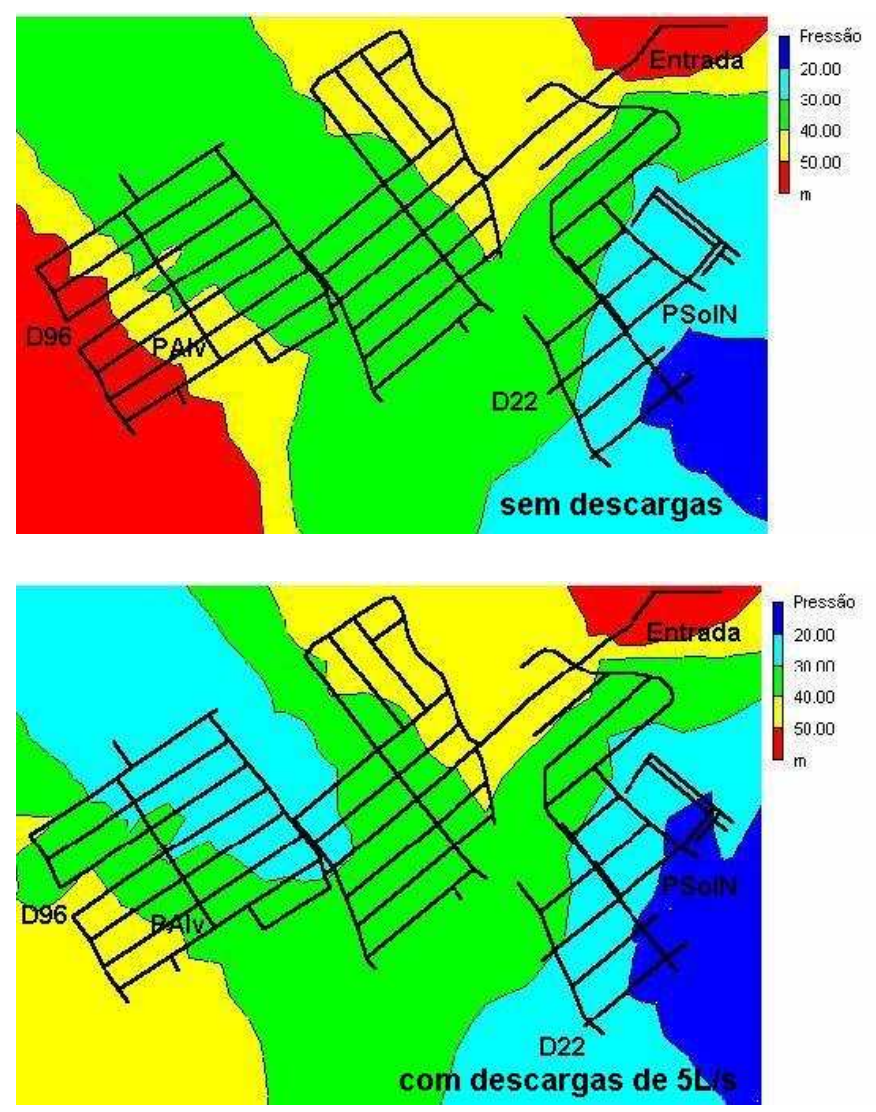

Figura 4.12 - propagação das descargas no software EPANET

Nas Figuras 4.11 e 4.12, Qe é a vazão de entrada do setor; Qalv é a vazão da descarga D96 (Alvorada); QsolN é vazão descarregada na descarga D22 (Sol Nascente); $P e$ é a pressão na entrada do setor; Palv é a pressão em ponto de referência no bairro Alvorada; e PsolN é pressão no ponto crítico (P41) no bairro Sol Nascente.

\subsubsection{Monitoramento da VMN - CEP}

O Controle Estatístico do Processo (CEP) é uma ferramenta de qualidade amplamente empregada em rotinas de produção e garantia de qualidade.

A partir do princípio de que todo processo é sujeito a variabilidades, o controle de parâmetros específicos do processo garante a identificação segura e expedita de causas especiais (ou aleatórias) e causas comuns. 
As causas especiais diferenciam-se pelo fato de produzirem alterações imprevisíveis no processo, como a quebra de ferramenta de determinada máquina de usinagem. Uma causa comum, na mesma máquina, seria o desgaste natural desta ferramenta.

O processo deve ser controlado a partir de uma carta de controle, denominada "carta X" na qual são lançados os parâmetros controlados em intervalos de tempo ou em função do número de amostras. A carta possui limites superior e inferior a partir da média de observações ou da existência de esperança pré-definida, que são:

$$
\begin{aligned}
& L S C=\bar{x}+2,66 \overline{R m} \\
& L C=\bar{x} \\
& L I C=\bar{x}-2,66 \overline{R m}
\end{aligned}
$$

onde $L S C$ é limite superior de controle; $L C$ é limite médio de controle e; $L I C$ é limite inferior de controle. $\mathrm{O}$ valor médio das medições é designado por $\bar{x}$ e o range ou amplitude média $\overline{R m}$ é dado por:

$$
\begin{gathered}
R m_{i}=\left|x_{i}-x_{i-1}\right| \quad i=2, \ldots, k \\
\overline{R m}=\frac{\sum_{i=2}^{k} R m_{i}}{k-1}
\end{gathered}
$$

A proposta consiste em determinar um período de estudo diário de ocorrência das menores vazões registradas, do qual a vazão mínima noturna será a média do período:

$$
\overline{\overline{Q m}}=\frac{\sum_{j=1}^{n} \overline{Q m}_{j}}{n}
$$

onde $\overline{\overline{Q m}}$ é media da média $\overline{Q m}$ das vazões mínimas diárias em um período de $n$ dias.

De posse da carta de controle, possíveis anomalias podem ser detectadas conforme ocorrência do ponto fora do padrão. Posição do ponto sob ou sobre os limites de controle e tendências crescentes ou decrescentes dos pontos, além da existência de 
ações corretivas, devem guiar a análise do parâmetro VMN na identificação das causas prováveis.

A média e os limites de controle podem ser alterados em caso de ações corretivas, principalmente quando do acompanhamento contínuo de processos.

\subsection{Balanço hídrico mensal corrigido}

O balanço hídrico mensal é técnica amplamente empregada pelas companhias de saneamento, pelo seu baixo custo e facilidade de implementação. Permite, com reservas, algum controle sobre ações contra perdas físicas e não-físicas (SILVA et al., 1998; LAMBERT \& HIRNER, 2000; CARVALHO FILHO et al., 2000).

A relação entre o volume aportado a um sistema e o volume micromedido pode esconder vários erros que ameaçam a validade da técnica, como os erros dos macro e micromedidores, ligações clandestinas e problemas de cadastro comercial e isolamento hidráulico.

Estudar as características metrológicas dos hidrômetros instalados é muito importante, tendo em vista que são instrumentos de medida de precisão relativamente frágil e sujeitos a fatores dos mais diversos, tais como idade, pressão de operação, consumos altos que induzem ao desgaste prematuro, tipo de acionamento, fabricante, entre vários outros.

Do ponto de vista financeiro, a precisão dos medidores interfere diretamente na receita da concessionária que administra a distribuição de água, pois praticamente toda a água faturada passa por eles.

As características metrológicas dos diversos tipos de hidrômetros instalados são informações vitais para quem administra um parque de medidores, devendo ditar quais devem ser substituídos para fins de ganho de receita e redução das perdas não-físicas. 


\subsubsection{Estimativa dos erros de indicação}

Os hidrômetros domiciliares que compõem o parque de medição do Setor Alvorada foram estratificados em função de três variáveis - pressão de operação, idade da instalação e consumo registrado no mês pesquisado. Também foi anotada a última leitura dos mostradores - que indica o volume total que atravessou o hidrômetro desde sua instalação - além de dados sobre classe metrológica e fabricação, que constam na numeração normalizada. Em ligações residenciais o SEMAE Piracicaba emprega, por convenção, apenas hidrômetros de $3 \mathrm{~m}^{3} / \mathrm{h}$ de capacidade e do tipo multijato classe B.

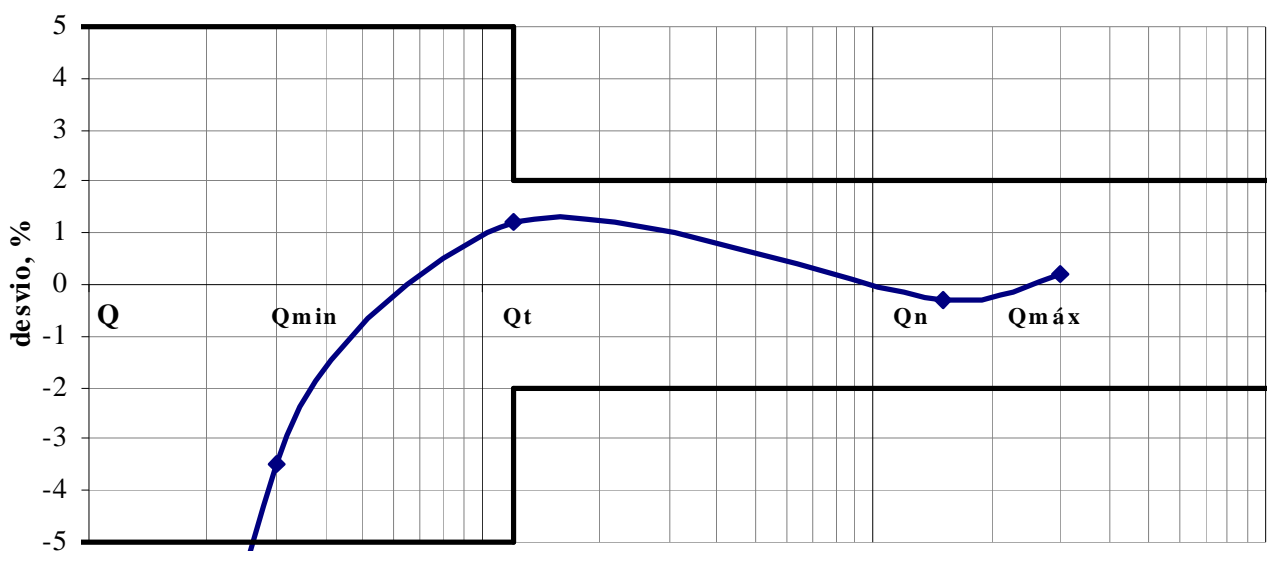

Figura 4.13 - curva característica de erros de hidrômetros taquimétricos Fonte: NBR 8195/1996, Anexo B.

As pressões de referência foram obtidas a partir da simulação da rede sob uma demanda média de $0,1 \mathrm{~L} / \mathrm{s}$ para cada nó. As pressões de referência nos nós simulados foram atribuídas aos medidores que estavam sob área de influência de cada nó.

Substratos com idade da instalação e consumo do mês de abril/2003 foram criados, com dados a partir do banco de dados do SEMAE Piracicaba.

\begin{tabular}{|c|c|c|c|c|c|c|}
\hline \multirow[t]{2}{*}{ população } & \multicolumn{3}{|c|}{0 a 5 anos } & \multicolumn{3}{|c|}{$>5$ anos } \\
\hline & 0 a $10 m^{3}$ & 11 a $20 m^{3}$ & $>20 \mathrm{~m}^{3}$ & 0 a $10 \mathrm{~m}^{3}$ & 11 a $20 \mathrm{~m}^{3}$ & $>20 \mathrm{~m}^{3}$ \\
\hline até $40 \mathrm{mH} 20$ & 30 & 38 & 17 & 45 & 70 & 33 \\
\hline 41 a $60 \mathrm{mH} 2 \mathrm{O}$ & 53 & 72 & 30 & 354 & 563 & 168 \\
\hline$>60 \mathrm{mH} 2 \mathrm{O}$ & 4 & 8 & 4 & 46 & 74 & 22 \\
\hline
\end{tabular}

Tabela 4.3 - população do parque de medidores do setor Alvorada 
A partir das populações estratificadas foram selecionadas, aleatoriamente, amostras iguais a $10 \%$ da população de cada extrato; este percentual removido foi determinado em função de fatores econômicos e da capacidade funcional da Hidrometria do SEMAE Piracicaba.

Nos casos onde a porcentagem indicada levaria a amostras menores ou iguais a unidade, foram selecionados um número de elementos amostrais igual a três.

As amostras foram retiradas e analisadas no laboratório de Hidrometria do SEMAE Piracicaba, conforme NBR8195/1996, sob vazões de 30,120 e 1500 L/h, respectivamente as vazões mínima, de transição e nominal dos hidrômetros taquimétricos de $3 \mathrm{~m} / \mathrm{h}$.

O modelo de Student foi aplicado, através de testes de hipótese, aos valores de média amostral e desvio-padrão observados em cada extrato e para cada vazão ensaiada.

Foram instalados registradores de vazão (data loggers) em residências com diferentes faixas médias de consumo, a fim de se estudar o comportamento das vazões que usualmente atravessam os medidores domiciliares.

\subsection{Modelo de GERMANOPOULOS \& JOWITT (1989)}

O modelo hidráulico proposto por GERMANOPOULOS \& JOWITT (1989) promove o equilíbrio hidráulico entre os nós e considera os vazamentos explicitamente na formulação do problema.

Os autores apresentam uma relação não linear, obtida experimentalmente em testes noturnos, para o modelo de pressão-vazamento:

$$
S_{i j}=c_{l} L_{i j}\left(P_{i j}^{A V}\right)^{1,18}
$$

onde $S_{i j}=$ vazão de vazamento no tubo conectado aos nós $i$ e $j ; c_{l}$ é uma constante; $L_{i j}$ é o comprimento da tubulação e; $P_{i j}{ }^{A V}$ é a pressão média entre os nós conectados. 
A partir de dados de entrada como demandas e cotas dos nós, além das características hidráulicas da rede e das estimativas iniciais dos parâmetros pressãovazamento, as cargas hidráulicas foram obtidas através da rotina de simulação.

Incógnitas do problema de calibração, os parâmetros do modelo pressão-vazamento - coeficiente de perda linear e expoente de pressão, C1 e N1, respectivamente - foram obtidos através de rotina de minimização dos desvios entre valores simulados e observados no setor, detalhadas em capítulo específico, conforme equação (4.6):

$$
q_{i j}=C 1 \cdot L_{i j} \cdot\left(\bar{P}_{i j}\right)^{N 1}
$$

onde: $q_{i j}$ é o vazamento no trecho entre os nós $i$ e $j ; C 1$ é coeficiente de perda linear a ser calibrado; $L_{i j}$ é o comprimento do trecho entre os nós $i$ e $j ; \bar{P}_{i j}$ é a pressão média entre os nós $i$ e $j$ e; $N 1$ é expoente de pressão a ser calibrado.

\subsection{EPANET}

O EPANET é um simulador hidráulico de código aberto, disponibilizado gratuitamente pela EPA - Environmental Protection Agency, agência norte-americana. Largamente empregado e discutido, trata-se de pacote consagrado de simulação hidráulica, que permite comunicação com a linguagem de programação empregada na elaboração das rotinas de calibração - C++.

As equações da continuidade e da conservação de energia são resolvidas através do "Método do Gradiente", com a promoção do equilíbrio hidráulico entre os nós e atualização das vazões com sucessivas alterações na carga hidráulica, em processo iterativo, conforme TODINI \& PILATI (1987) apud ROSSMAN (2000).

A relação entre vazão e perda de carga, em dada tubulação que interliga os nós $i$ e $j$, pode ser dada pela expressão:

$$
H_{i}-H_{j}=h_{i j}=r Q_{i j}^{n}+m Q_{i j}^{2}
$$


onde $H_{i}$ é a cota piezométrica no nó $i ; h$ é a perda de carga entre os nós; $r$ é constante de perda de carga; $Q_{i j}$ é a vazão que atravessa o tubo entre os nós $i$ e $j ; n$ é expoente de vazão e; $m$ é coeficiente de perda de carga localizada.

O bombeamento é representado pela lei:

$$
h_{i j}=-\omega^{2}\left(h_{0}-r\left(\frac{Q_{i j}}{\omega}\right)^{n}\right)
$$

onde $h_{0}$ é a altura de elevação para vazão nula; $\omega$ é regulação de velocidade e; $r$ e $n$ são coeficientes que definem a curva da bomba.

A conservação de massa nos nós pode ser dada por:

$$
\sum_{j} Q_{i j}-D_{i}=0 \quad \text { para } i=1, \ldots, N
$$

onde $D_{i}$ é a demanda no nó, por convenção com sinal positivo.

Conhecidas as cotas fixas (reservatórios), os valores das energias nos nós e vazões nos trechos devem satisfazer as equações (4.7) e (4.9).

O Método do Gradiente faz uma distribuição inicial de vazões no modelo - que não necessariamente satisfaça as equações (4.7) e (4.9) - e inicia o procedimento iterativo, onde é resolvido o sistema de equações:

$$
\mathbf{A H}=\mathbf{F}
$$

onde $\mathbf{A}=$ matriz Jacobiana $(N x N) ; \mathbf{H}=$ vetor de incógnitas em termos de energia e $\mathbf{F}=$ vetor dos termos do lado direito da equação.

A diagonal da matriz Jacobiana é formada por:

$$
A_{i j}=\sum_{j} p_{i j}
$$

enquanto que os elementos não nulos, fora da diagonal, são:

$$
A_{i j}=-p_{i j}
$$


onde $p_{i j}$ é o inverso da derivada da perda de carga total promovida pela vazão no trecho entre os nós $i$ e $j$.

Para trechos e bombas temos, respectivamente,

$$
\begin{gathered}
p_{i j}=\frac{1}{n r\left|Q_{i j}\right|^{n-1}+2 m\left|Q_{i j}\right|} \\
p_{i j}=\frac{1}{n \omega^{2} r\left(\frac{Q_{i j}}{\omega}\right)^{n-1}}
\end{gathered}
$$

Os termos do lado direito da matriz são formados por uma parcela que respeita o balanço de massa no nó somado a um fator de correção de vazão, na forma:

$$
F_{i}=\left(\sum_{j} Q_{i j}-D_{i}\right)+\sum_{j} y_{i j}+\sum_{j} p_{i f} H_{f}
$$

O último termo é aplicável a qualquer trecho que conecte um nó de carga fixa. O fator de correção de vazão é dado, para trechos e bombas, respectivamente pelas seguintes equações:

$$
\begin{gathered}
\left.y_{i j}=\left.p_{i j}|r| Q_{i j}\right|^{n}+m\left|Q_{i j}\right|^{2}\right) \operatorname{sgn}\left(Q_{i j}\right) \\
y_{i j}=-p_{i j} \omega^{2}\left(h_{0}-r\left(\frac{Q_{i j}}{\omega}\right)^{n}\right)
\end{gathered}
$$

onde $\operatorname{sgn}(x)$ vale 1 se $x>0$ e -1 , caso contrário. $Q_{i j}$ é sempre positivo para bombas.

Após o cálculo das energias conforme a equação (4.10) as novas vazões são obtidas na forma:

$$
Q_{i j}=Q_{i j}-\left(y_{i j}-p_{i j}\left(H_{i}-H_{j}\right)\right)
$$

O processo iterativo continua até que a diferença entre vazões calculadas satisfaça a uma tolerância previamente estabelecida. Os valores das vazões obrigatoriamente satisfazem as equações da continuidade a partir da primeira iteração. 
Para a equação de resistência de Darcy-Weisbach o fator $f$ é determinado conforme o número de Reynolds, a partir da fórmula de Hagen-Poiseuille para escoamento laminar, equação de Dunlop (interpolação cúbica do ábaco de Moody) para o regime de transição e fórmula aproximada de Swamee-Jain para Re>4000.

\subsection{Modelo hidráulico do setor}

O modelo hidráulico do setor Alvorada utilizado nas simulações foi construído a partir de mapas cadastrais do SEMAE Piracicaba que, digitalizados e georreferenciados, constituem referência importante e segura quanto a comprimentos e diâmetros das tubulações. Fichas cadastrais com detalhes e profundidades a cada cruzamento costumam ser empregados, mas no caso dos bairros Sol Nascente e Alvorada, poucas fichas foram encontradas devido às características do empreendimento - conjunto habitacional de construção rápida e padronizada.

Uma equipe de topografia do SEMAE Piracicaba providenciou um levantamento planialtimétrico das redes de água do setor Alvorada ao nível dos pavimentos. As profundidades das redes foram estimadas a partir das fichas existentes e de medições de profundidades dos registros de manobra existentes.

Engenheiros e funcionários da autarquia foram entrevistados e dirimiram dúvidas durante a fase de identificação do setor. Campanhas de certificação do isolamento hidráulico, a partir de medições de pressão e conferência do fechamento de válvulas, foram empreendidas e bem sucedidas em 2001 e 2002.

As simulações durante a ocorrência da vazão mínima noturna exigem emprego da Fórmula Universal, frente às baixas velocidades e diferentes regimes de escoamento encontrados. As rugosidades absolutas das redes foram estimadas a partir da bibliografia existente dado que possuem, ao menos para o modelo, um significado 
estritamente matemático e não hidráulico - trata-se, aqui, da rugosidade de um trecho de rede real com ligações prediais, transições de diâmetros e materiais, peças de intervenções de operação e manutenção, entre outros, e não de um simples trecho de tubulação ensaiado em laboratório.

A Tabela 4.4 traz as rugosidades adotadas no modelo do Setor Alvorada e respectivas referências:

Tabela 4.4 - rugosidades absolutas empregadas no modelo do setor Alvorada

\begin{tabular}{c|c|c}
\hline Material & $\boldsymbol{\varepsilon}(\mathbf{m m})$ & Referência \\
\hline PVC & 0,06 & BAPTISTA \& COELHO (2002) \\
\hline CA & 0,03 & BAPTISTA \& COELHO (2002) \\
\hline $\begin{array}{c}\text { FoFo sem } \\
\text { revestimento }\end{array}$ & 0,10 & LAMONT (1981) \\
\hline
\end{tabular}

Perdas de carga localizadas não foram consideradas.

A derivação da entrada do setor a partir de sub-adutora por recalque foi simulada com a aplicação de um reservatório de nível variável como fonte de entrada ao setor. A cada simulação é atribuída à linha d'água do reservatório uma altura numericamente igual à pressão medida na entrada do setor, no instante simulado.

As demandas de consumo nos nós durante ocorrência da vazão mínima noturna foram consideradas nulas, sendo o sistema solicitado tão somente pelos vazamentos conforme equação (4.6).

Durante as simulações diurnas as demandas de consumo foram estimadas como variáveis com a pressão a partir de um vetor de demandas de consumo de referência, $D R$. 
Dois modelos de estimativa da demanda de consumo de referência foram aplicados: a partir do consumo médio global corrigido e a partir da média do somatório dos consumos em cada nó, também corrigido pelos erros de micromedição.

No primeiro caso (modelo I), a demanda de consumo de referência em determinado nó $i$ é o produto do consumo total corrigido do setor pela parcela da área de influência do nó $i$ :

$$
D R_{i}=\frac{\sum m \delta m}{2592} \frac{A_{i}}{\sum_{i=1}^{n} A_{i}}[L / s]
$$

onde $D R_{i}$ é a demanda de consumo de referência no nó $i ; \Sigma m$ é o somatório global da micromedição, em m³/mês; $\delta m$ é o desvio da micromedição; $A_{i}$ é área de influência do nó $i$ e; $n$ é o número de nós.

Outra abordagem ao cálculo da demanda de consumo de referência em cada nó $i$ é a partir do somatório do consumo, corrigido pelo índice de submedição, dentro da área de influência de cada nó (modelo II):

$$
D R_{i}=\frac{\sum_{i=1}^{n} m_{i} \delta m}{2592}[L / s]
$$

A transformação da demanda de consumo de referência na demanda efetivamente consumida em cada nó em função da pressão de serviço, bem como a composição da demanda total - consumo mais vazamento - será detalhada em capítulo específico.

\subsection{Busca Direta Univariada}

O método de busca direta univariada aplicado promove a evolução do valor das variáveis de decisão da Função Objetivo a ser otimizada através da calibração de uma variável a cada passo, através da relação: 


$$
X_{q+1}=X_{q}+\alpha_{q} S_{q}
$$

onde $X_{q+1}$ é a nova posição do ponto $X(a, b, \ldots, n) ; X_{q}$ é a posição de partida da busca na direção $q ; \alpha_{q}$ é o tamanho do passo dado na direção $S_{q}$ e; $S_{q}$ é direção de busca cíclica padrão, que determina qual das variáveis sofrerá mudança na otimização, por exemplo, $S_{a}=(1,0, \ldots, 0), S_{b}=(0,1, \ldots, 0), S_{n}=(0,0, \ldots, 1)$.

A principal diferença entre os métodos de busca de grau nulo disponíveis na literatura reside nos procedimentos de determinação do tamanho do passo a ser dado, $\alpha_{q}$. O procedimento empregado permite rápida convergência através da duplicação ou da redução pela metade do tamanho do passo $t$ com avaliações sucessivas da melhora na FO, em processo iterativo (FOX, 1971).

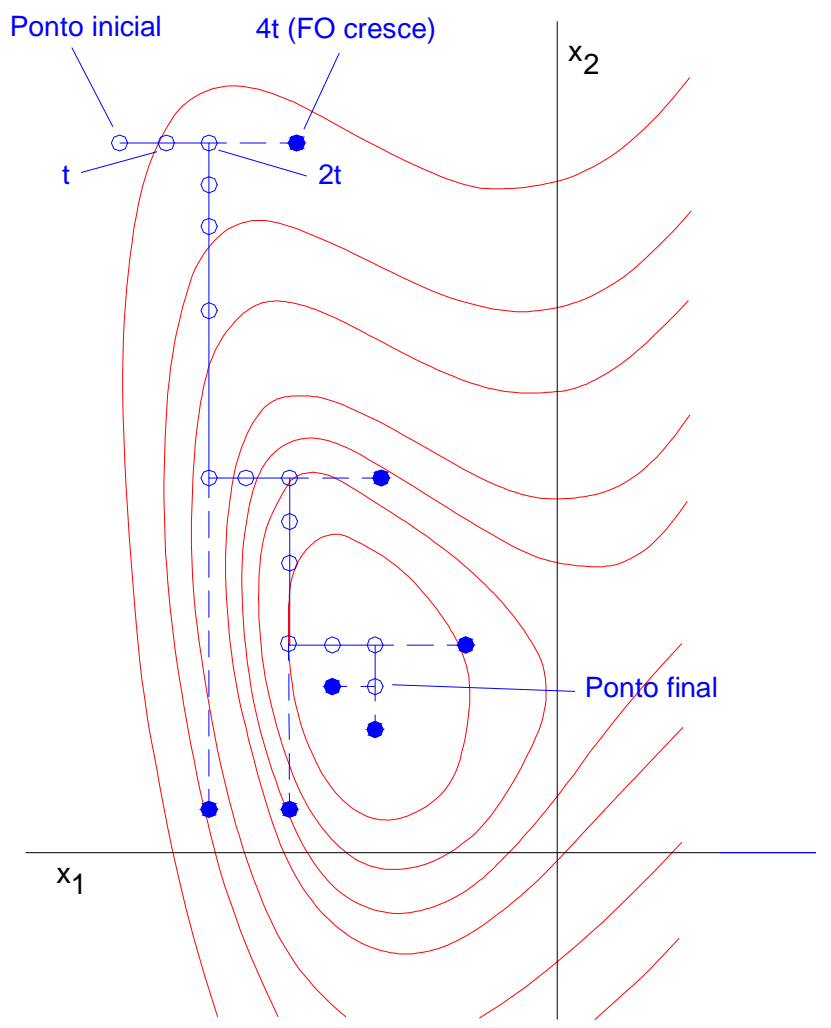

Figura 4.14 - caminhamento do método de busca direta univariada Fonte: FOX, 1971 
O fluxograma apresenta o método empregado, onde $K$ é critério de parada da otimização; $J$ indica se houve sucesso em dada direção $q$ e; $\varepsilon$ é um número pequeno considerado, no caso, como igual a $10 \%$ do passo inicial de referência $t_{i}$ - aplicado antes do emprego do passo $t$ (FOX, 1971).

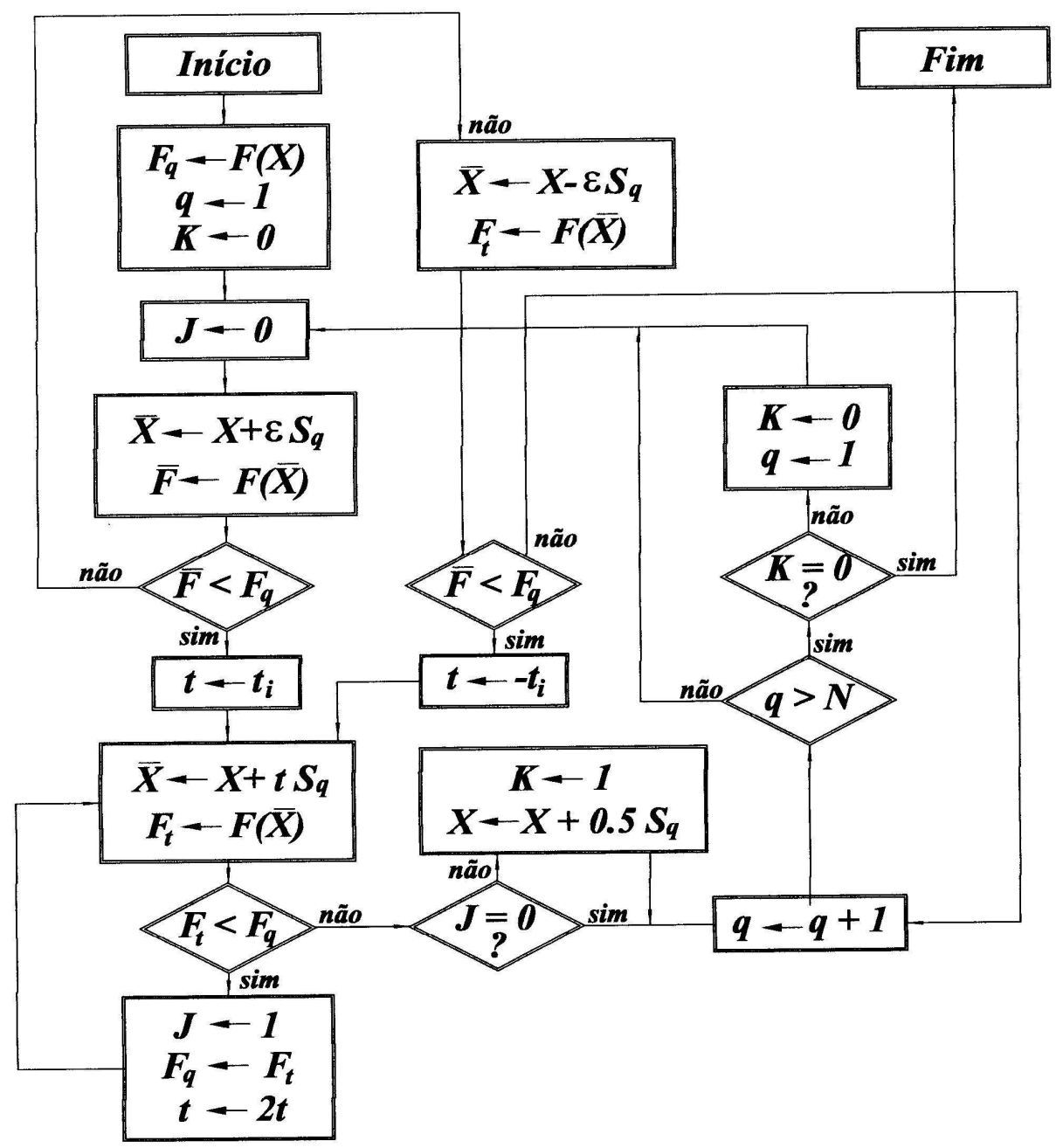

Figura 4.15 - fluxograma do método de busca direta univariada empregado Fonte: FOX, 1971

Em cada direção de busca uma única variável é incrementada e o processo segue até que não haja melhora em qualquer das variáveis. O procedimento garante ajuste do sinal do passo inicial durante o processo iterativo de otimização. 
Os parâmetros C1 e N1 de vazamento, variáveis a otimizar, apresentam ordens de grandeza distintas (aproximadamente $10^{-5}$ e 1, respectivamente), o que exige o emprego de passos $t$ distintos para cada variável.

\subsection{Simulador Hidráulico}

\subsubsection{Simulador hidráulico sob consumo noturno nulo}

O simulador hidráulico é executado cada vez que o método de busca avalia melhora no valor da Função Objetivo e compõe, portanto, o modelo de calibração dos parâmetros de vazamento.

Sob consumo noturno nulo o vetor de demandas de consumo de referência, $D R$, assume valores nulos.

A rotina inicia processo iterativo que analisa cada trecho da rede e atribui a seus nós de montante e jusante demandas de vazamento conforme GERMANOPOULOS \& JOWITT (1989) até que a diferença entre pressões calculadas nas iterações $i$ e $i_{-1}$ seja menor que uma determinada tolerância $\Delta_{l}$.

O procedimento é repetido em loop externo para os $n p$ patamares estudados e a Função Objetivo de SANTOS (2000), equação (4.22), é calculada:

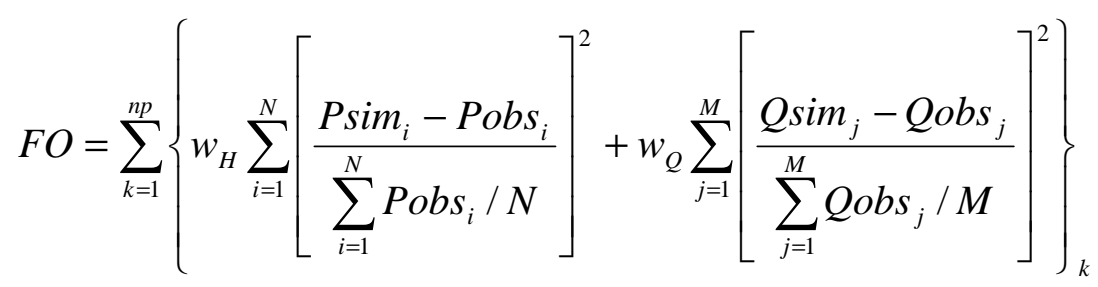

onde: Psim e Pobs são pressões simuladas e observadas, respectivamente, em $\mathrm{mH}_{2} \mathrm{O}$; Qsim e Qobs são vazões simuladas e observadas, respectivamente, em $\mathrm{L} / \mathrm{s} ; N$ é o conjunto de pontos de observação de pressão; $M$ é o conjunto de pontos de observação de vazão; $n p$ é o número de padrões hidráulicos considerados; $w_{H}$ e $w_{Q}$ são pesos 
atribuídos aos desvios de carga e vazão, nos quais os índices $H$ e $Q$ denotam pressão e vazão, respectivamente.

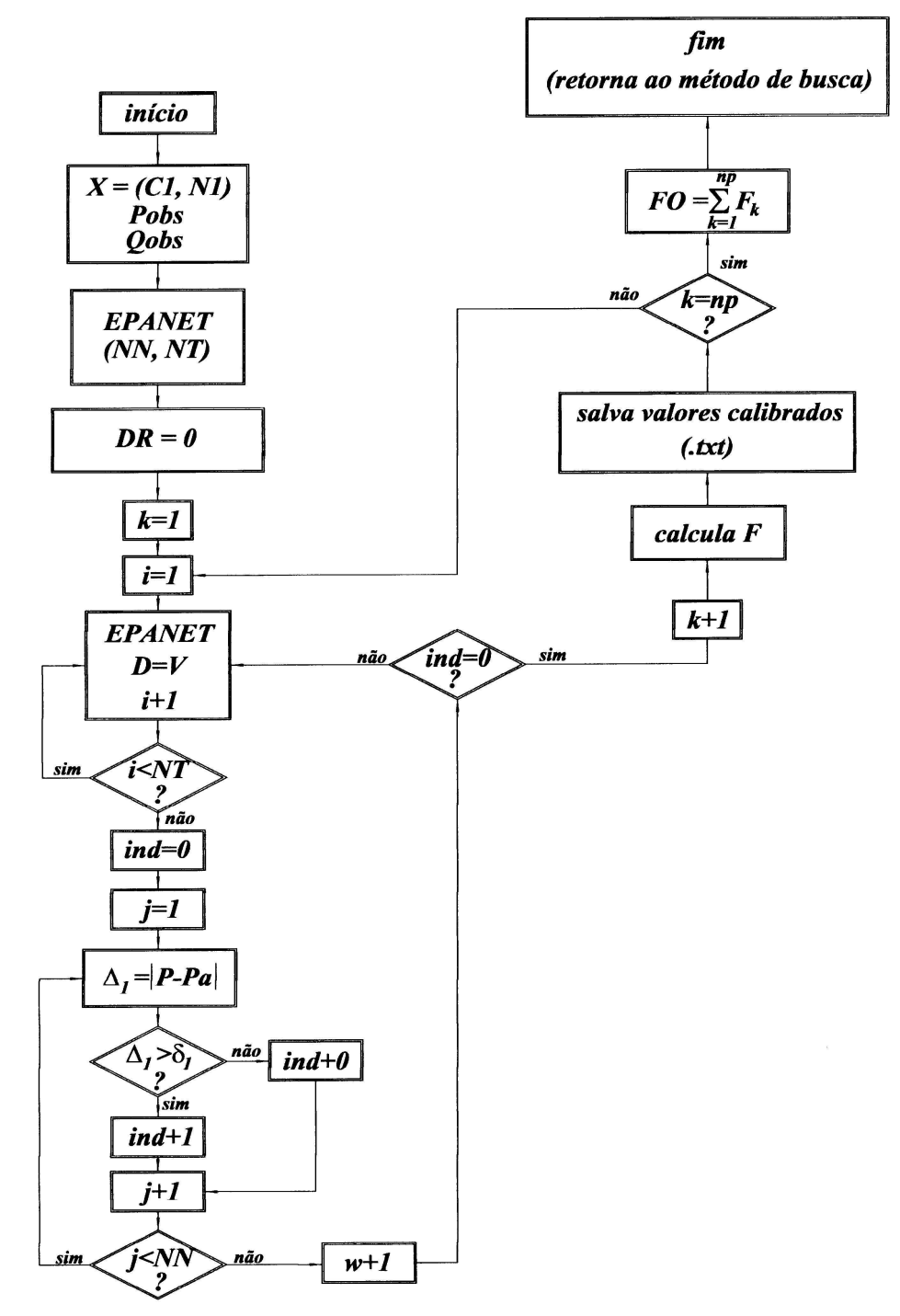

Figura 4.16 - fluxograma do simulador hidráulico com consumo noturno

\subsubsection{Simulador hidráulico sob demanda de consumo dirigida pela pressão}

De forma análoga aos procedimentos sob consumo noturno nulo, as simulações sob demanda variável com a pressão partem de um ponto inicial $X=(C 1, N 1)$ - advindo do método de busca - e inicia-se o procedimento de calibração desses parâmetros frente aos dados observados no setor. 
Um vetor de demandas de referência, $D R$, é obtido de arquivo com extensão .txt.

Um fator temporal de consumo, FTl, é estimado em função da vazão observada de entrada $\left(Q o b s_{E}\right)$ e do somatório das demandas de consumo de referência $(D R)$.

$$
F T 1=\frac{Q o b s_{E}}{\sum_{i=1}^{n} D R_{i}}
$$

O processo iterativo percorre os trechos do sistema aplicando as relações de vazamento e consumo dirigidos pela pressão, $V$ e $D$, respectivamente, até que a diferença entre qualquer pressão calculada nas iterações $i$ e $i_{-1}$ seja menor que dada tolerância $\Delta_{l}$. Os vazamentos foram modelados conforme GERMANOPOULOS \& JOWITT (1989) tendo como variáveis C1 e N1 - equação (4.6). As demandas de consumo dirigidas pela pressão resultam do produto do fator temporal $F T$, da demanda de referência $D R$ e do adimensional $\rho$, conforme equação (4.24):

$$
D_{i}=D R_{i} \cdot F T 1 . \rho
$$

\begin{tabular}{|c|c|c|c|}
\hline \multirow{2}{*}{\multicolumn{2}{|c|}{$0 \leq H \leq H_{\min }$}} & \multirow{3}{*}{$\begin{array}{c}H_{\min } \leq H \leq H_{d e s} \\
\rho=\frac{\left(H-H_{\min }\right)^{2}\left(3 H_{d e s}-2 H-H_{\min }\right)}{\left(H_{d e s}-H_{\min }\right)^{3}}\end{array}$} & \multirow{3}{*}{$\begin{array}{c}H \geq H_{\text {des }} \\
\rho=1\end{array}$} \\
\hline & & & \\
\hline $\begin{array}{l}\text { FUJIWARA \& LI } \\
(1998)-\text { eq.(4.25) }\end{array}$ & $\rho=0$ & & \\
\hline $\begin{array}{c}\text { TABESH \& } \\
\text { KARIMZADEH } \\
\text { (2000) } \operatorname{com} n=2- \\
\text { eq. }(4.26)\end{array}$ & $\rho=0$ & $\rho=\left(\frac{H-H_{\min }}{H_{d e s}-H_{\min }}\right)^{1 / n}$ & $\rho=1$ \\
\hline $\begin{array}{l}\text { EXPONENCIAL } \\
(2003)-\text { eq.(4.27) }\end{array}$ & $\rho=0$ & $\rho=\frac{\left(H-H_{\min }\right) e^{\frac{H-H d e s}{H d e s}}}{\left(H_{d e s}-H_{\min }\right)}$ & $\rho=1$ \\
\hline $\begin{array}{l}\text { SENOIDAL }(2003)- \\
\text { eq. }(4.28)\end{array}$ & $\rho=0$ & $\rho=\frac{H-H_{\min }}{H_{d e s}-H_{\min }} \operatorname{sen}^{3}\left(\frac{\pi H}{2 H_{d e s}}\right)$ & $\rho=1$ \\
\hline
\end{tabular}

Tabela 4.5 - equações empregadas de demanda de consumo dirigida pela pressão 


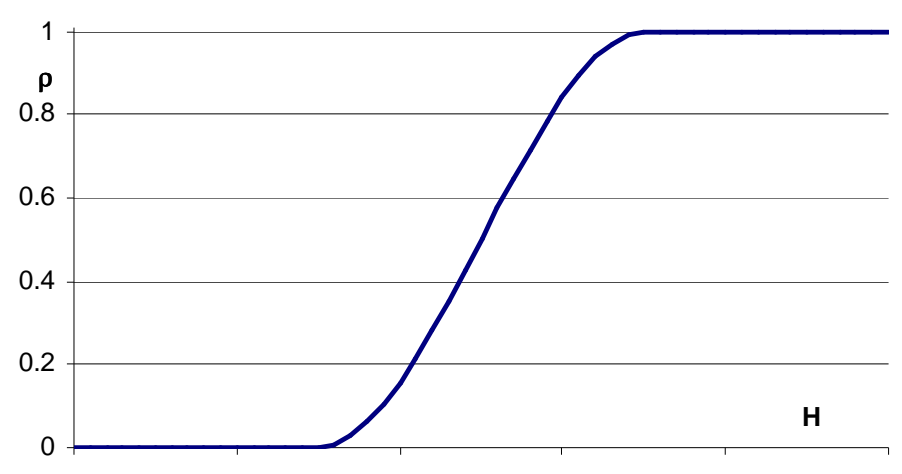

Figura 4.17 - curva de FUJIWARA \& LI (1998)

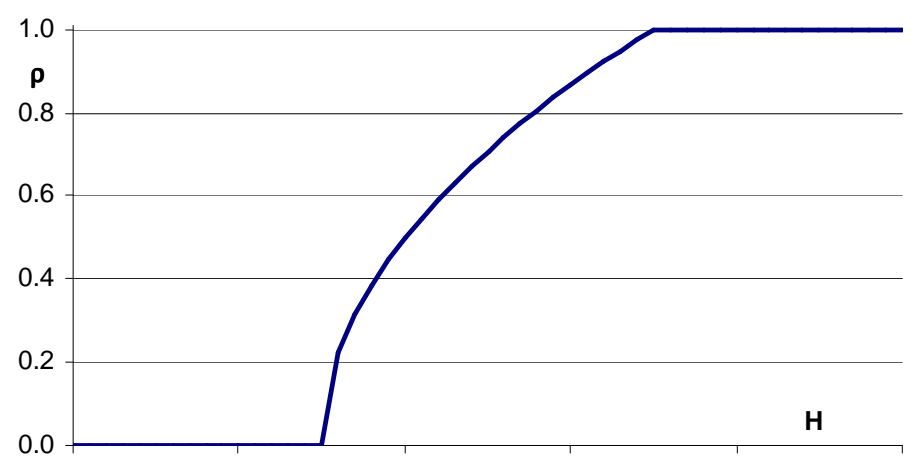

Figura 4.18 - curva de TABESH \& KARIMZADEH (2000) com $n=2$

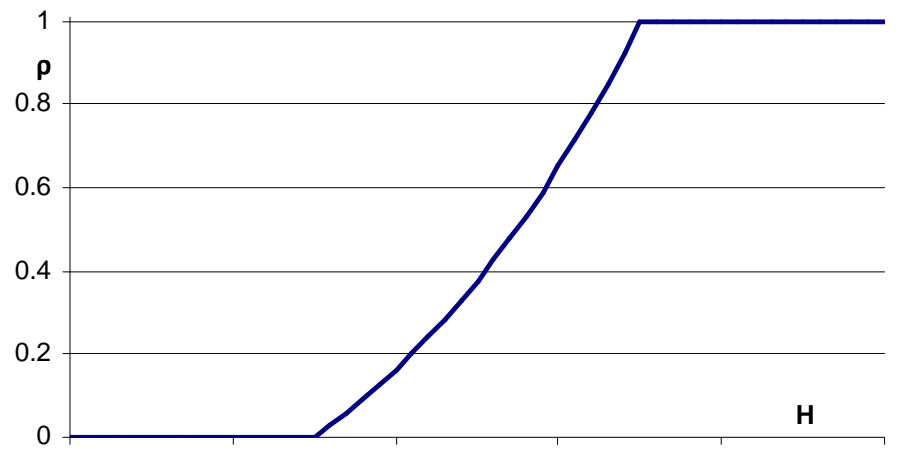

Figura 4.19 - curva EXPONENCIAL (2003)

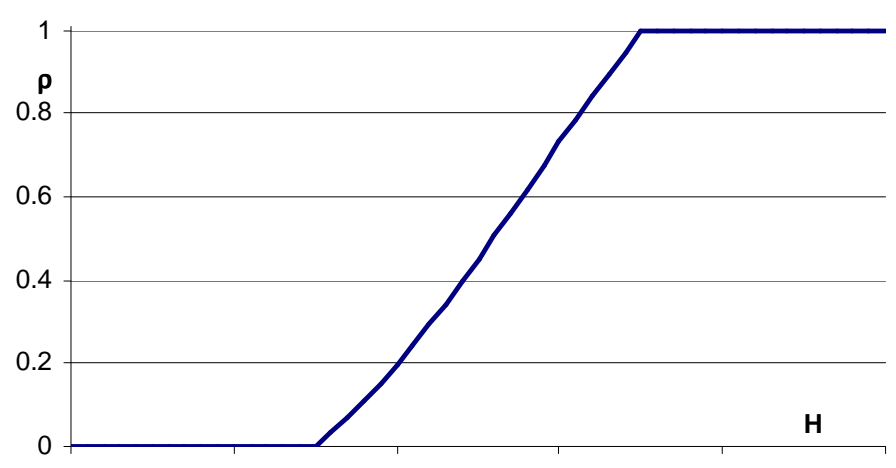

Figura 4.20 - curva SENOIDAL (2003) 
Atingido o equilíbrio hidráulico, um novo fator temporal de consumo, FT2, é calculado e duas outras tolerâncias são verificadas: diferença entre fatores temporais nas iterações $i$ e $i_{-1}\left(\Delta_{2}\right)$ e equação da continuidade entre a vazão aportada e as parcelas devidas aos vazamentos e consumos $\left(\Delta_{3}\right)$. O processo retorna em loop externo até que sejam satisfeitas as tolerâncias $\Delta_{2}$ e $\Delta_{3}$.

Finalizado o processo de simulação e estabilização hidráulica é calculada a Função Objetivo da equação (4.29), que considera isoladamente cada padrão hidráulico estudado para análise das variações entre diferentes instantes e curvas de consumo:

$$
F O=w_{H} \sum_{i=1}^{N}\left[\frac{\operatorname{Psim}_{i}-\operatorname{Pobs}_{i}}{\sum_{i=1}^{N} \operatorname{Pobs}_{i} / N}\right]^{2}+w_{Q} \sum_{j=1}^{M}\left[\frac{Q \operatorname{sim}{ }_{j}-Q o b s_{j}}{\sum_{j=1}^{M} Q o b s_{j} / M}\right]^{2}
$$

onde: Psim e Pobs são pressões simuladas e observadas, respectivamente, em $\mathrm{mH}_{2} \mathrm{O}$; Qsim e Qobs são vazões simuladas e observadas, respectivamente, em L/s; $N$ é o conjunto de pontos de observação de pressão; $M$ é o conjunto de pontos de observação de vazão; $w_{H}$ e $w_{Q}$ são pesos atribuídos aos desvios de carga e vazão, nos quais os índices $H$ e $Q$ denotam pressão e vazão, respectivamente.

A simulação hidráulica cessa com a criação de arquivo que reporta os valores simulados e com a exportação do valor da Função Objetivo para julgamento do método de busca. O fluxograma a seguir ilustra todo o processo de simulação hidráulica sob consumo variável com a pressão. 


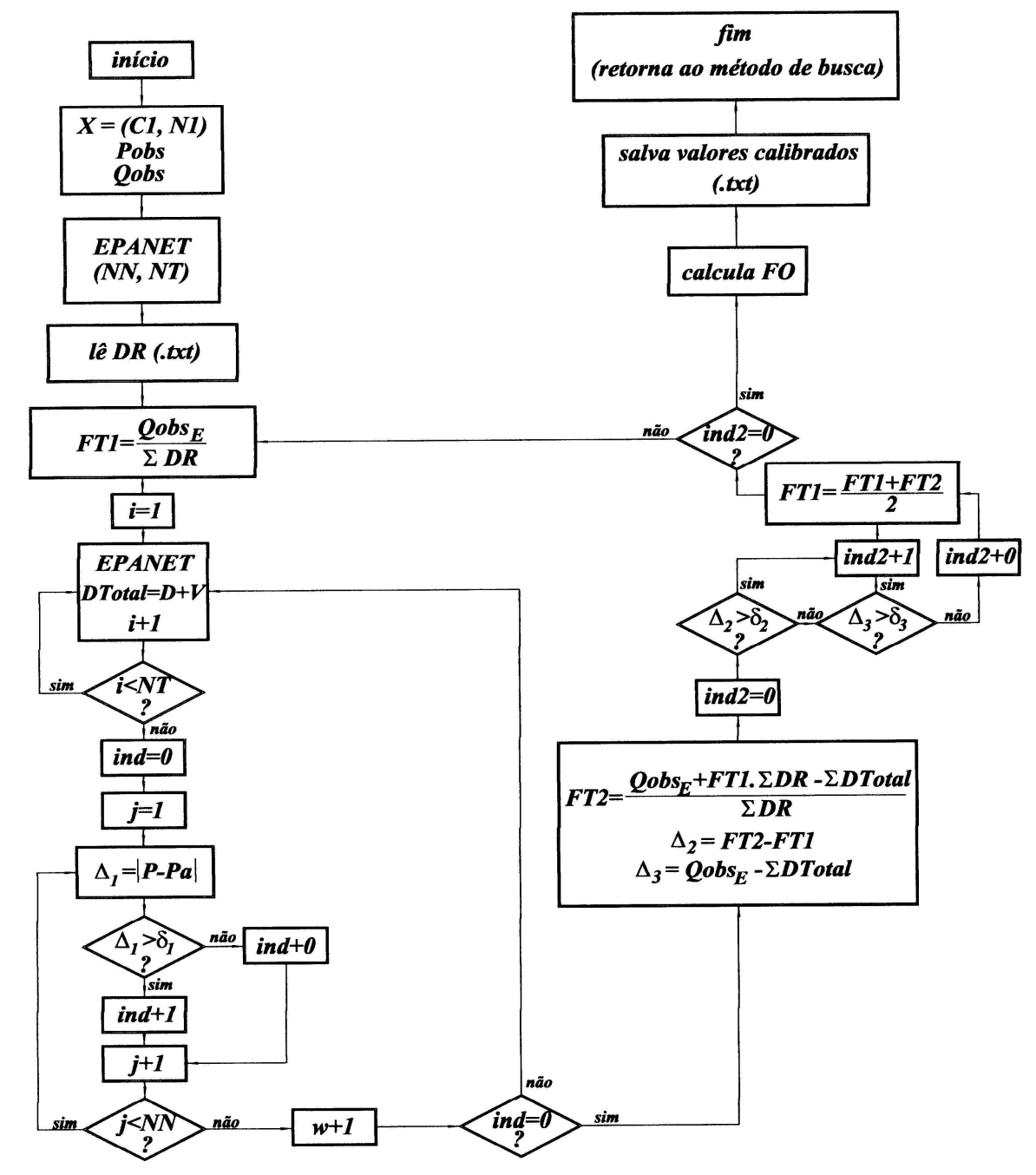

Figura 4.21 - fluxograma do simulador hidráulico com vazamentos e consumos dirigidos pela pressão 


\section{RESULTADOS E DISCUSSÕES}

\subsection{Coleta de dados}

No período de 05 a 17 de maio de 2003 foram coletados dados de pressão em pontos estratégicos do Setor Alvorada, em Piracicaba, SP, inclusive a montante e jusante da VRP de entrada. Valores de vazão também foram coletados na entrada do setor e em duas descargas de rede localizadas em ponto alto e baixo do setor.

Conectados a coletores de dados, os sensores de pressão foram instalados em cavaletes domiciliares através de peça tipo "tê", de forma a permitir ao consumidor o uso da torneira do cavalete durante o período de coleta.

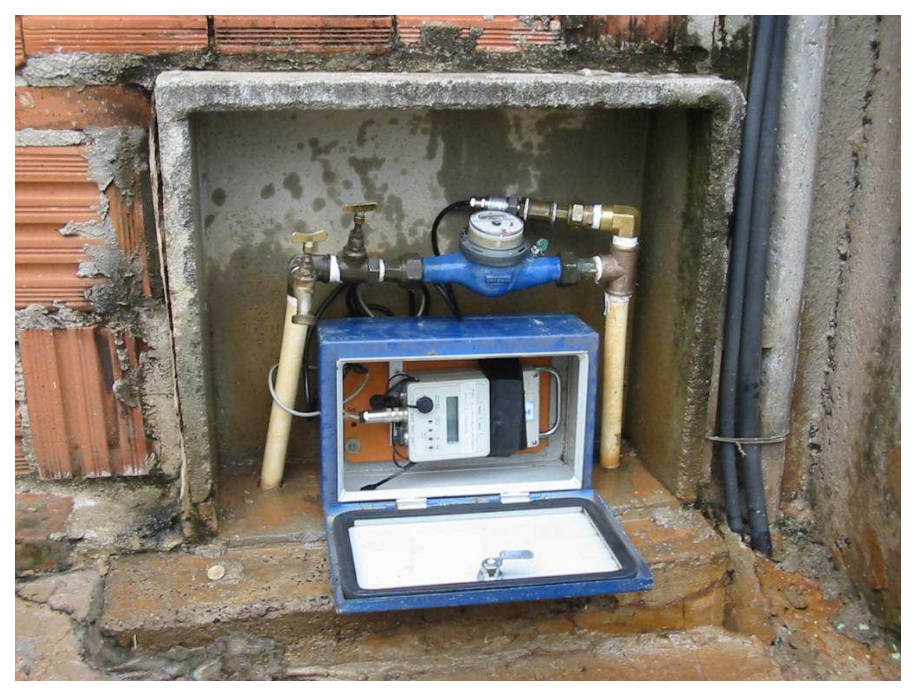

Figura 5.1 - instalação típica de sensor de pressão

Os sensores de pressão foram instalados nas adjacências dos nós cujos monitoramentos eram desejados e os desníveis geométricos entre cavalete e nó foram obtidos, considerados e corrigidos nos valores finais utilizados nas simulações. 
Tabela 5.1 - pontos monitorados no setor Alvorada

\begin{tabular}{|c|c|c|c|c|c|c|}
\hline $\begin{array}{c}\text { Nó/ } \\
\text { trecho }\end{array}$ & Descrição & Medida & Instrumentação & $\begin{array}{c}\text { Cota terreno, } \\
\text { m }\end{array}$ & $\begin{array}{c}\text { Correção, } \\
\text { m }\end{array}$ & $\begin{array}{c}\text { Cota real, } \\
\text { m }\end{array}$ \\
\hline 07 & Ponto médio & Pressão & Sensor 10,0 bar & 558,580 & $+1,690$ & 560,270 \\
\hline 41 & Ponto mais alto & Pressão & Sensor 10,0 bar & 580,435 & $-1,030$ & 579,405 \\
\hline 69 & Ponto médio & Pressão & Sensor 10,0 bar & 557,857 & $+0,290$ & 558,147 \\
\hline 87 & Ponto mais baixo & Pressão & Sensor 10,0 bar & 540,718 & $+1,050$ & 541,768 \\
\hline 22 & Descarga Sol Nascente & Vazão & $\begin{array}{l}\text { Voltman horizontal } \\
\text { DN50 com saída OPTO }\end{array}$ & 564,593 & - & 564,593 \\
\hline 96 & Descarga Alvorada & Vazão & $\begin{array}{l}\text { Voltman horizontal } \\
\text { DN50 com saída OPTO }\end{array}$ & 538,652 & - & 538,652 \\
\hline 141 & Entrada e VRP & $\begin{array}{l}\text { Pressões } \\
\text { e vazão }\end{array}$ & $\begin{array}{l}\text { Voltman horizontal } \\
\text { com saída REED e } \\
\text { sensor } 20,7 \text { bar }\end{array}$ & 558,120 & - & 558,120 \\
\hline
\end{tabular}

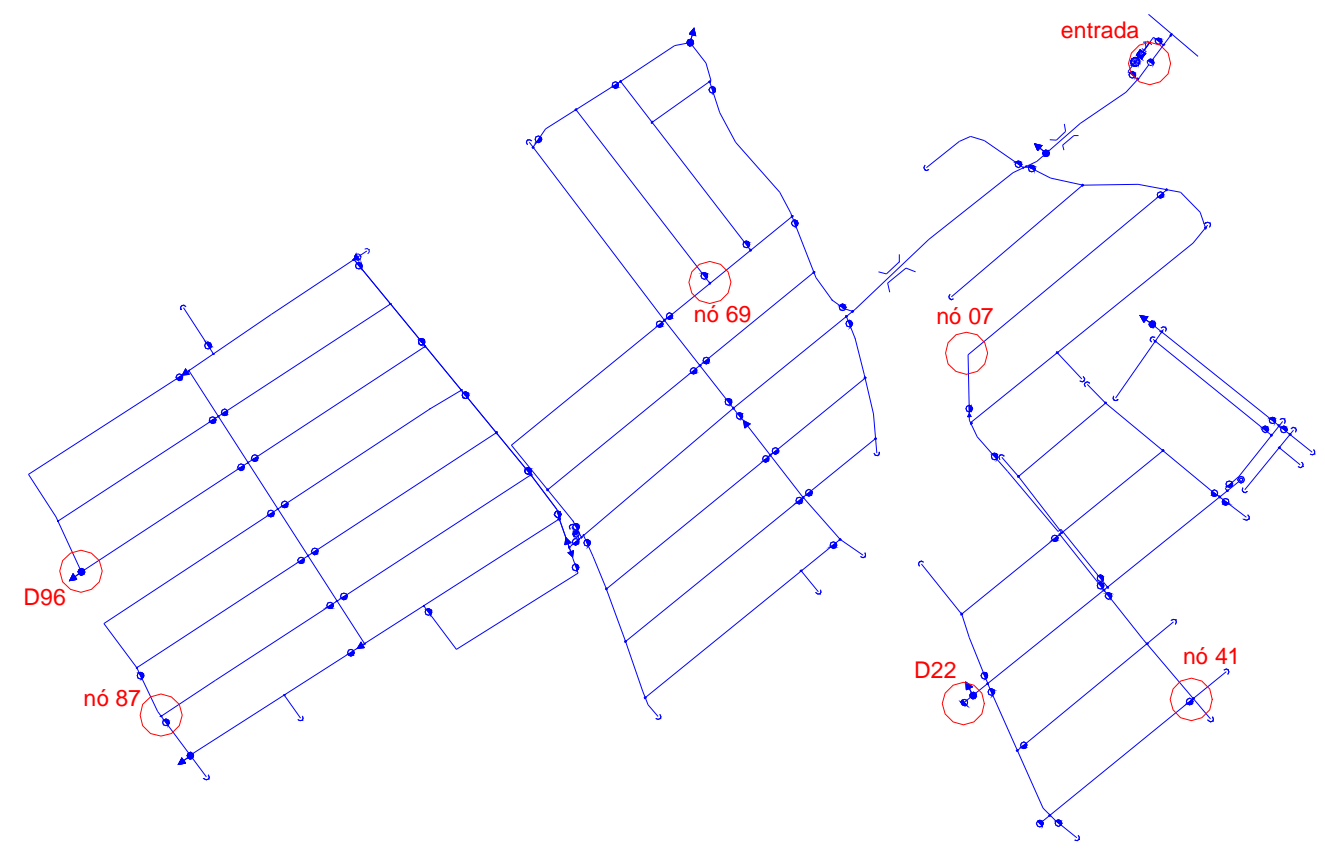

Figura 5.2 - localização dos pontos monitorados

Após o início da coleta de dados foram observadas pressões menores que as esperadas no nó 41, ponto mais elevado do setor. Reclamações de consumidores davam conta de um vazamento de grande monta a cerca de 100 m do nó 41 . 
O vazamento, causado pela desconexão de um cap (extremidade de rede) em rede em PVC DN50, foi localizado e reparado na tarde do dia 09 de maio, a partir de quando se observou forte recuperação de pressões e alívio nas vazões de entrada. Com o reparo as pressões retornaram aos valores esperados e cessaram as reclamações de falta de água que se referiam ao vazamento.

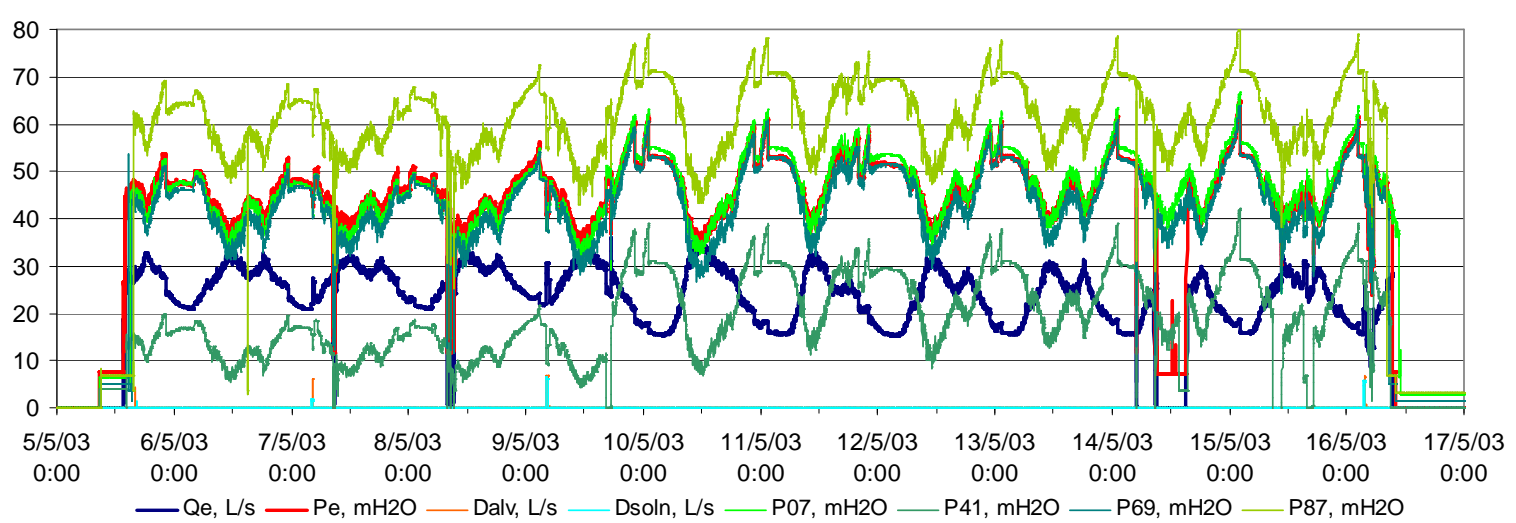

Figura 5.3 - dados coletados no setor Alvorada

Nos dias 07, 09, 14 e 16 de maio houve acionamento das descargas de rede hidrometradas instaladas nos nós 22 e 96 - bairros Sol Nascente e Alvorada, respectivamente, cujos dados foram armazenados e utilizados nas simulações noturnas.

As descargas foram acionadas segundo um procedimento de seqüências e horários, definido a partir de observações prévias de campo e com o propósito de facilitar a interpretação e comparação dos dados:

- 4h00: abertura da descarga D22 (Sol Nascente);

- 4h15: abertura da descarga D96 (Alvorada);

- 4h30: fechamento da descarga D22 (Sol Nascente) e;

- 4h45: fechamento da descarga D96 (Alvorada). 
Apenas as descargas que antecederam os patamares de pressão foram promovidas antecipadamente e com intervalos de apenas 10 minutos entre acionamentos, para que não houvesse interferência com os períodos de consumo não nulo.

O procedimento permite a avaliação de situações com descargas alternadas e sobrepostas, em três padrões hidráulicos distintos: acionamento somente da descarga Sol Nascente; descargas Sol Nascente e Alvorada simultaneamente e; apenas a descarga Alvorada.

Como abertura das descargas entende-se seu acionamento com duas voltas em sua válvula (registro) de manobra, procedimento definido previamente em testes de campo como aquele que garante vazões da ordem de 5,0 a 6,0 L/s em cada descarga.

No dia 16 de maio foram promovidos patamares de redução de pressão na VRP de entrada do setor, logo após descargas de rede. A partir de uma condição de referência (VRP livre ou sem redução de pressão) houve descargas de rede com intervalos de 10 minutos entre si, conforme o procedimento descrito anteriormente.

Em seguida foram promovidos patamares de redução através da regulagem do piloto hidráulico da VRP de entrada. Foram promovidos quatro patamares e mantidos por aproximadamente 15min. A Figura 5.4 ilustra os resultados obtidos com o procedimento adotado.

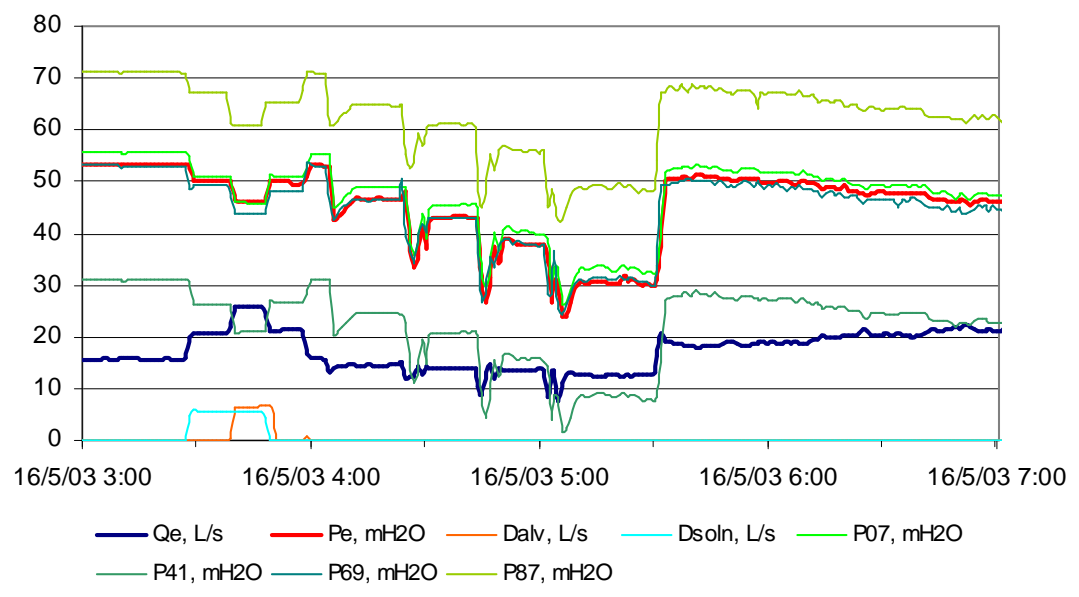

Figura 5.4 - detalhe de dados durante descargas e patamares de redução de pressão 
Neste dia, bem como nos outros nos quais houve acionamento de descargas de rede, observou-se que no período onde a descarga D96 (Alvorada) deveria estar aberta praticamente não há registro de vazão. Como houve registro de vazão desta descarga nas outras duas situações, entende-se que com o fechamento da descarga D22 a turbina do medidor da descarga D96 - a notar-se sua localização em região de altas pressões emperrou, e as vazões que atravessaram o medidor neste instante não foram registradas.

O emprego de dispositivos que garantam que os mecanismos de medição fiquem imersos em $100 \%$ do tempo talvez evite tais contratempos.

\subsection{Controle Estatístico do Processo - CEP}

As vazões de entrada foram monitoradas desde o início da coleta de dados (abril/2003) até o final de fevereiro/2004. A cada noite foi avaliada a menor vazão registrada, com precisão do registrador de 1 minuto, que foi considerada como a vazão mínima noturna (VMN) daquela noite.

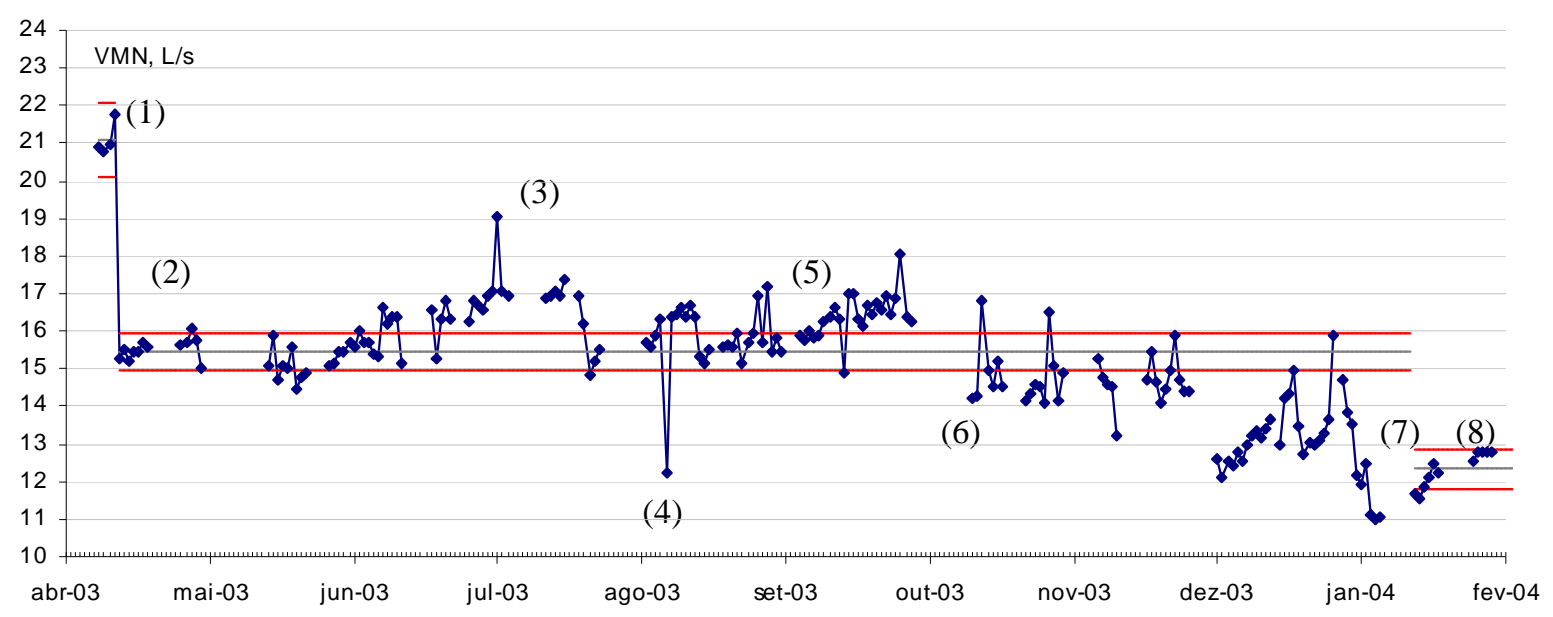

Figura 5.5 - monitoramento da VMN no setor Alvorada

Sob condição de vazamento localizado foram calculados os limites inferior e superior de controle estatístico através do método apresentado por KUROKAWA \& BORNIA (2002), localizados no início do monitoramento. Com o reparo de vazamento 
pontual localizado (1), em 09/maio/2003, houve redução brusca das vazões mínimas noturnas (VMN) e novos limites de controle foram definidos (2).

Ao final de julho ocorreu registro de pico na VMN (3), possivelmente devido a consumo excepcional; mas os dias que antecedem e sucedem o pico dão conta de que a VMN já está acima dos limites de controle calculados, com possível aumento de vazamentos.

A parada dos conjuntos de motobombas que abastecem o setor forçou a queda da VMN em 01/setembro/2003 (4).

Uma pesquisa de vazamentos foi empreendida por equipe de Pitometria do SEMAE Piracicaba e cerca de 30 vazamentos foram localizados. Em outubro/2003 foram iniciados os trabalhos de reparo dos vazamentos localizados (5) e a partir de novembro/2003 já puderam ser observados valores da VMN abaixo do limite inferior estatístico fixado, graças à redução dos vazamentos (6). Com a conclusão dos reparos (7) novos limites de controle foram determinados (8).

Dos 30 vazamentos em potencial, localizados por equipe de Pitometria munida de hastes de escuta e geofones eletrônicos, 16 foram efetivamente confirmados, sendo 14 $(87,5 \%)$ vazamentos em ramais prediais e $2(12,5 \%)$ em redes de distribuição.

Problemas técnicos com a instalação dos coletores de dados ocasionaram falhas na coleta em alguns dias.

\subsection{Estimativa dos erros de micromedição}

A leitura dos medidores do setor ocorre entre os dias 20 e 21 de cada mês. Assim, as leituras que interessam ao período estudado do setor se referem ao período de 20/abril a 20/maio e compõem o mês de leitura de abril/2003. 
No mês de referência de abril/2003 o conjunto de hidrômetros do setor era composto por 1631 medidores taquimétricos de $3 \mathrm{~m} / \mathrm{h}$ de capacidade (padrão SEMAE), que foram estratificados em função de pressão de operação esperada, consumo no mês de referência e idade do hidrômetro.

A pressão de operação esperada para cada hidrômetro é aquela simulada para o nó de influência do medidor com uma demanda de $0,1 \mathrm{~L} / \mathrm{s}$ para cada nó, utilizada como referência de uma pressão esperada durante consumo diurno.

Amostras iguais a $10 \%$ da população foram retiradas, substituídas por hidrômetros novos e levadas ao Laboratório de Hidrometria do SEMAE Piracicaba para ensaios de erros de indicação. Em extratos onde as amostras resultariam em valores menores ou iguais à unidade, foram selecionados, no mínimo, três hidrômetros. A Tabela 5.2 traz as populações por extrato, as amostras calculadas e efetivamente retiradas da rede.

Tabela 5.2 - população e amostragens dos hidrômetros do setor Alvorada

\begin{tabular}{|c|c|c|c|c|c|c|}
\hline \multirow[t]{2}{*}{ população } & \multicolumn{3}{|c|}{0 a 5 anos } & \multicolumn{3}{|c|}{$>5$ anos } \\
\hline & 0 a $10 \mathrm{~m}^{3}$ & 11 a $20 m^{3}$ & $>20 \mathrm{~m}^{3}$ & 0 a $10 \mathrm{~m}^{3}$ & 11 a $20 \mathrm{~m}^{3}$ & $>20 \mathrm{~m}^{3}$ \\
\hline até $40 \mathrm{mH} 2 \mathrm{O}$ & 30 & 38 & 17 & 45 & 70 & 33 \\
\hline 41 a $60 \mathrm{mH} 20$ & 53 & 72 & 30 & 354 & 563 & 168 \\
\hline$>60 \mathrm{mH} 2 \mathrm{O}$ & 4 & 8 & 4 & 46 & 74 & 22 \\
\hline
\end{tabular}

\begin{tabular}{|c|c|c|c|c|c|c|}
\hline \multirow[t]{2}{*}{ amostras } & \multicolumn{3}{|c|}{0 a 5 anos } & \multicolumn{3}{|c|}{$>5$ anos } \\
\hline & 0 a $10 m^{3}$ & 11 a $20 \mathrm{~m}^{3}$ & $>20 \mathrm{~m}^{3}$ & 0 a $10 \mathrm{~m}^{3}$ & 11 a $20 \mathrm{~m}^{3}$ & $>20 \mathrm{~m}^{3}$ \\
\hline até $40 \mathrm{mH} 2 \mathrm{O}$ & 3 & 4 & 2 & 5 & 7 & 3 \\
\hline 41 a $60 \mathrm{mH} 2 \mathrm{O}$ & 5 & 7 & 3 & 35 & 56 & 17 \\
\hline$>60 \mathrm{mH} 2 \mathrm{O}$ & 3 & 3 & 3 & 5 & 7 & 2 \\
\hline
\end{tabular}

\begin{tabular}{|c|c|c|c|c|c|c|}
\hline \multirow{2}{*}{$\begin{array}{l}\text { efetivamente } \\
\text { retirados }\end{array}$} & \multicolumn{3}{|c|}{0 a 5 anos } & \multicolumn{3}{|c|}{$>5$ anos } \\
\hline & 0 a $10 \mathrm{~m}^{3}$ & 11 a $20 \mathrm{~m}^{3}$ & $>20 \mathrm{~m}^{3}$ & 0 a $10 m^{3}$ & 11 a $20 m^{3}$ & $>20 \mathrm{~m}^{3}$ \\
\hline até $40 \mathrm{mH} 2 \mathrm{O}$ & 3 & 4 & 2 & 5 & 7 & 3 \\
\hline 41 a $60 \mathrm{mH} 2 \mathrm{O}$ & 5 & 7 & 3 & 32 & 55 & 17 \\
\hline$>60 \mathrm{mH} 2 \mathrm{O}$ & 3 & 3 & 3 & 5 & 7 & 2 \\
\hline
\end{tabular}


Volumes definidos e calibrados atravessaram os medidores retirados três vezes em cada uma das três vazões-limites ensaiadas de medição, conforme normas internas do Setor de Hidrometria do SEMAE e NBR 8195/1996.

Os erros de indicação e desvios-padrão médios para cada extrato foram calculados em cada uma das vazões ensaiadas. O valor médio esperado, ao nível de significância de $80 \%$, conforme teste de hipótese de Student, foi determinado também para cada uma das vazões.

Tabela 5.3 - erros de indicação observados e esperados por extrato e vazão

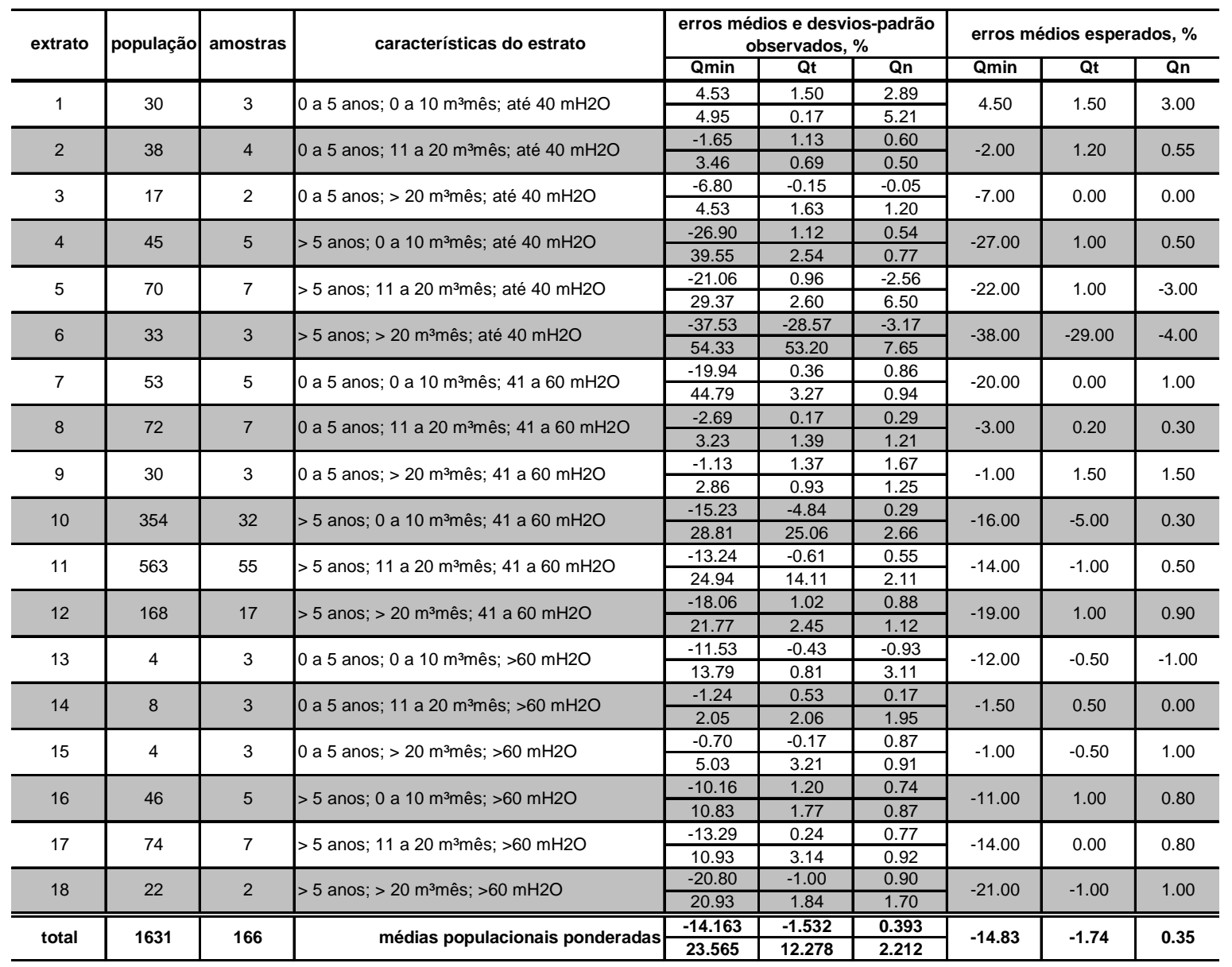




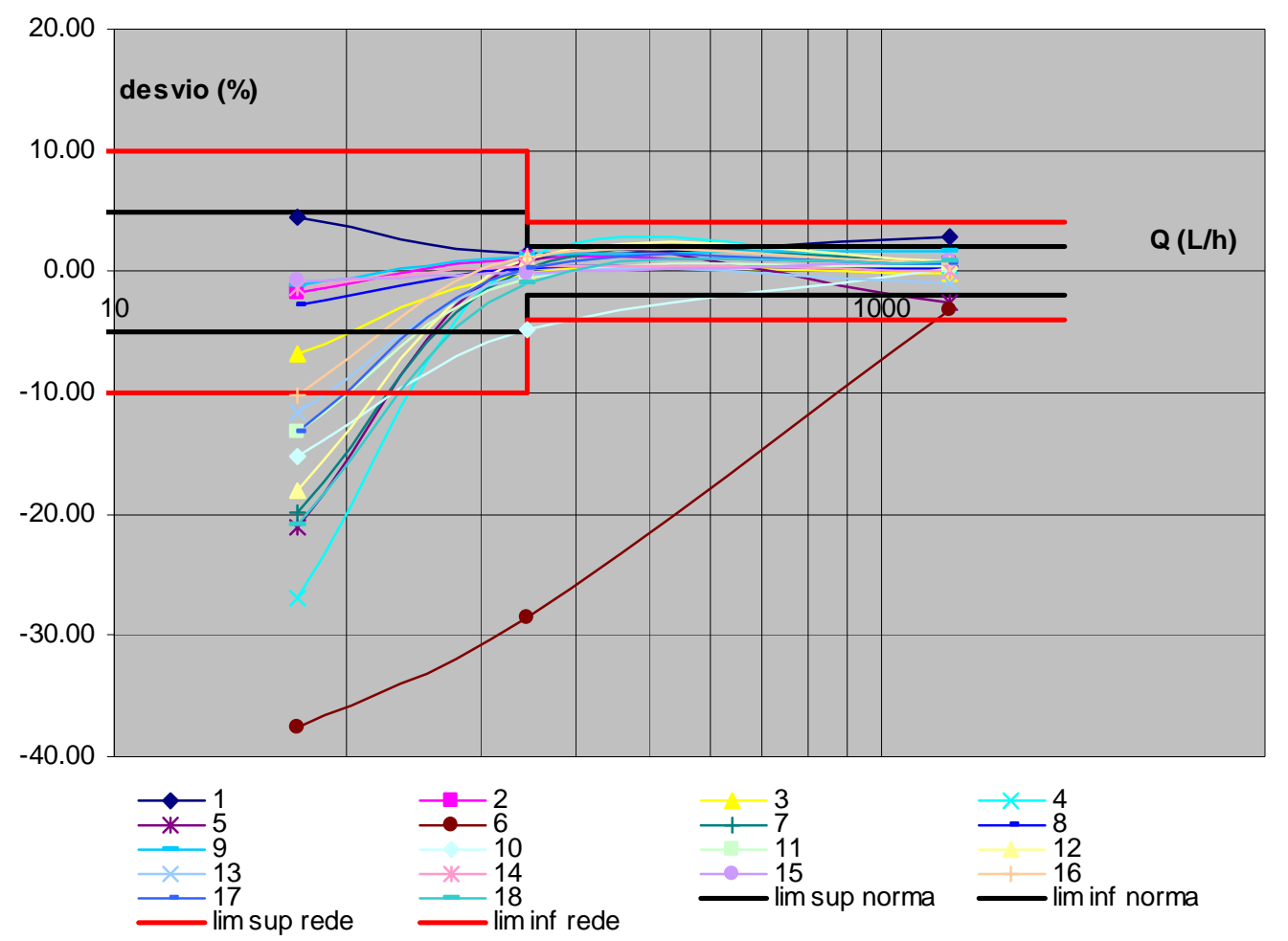

Figura 5.6 - curvas de erros de indicação por extrato

A análise trouxe a maioria dos extratos com desvios negativos durante vazão mínima. Mais da metade dos extratos apresentaram valores médios dos erros de indicação fora dos limites de norma e rede para Qmin.

Nesta estratificação, apenas dois extratos apresentaram valores fora dos limites para as vazões de transição e máxima.

A curva fora dos padrões esperados (extrato \#6) justifica-se pelo seu pequeno número de elementos - apenas três - e pela presença de hidrômetro de acionamento mecânico com mais de 10 anos de instalação, cujos desvios na $Q \min$ e $Q t$ foram, respectivamente, $-100 \%$ e $-90 \%$.

O volume totalizado pelo medidor em sua vida útil é fator importante no estudo de seu desgaste e foi avaliado a partir de quatro faixas de totalização, conforme tabela e gráficos. 
Tabela 5.4 - erros de indicação por faixa de totalização

\begin{tabular}{c|l|c|c|c|c}
\hline \multirow{2}{*}{ faixas de totalização } & \multirow{2}{*}{$\mathbf{n}$} & \multicolumn{2}{c}{ erros médios observados de indicação } \\
\cline { 4 - 6 } \multicolumn{2}{l}{} & & Qmin & $\mathbf{Q t}$ & Qn \\
\hline A & 0 a $1000 \mathrm{~m}^{3}$ & 58 & -9.87 & 0.71 & 0.57 \\
\hline B & 1001 a $2000 \mathrm{~m}^{3}$ & 76 & -13.63 & -1.63 & 0.45 \\
\hline C & 2001 a $3000 \mathrm{~m}^{3}$ & 26 & -21.20 & -5.63 & 0.27 \\
\hline D & acima de $3001 \mathrm{~m}^{3}$ & 6 & -18.63 & 1.03 & -1.73 \\
\hline
\end{tabular}

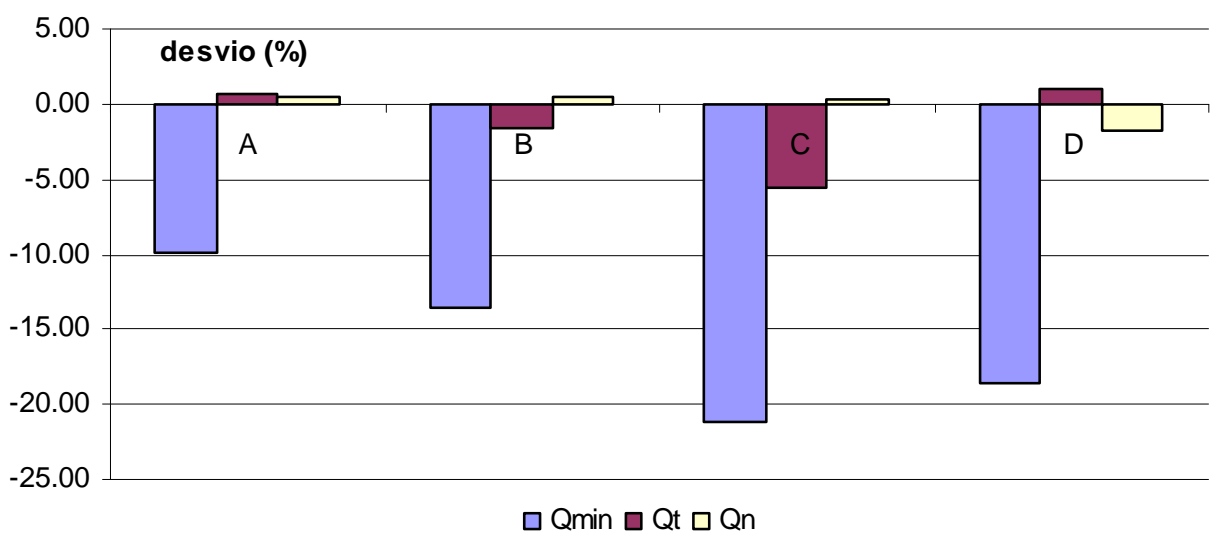

Figura 5.7 - erros de indicação por faixa de totalização (gráfico de barras)

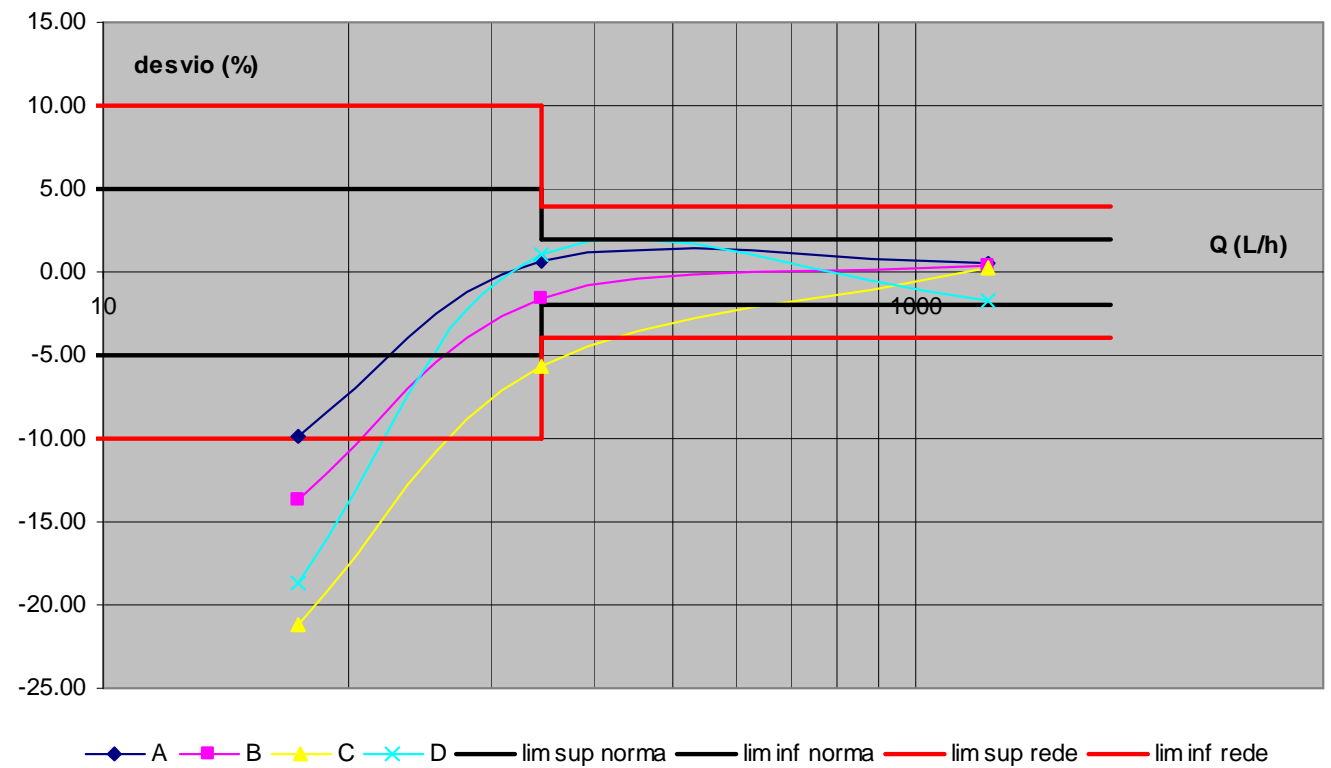

Figura 5.8 - curvas de erros de indicação por faixa de totalização

Os resultados observados na estratificação em função de pressão, idade e consumo revelam que não há relação clara entre os resultados obtidos e as variáveis estudadas, 
principalmente no caso dos consumos, que se misturam às outras variáveis. A estratificação proposta mistura as influências das variáveis de interesse e apresenta valores muito elevados de desvio-padrão para certos extratos, o que aumenta as incertezas acerca dos valores e efeitos a considerar.

Em termos da operação e manutenção de um parque de medidores, são importantes as variáveis acionamento e fabricação.

A tabela a seguir traz os desvios classificados em função de idade, acionamento e fabricação, que se mostra mais reveladora e separa melhor os hidrômetros que erram mais, definindo em quais dos extratos são esperadas maiores incertezas.

Tabela 5.5 - erros de indicação em função do tipo de acionamento, idade e fabricação

\begin{tabular}{|c|c|c|c|c|c|c|}
\hline \multirow{2}{*}{ acionamento } & \multirow{2}{*}{ fabricante } & \multirow{2}{*}{ idade } & \multirow{2}{*}{ amostras } & \multicolumn{3}{|c|}{ erros médios e desvios-padrão } \\
\hline & & & & Qmin & Qt & Qn \\
\hline \multirow{2}{*}{ mecânico } & \multirow{2}{*}{ Tecnobras } & \multirow{2}{*}{$>10$ anos } & \multirow{2}{*}{10} & -39.83 & -37.36 & -6.04 \\
\hline & & & & 51.83 & 51.91 & 6.10 \\
\hline \multirow{2}{*}{ magnético } & \multirow{2}{*}{ Tecnobras } & \multirow{2}{*}{$>10$ anos } & \multirow{2}{*}{2} & -55.65 & -5.95 & -2.20 \\
\hline & & & & 62.72 & 6.58 & 0.99 \\
\hline \multirow{2}{*}{ magnético } & \multirow{2}{*}{ Tecnobras } & \multirow{2}{*}{$>5$ anos } & \multirow{2}{*}{121} & -12.56 & 1.23 & 0.99 \\
\hline & & & & 19.71 & 2.68 & 0.95 \\
\hline \multirow{2}{*}{ magnético } & \multirow{2}{*}{ Turbimax } & \multirow{2}{*}{$>5$ anos } & \multirow{2}{*}{2} & -43.95 & 0.15 & -3.55 \\
\hline & & & & 54.66 & 2.05 & 0.92 \\
\hline \multirow{2}{*}{ magnético } & \multirow{2}{*}{ Schlumberger } & \multirow{2}{*}{$<5$ anos } & \multirow{2}{*}{2} & -0.85 & 1.14 & 0.92 \\
\hline & & & & 7.28 & 2.82 & 1.03 \\
\hline \multirow{2}{*}{ magnético } & \multirow{2}{*}{ Tecnobras } & \multirow{2}{*}{$<5$ anos } & \multirow[b]{2}{*}{8} & -1.28 & 1.64 & 1.15 \\
\hline & & & & 2.11 & 0.63 & 0.84 \\
\hline \multirow{2}{*}{ magnético } & \multirow{2}{*}{ LAO } & \multirow{2}{*}{$<5$ anos } & \multirow{2}{*}{8} & -2.58 & -0.49 & 0.36 \\
\hline & & & & 1.44 & 1.88 & 1.32 \\
\hline \multirow{2}{*}{ magnético } & \multirow{2}{*}{ Turbimax } & \multirow{2}{*}{$<5$ anos } & \multirow{2}{*}{13} & -9.42 & 0.22 & 0.25 \\
\hline & & & & 27.78 & 2.15 & 3.33 \\
\hline
\end{tabular}




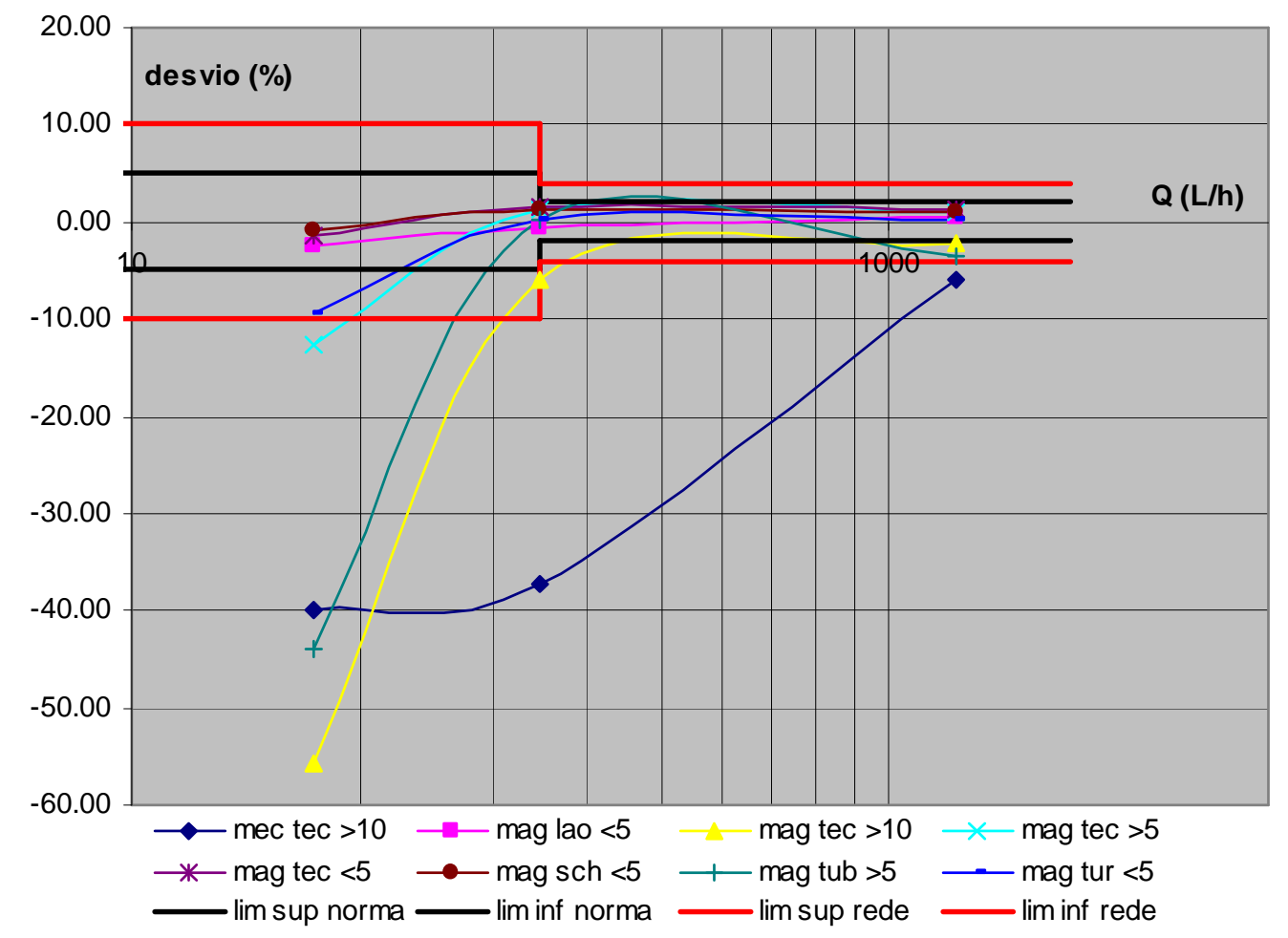

Figura 5.9 - curvas dos erros de indicação em função do tipo de acionamento, idade e fabricação

Os resultados indicam que hidrômetros com mais de 5 anos de instalação ainda comportam-se conforme limites esperados de operação em rede, mas merecem acompanhamento, principalmente de fabricação Turbimax durante a vazão mínima eis que este apresentou, nesta vazão, desvios maiores do que o limite de norma.

Observou-se que os hidrômetros de fabricação Tecnobrás e Turbimax, com idade entre cinco e dez anos, indicaram desvios positivos a partir da vazão de transição, ou seja, a favor da concessionária dos serviços.

\subsubsection{Avaliação do tempo de permanência em vazões limites de medição}

Definidos os desvios médios observados e esperados por vazão característica, são necessárias informações acerca das vazões de operação em cavaletes residenciais. 
Acredita-se não haver uma curva característica de consumo residencial, dado que este é influenciado por fatores espaciais, temporais e pelas pressões de operação, além dos hábitos e renda dos consumidores. A existência de reservatórios domiciliares é de fundamental importância e acredita-se que, no setor Alvorada, estejam presentes em quase a totalidade das residências por compor a planta padrão de conjunto habitacional, característica da região.

Seis ligações - cujos hidrômetros foram substituídos durante a avaliação dos erros de indicação dos medidores - receberam medidores de vazão volumétricos e com saída pulsada para coletores de dados. Instalados em série com o hidrômetro "oficial" da ligação, permitiram o monitoramento das vazões de operação das ligações residenciais durante uma semana sem implicar em problemas de leitura do medidor original, para efeito de cobrança.

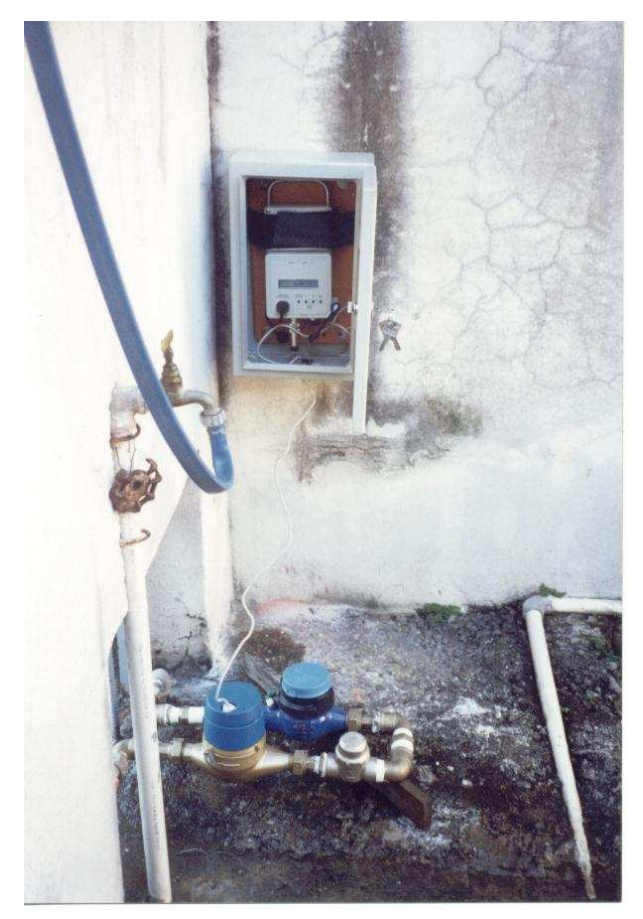

Figura 5.10 - instalação típica de medidor com coletor de dados 
Os resultados mostram que os hidrômetros trabalham cerca de $90 \%$ do tempo em vazões maiores que a nula e menores que a vazão mínima de medição do hidrômetro e, portanto, na faixa onde ocorrem os maiores erros de indicação.

Rua Sônia Mamede, 171

Média 6 últimos consumos $=11,7 \mathrm{~m}^{3}$

Pressão média esperada $=48 \mathrm{mH} 2 \mathrm{O}$

\begin{tabular}{c|c}
\hline faixas de vazão & permanência (\%) \\
\hline$Q=0$ & 6.57 \\
\hline $0<Q<=Q \min$ & 90.59 \\
\hline$Q \min >Q>=Q t$ & 4.64 \\
\hline$Q>Q t$ & 4.77 \\
\hline & 100.00
\end{tabular}

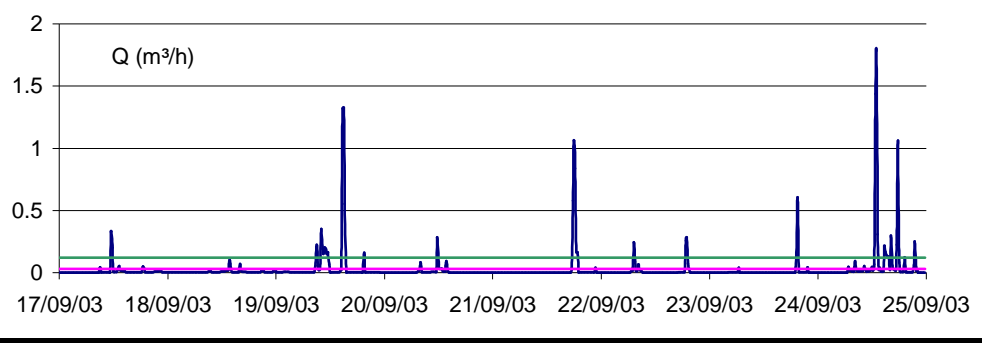

Rua Janete Clair, 256

Média 6 últimos consumos $=19,0 \mathrm{~m}^{3}$

Pressão média esperada $=50 \mathrm{mH} 2 \mathrm{O}$

\begin{tabular}{c|c}
\hline faixas de vazão & permanência (\%) \\
\hline$Q=0$ & 8.89 \\
\hline $0<Q<=Q \min$ & 97.04 \\
\hline Qmin $>Q>=Q t$ & 1.80 \\
\hline$Q>Q t$ & 1.16 \\
\hline & 100.00 \\
\hline
\end{tabular}

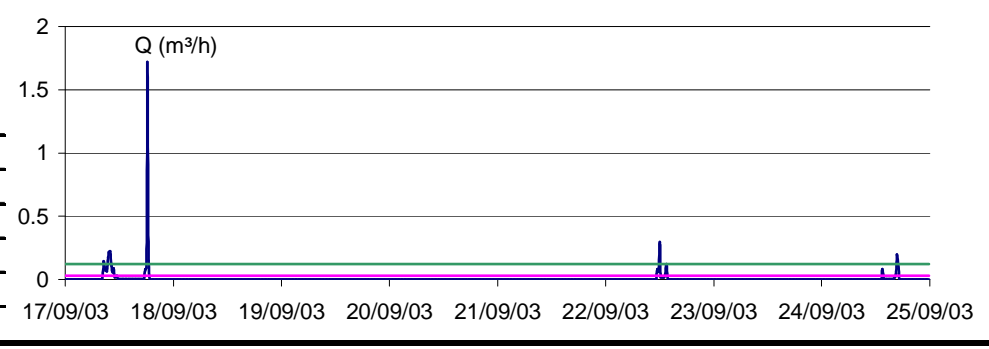

Rua Cassiano Gabus Mendes, 179

Média 6 últimos consumos $=22,5 \mathrm{~m}^{3}$

Pressão média esperada $=47 \mathrm{mH} 2 \mathrm{O}$

\begin{tabular}{c|c}
\hline faixas de vazão & permanência (\%) \\
\hline$Q=0$ & 21.52 \\
\hline $0<Q<=Q \min$ & 84.41 \\
\hline$Q \min >Q>=Q t$ & 9.15 \\
\hline$Q>Q t$ & 6.44 \\
\hline & 100.00
\end{tabular}

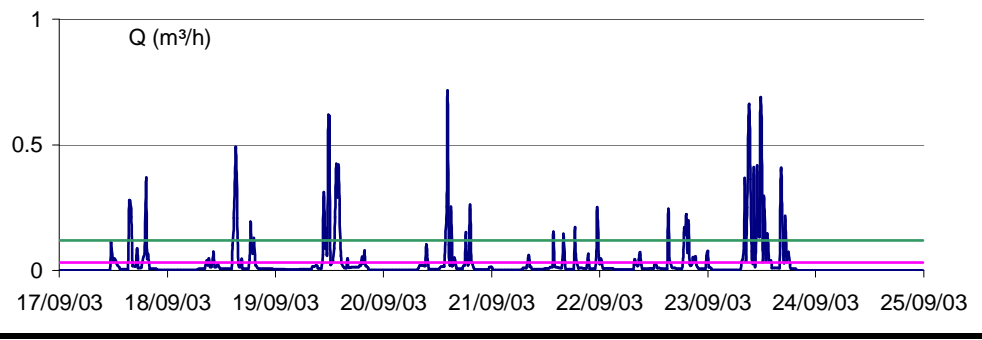

Rua Felipe Carone, 166

Média 6 últimos consumos $=9,5 \mathrm{~m}^{3}$

Pressão média esperada $=49 \mathrm{mH} 2 \mathrm{O}$

\begin{tabular}{c|c}
\hline faixas de vazão & permanência (\%) \\
\hline$Q=0$ & 8.63 \\
\hline $0<Q<=Q \min$ & 90.34 \\
\hline Qmin $>Q>=Q t$ & 5.93 \\
\hline$Q>Q t$ & 3.74 \\
\hline & 100.00
\end{tabular}

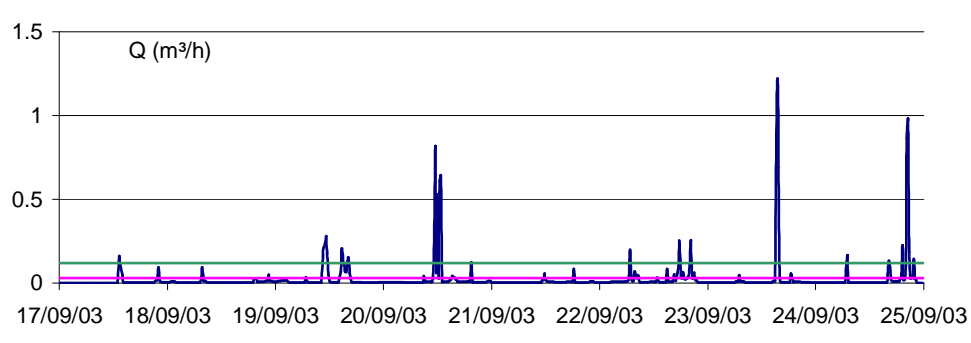


Rua Sergio Cardoso, 90

Média 6 últimos consumos $=22,2 \mathrm{~m}^{3}$

Pressão média esperada $=50 \mathrm{mH} 2 \mathrm{O}$

\begin{tabular}{c|c}
\hline faixas de vazão & permanência (\%) \\
\hline$Q=0$ & 6.06 \\
\hline $0<Q<=Q \min$ & 32.86 \\
\hline$Q \min >Q>=Q t$ & 58.63 \\
\hline$Q>Q t$ & 8.51 \\
\hline & 100.00
\end{tabular}

Rua Cassiano Gabus Mendes, 227

Média 6 últimos consumos $=9,8 \mathrm{~m}^{3}$

Pressão média esperada $=51 \mathrm{mH} 2 \mathrm{O}$

\begin{tabular}{c|c}
\hline faixas de vazão & permanência (\%) \\
\hline$Q=0$ & 9.54 \\
\hline $0<Q<=Q \min$ & 93.17 \\
\hline$Q \min >Q>=Q t$ & 5.03 \\
\hline$Q>Q t$ & 1.80 \\
\hline & 100.00
\end{tabular}

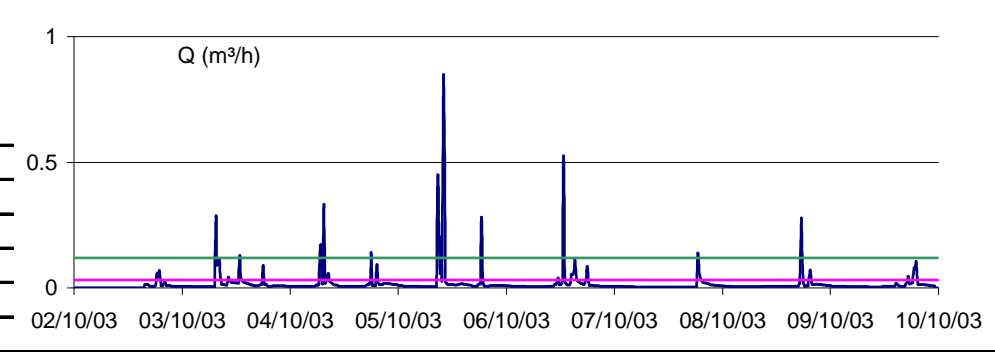

Figura 5.11 - curvas coletadas de vazão de entrada em ligações residenciais (as linhas magentas delimitam as vazões mínimas e as verdes, as vazões de transição)

Os picos dos gráficos se devem a usos diretos, ou seja, acionamentos de torneiras ou outros dispositivos ligados diretamente à rede pública de distribuição que, auxiliados pelas altas pressões do setor, induzem a vazões sensivelmente maiores.

Observa-se que o consumo mensal de uma economia sofre influência direta da freqüência, intensidade e duração com que a água é utilizada diretamente da rede pública, já que neste caso há vazões mais pronunciadas e conseqüentemente erros (bastante) menores de indicação dos hidrômetros.

Os valores observados na Rua Sérgio Cardoso, 90, fogem aos resultados obtidos nas outras cinco ligações monitoradas e, após visita técnica do Setor de Hidrometria, descobriu-se haver vazamento nas instalações internas do consumidor.

O valor médio esperado para a vazão mínima dos medidores instalados no setor é igual a $-14,83 \%$ e, com base nos tempos de permanência registrados, é o valor que deve ser considerado como erro médio de micromedição do setor. 
O emprego de medidores de vazão máxima igual a $1,5 \mathrm{~m}^{3} / \mathrm{h}$, que possuem $Q t$ igual a 22,5 L/s e Qmin de $15 \mathrm{~L} / \mathrm{s}$, pode diminuir sensivelmente os desvios de indicação em ligações domiciliares, ao estreitar o limite inferior de medição e acolher uma parte maior das vazões de trabalho acima da vazão separadora, com erros máximos tolerados de $\pm 2 \%$. Com isso, espera-se a ocorrência de redução das perdas não-físicas, coibição do desperdício e recuperação de receita do ente fornecedor.

\section{4 Índices globais}

Com base nos dados coletados são determinados os índices globais de eficiência do setor para o mês de referência de abril/2003:

Tabela 5.6 - índices globais do setor Alvorada

\begin{tabular}{l|c}
\hline Número de ligações & 1631 \\
\hline Comprimento das redes & $11,5 \mathrm{~km}$ \\
\hline Volume macromedido & $60963 \mathrm{~m}^{3}$ \\
\hline Volume micromedido & $23323 \mathrm{~m}^{3}$ \\
\hline Consumo médio por ligação (sem correção) & $14,5 \mathrm{~m}^{3} / \mathrm{mês}$ \\
\hline Idade média dos hidrômetros & 8,1 anos \\
\hline Pressão média simulada para o dia & $47,4 \mathrm{mH} \mathrm{O}$ \\
\hline Índice de perdas na distribuição (perdas totais) & $61,74 \%$ \\
\hline Desvio médio esperado da micromedição & $-14,83 \%$ \\
\hline Volume fisicamente utilizado (aportado corrigido) & $27015 \mathrm{~m} 3$ \\
\hline Índice de perdas físicas na distribuição & $55,69 \%$ \\
\hline Perda física média & $14,52 \mathrm{~L} / \mathrm{s}$ \\
\hline Perda física média linear & $1,26 \mathrm{~L} / \mathrm{s} . \mathrm{km}$ \\
\hline Perda física média por ligação & $8,90.10^{-3} \mathrm{~L} / \mathrm{s} .1$ ligação \\
\hline
\end{tabular}

Importante salientar que os índices obtidos consideram o vazamento de monta, localizado e reparado em 09/maio/2003. Os índices devem diminuir sensivelmente com o reparo de outros vazamentos localizados na região entre agosto, setembro e 
outubro/2003 e também com a redução de pressões em virtude do aumento dos consumos em dias quentes.

\subsection{Simulações sob consumo noturno nulo}

\subsubsection{Simulações sob patamares de redução de pressão}

O modelo de calibração dos parâmetros $\mathrm{C} 1$ e N1 sob consumo noturno nulo foi aplicado aos valores observados na madrugada de 16/maio, quando houve descargas de rede e execução de patamares de redução da pressão de entrada com ajuste da VRP instalada.

A busca direta univariada foi aplicada aos parâmetros com faixas de busca de $1.10^{-6}$ a $1.10^{-4}$ para $\mathrm{C} 1$ e 0,9 e 1,0 para N1. Os valores dos passos iniciais para os parâmetros $\mathrm{C} 1$ e $\mathrm{N} 1$ aplicados pelo método foram de $1.10^{-8}$ e $1.10^{-3}$, respectivamente. O método testou as direções de busca ao iniciar a otimização de cada variável com uma estimativa e igual a $10 \%$ do valor total do passo.

Quatro patamares foram executados através da regulagem do piloto hidráulico da Válvula Redutora de Pressão instalada na entrada do setor e mantidos por aproximadamente 15 minutos.

Ao considerar, simultaneamente, os quatro patamares foram obtidos os resultados da Tabela 5.7. 
Tabela 5.7 - resultados com simulação simultânea dos quatro patamares

\begin{tabular}{l|r}
\hline C1 & $3.71 \mathrm{E}-05$ \\
\hline N1 & 0.9601 \\
\hline FO & 0.0184 \\
\hline
\end{tabular}

\begin{tabular}{c|c|r|r|r|r}
\hline \multirow{2}{*}{ patamar } & \multirow{2}{*}{ nó/trecho } & \multicolumn{1}{c|}{ obs } & \multicolumn{1}{c|}{ sim } & \multicolumn{2}{c}{ desvios } \\
\cline { 3 - 6 } & & \multicolumn{2}{|c|}{$\mathbf{m H}_{\mathbf{2}} \mathbf{O}, \mathbf{L} / \mathbf{s}$} & $\mathbf{m H}_{\mathbf{2}} \mathbf{O}, \mathbf{L} / \mathbf{s}$ & \multicolumn{1}{c}{$\%$} \\
\hline \hline \multirow{4}{*}{$\# 1$} & nó 7 & 49.08 & 46.30 & 2.78 & 5.67 \\
\cline { 2 - 6 } & nó 41 & 24.65 & 24.50 & 0.15 & 0.59 \\
\cline { 2 - 6 } & nó 69 & 46.72 & 46.22 & 0.50 & 1.07 \\
\cline { 2 - 6 } & nó 87 & 64.84 & 62.00 & 2.84 & 4.38 \\
\cline { 2 - 6 } & trecho 141 & 14.41 & 15.69 & -1.28 & -8.91 \\
\hline \hline \multirow{4}{*}{ \#2 } & nó 7 & 45.31 & 42.58 & 2.73 & 6.02 \\
\cline { 2 - 6 } & nó 41 & 20.77 & 20.81 & -0.04 & -0.21 \\
\cline { 2 - 6 } & nó 69 & 43.04 & 42.60 & 0.44 & 1.03 \\
\cline { 2 - 6 } & nó 87 & 61.27 & 58.67 & 2.60 & 4.24 \\
\cline { 2 - 6 } & trecho 141 & 13.93 & 14.46 & -0.53 & -3.79 \\
\hline \hline \multirow{4}{*}{$\# 3$} & nó 7 & 39.91 & 37.33 & 2.58 & 6.46 \\
\cline { 2 - 6 } & nó 41 & 15.27 & 15.59 & -0.32 & -2.12 \\
\cline { 2 - 6 } & nó 69 & 34.95 & 37.46 & -2.51 & -7.19 \\
\cline { 2 - 6 } & nó 87 & 56.28 & 53.93 & 2.35 & 4.18 \\
\cline { 2 - 6 } & trecho 141 & 13.34 & 12.70 & 0.64 & 4.81 \\
\hline \hline \multirow{4}{*}{$\# 4$} & nó 7 & 33.69 & 31.06 & 2.63 & 7.82 \\
\cline { 2 - 6 } & nó 41 & 9.25 & 9.34 & -0.09 & -1.00 \\
\cline { 2 - 6 } & nó 69 & 31.22 & 31.32 & -0.10 & -0.31 \\
\cline { 2 - 6 } & nó 87 & 48.93 & 48.20 & 0.73 & 1.50 \\
\cline { 2 - 6 } & trecho 141 & 12.53 & 10.57 & 1.96 & 15.62 \\
\hline
\end{tabular}

A Tabela 5.8 ilustra os resultados obtidos a partir de simulações que consideraram cada patamar isoladamente.

Tabela 5.8 - resultados com simulação individual de cada patamar

\begin{tabular}{|c|c|c|c|c|c|c|c|c|}
\hline \multirow{2}{*}{ patamar } & \multirow{2}{*}{ nó/trecho } & \multirow{2}{*}{ C1 } & \multirow{2}{*}{ N1 } & \multirow{2}{*}{ FO } & obs & $\operatorname{sim}$ & \multicolumn{2}{|c|}{$\begin{array}{l}\text { desvios } \\
\end{array}$} \\
\hline & & & & & \multicolumn{2}{|c|}{$\mathrm{mH}_{2} \mathrm{O}, \mathrm{L} / \mathrm{s}$} & $\mathrm{mH}_{2} \mathrm{O}, \mathrm{L} / \mathrm{s}$ & $\%$ \\
\hline \multirow{5}{*}{ referência } & "nó 7 & \multirow{5}{*}{$3.69 E-05$} & \multirow{5}{*}{0.9344} & \multirow{5}{*}{0.0055} & $\begin{array}{l}63.87 \\
\end{array}$ & \begin{tabular}{ll|}
60.73 \\
\end{tabular} & 3.14 & 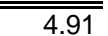 \\
\hline & nó 41 & & & & 39.02 & 38.88 & 0.14 & 0.35 \\
\hline & nó 69 & & & & 60.89 & 60.51 & 0.38 & $\overline{0.62}$ \\
\hline & nó 87 & & & & 78.92 & 75.77 & 3.15 & 3.99 \\
\hline & trecho 141 & & & & 18.08 & 17.95 & 0.13 & 0.74 \\
\hline \multirow{5}{*}{$\# 1$} & nó 7 & \multirow{5}{*}{ 3.78E-05 } & \multirow{5}{*}{0.9355} & \multirow{5}{*}{0.0061} & (49.08 & |46.34 & 2.74 & $\overline{5.58}$ \\
\hline & nó 41 & & & & 24.65 & 24.57 & 0.08 & 0.34 \\
\hline & nó 69 & & & & 46.72 & 46.39 & 0.33 & 0.72 \\
\hline & nó 87 & & & & 64.84 & 62.54 & 2.30 & 3.55 \\
\hline & trecho 141 & & & & 14.41 & 14.32 & 0.09 & 0.65 \\
\hline \multirow{5}{*}{$\# 2$} & nó 7 & \multirow{5}{*}{ 5.69E-05 } & \multirow{5}{*}{0.8485} & \multirow{5}{*}{0.0071} & 45.31 & 42.60 & 2.71 & 5.99 \\
\hline & nó 41 & & & & 20.77 & 20.83 & -0.06 & -0.28 \\
\hline & nó 69 & & & & 43.04 & 42.68 & 0.36 & $\overline{0.84}$ \\
\hline & nó 87 & & & & 61.27 & 58.96 & 2.31 & 3.78 \\
\hline & trecho 141 & & & & 13.93 & 13.83 & 0.10 & 0.73 \\
\hline \multirow{5}{*}{ \#3 } & nó 7 & \multirow{5}{*}{ 7.92E-05 } & \multirow{5}{*}{0.7999} & \multirow{5}{*}{0.0143} & 39.91 & |37.31 & 2.60 & $\overline{6.52}$ \\
\hline & nó 41 & & & & 15.27 & 15.55 & -0.28 & -1.86 \\
\hline & nó 69 & & & & 34.95 & 37.42 & -2.47 & -7.08 \\
\hline & nó 87 & & & & 56.28 & 53.82 & 2.46 & 4.38 \\
\hline & trecho 141 & & & & 13.34 & 13.25 & 0.09 & 0.66 \\
\hline \multirow{5}{*}{$\# 4$} & ב nó 7 & \multirow{5}{*}{ 8.32E-05 } & \multirow{5}{*}{0.8059} & \multirow{5}{*}{0.0094} & 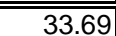 & (31.00 & 2.69 & $\overline{\overline{7.98}}$ \\
\hline & nó 41 & & & & 9.25 & 9.27 & -0.02 & -0.19 \\
\hline & nó 69 & & & & 31.22 & 31.15 & 0.07 & 0.24 \\
\hline & nó 87 & & & & 48.93 & 47.66 & 1.27 & 2.59 \\
\hline & trecho 141 & & & & 12.53 & 12.44 & 0.09 & 0.68 \\
\hline
\end{tabular}


A simulação simultânea dos quatro patamares revelou um par $(\mathrm{C} 1, \mathrm{~N} 1)$ que considerou padrões hidráulicos distintos em sua calibração, e que por isso pode ser entendido como a expressão esperada para o sistema.

A calibração dos parâmetros a partir da análise particular de cada patamar indicou um crescimento progressivo do parâmetro $\mathrm{C} 1$, acompanhado de queda de $\mathrm{N} 1$, conforme figuras a seguir.

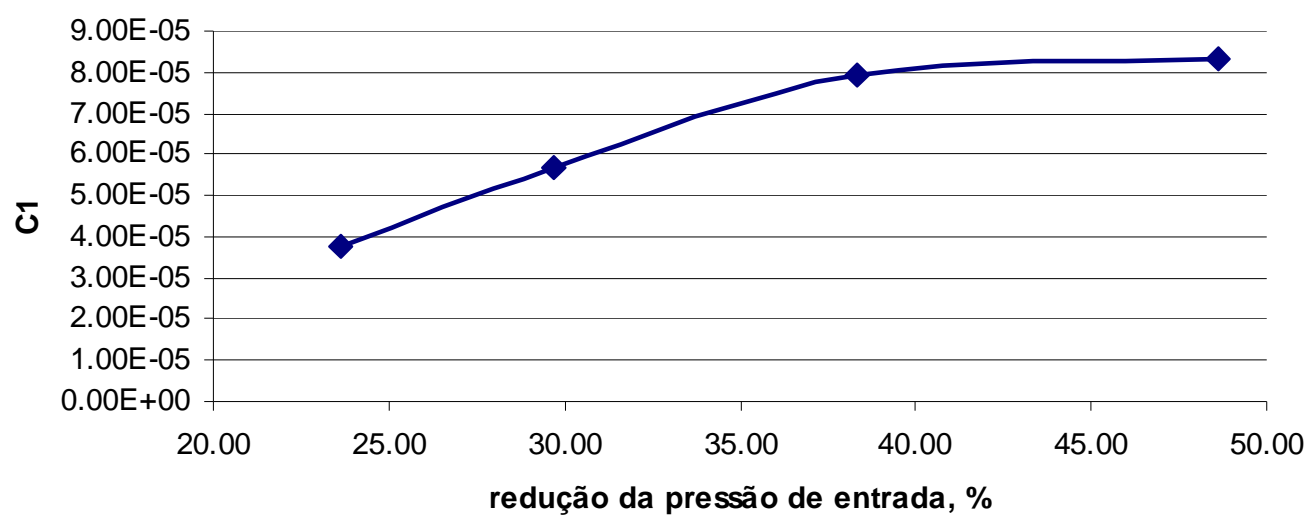

Figura 5.12 - variação do coeficiente $C 1$ em função da redução de pressão

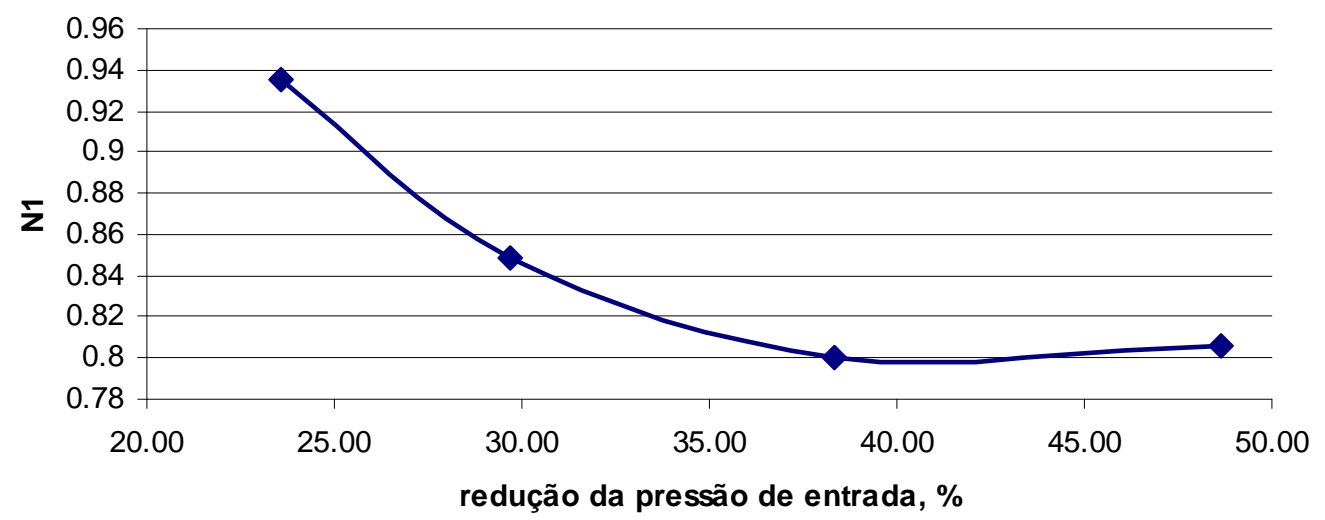

Figura 5.13 - variação do expoente N1 em função da redução de pressão

Como há redução da vazão de entrada com as manobras, acredita-se que em setores onde há redução de vazamentos com instalação de sistemas de redução de pressão o 
mesmo efeito possa ser observado; deve haver redução do expoente de vazamento com pressão (N1) e compensação matemática por parte do parâmetro C1.

Foram observados desvios considerados aceitáveis entre os valores observados e simulados, exceto no patamar \#3 no qual talvez um tempo maior de propagação fosse necessário. Existe a possibilidade de que no horário da manobra (5h00) possa ter ocorrido algum consumo excepcional e que influenciou a calibração.

\subsubsection{Simulações sem vazamento pontual}

O modelo de calibração dos parâmetros C1 e N1 sob consumo noturno nulo foi aplicado aos valores observados na madrugada de 16/maio, quando houve descargas de rede e execução de patamares de redução da pressão de entrada com ajuste da VRP instalada.

A busca direta univariada foi aplicada aos parâmetros com faixas de busca de $1.10^{-6}$ a $1.10^{-4}$ para $\mathrm{C} 1$ e 0,9 e 1,0 para N1. Foram aplicados pelo método valores iniciais dos passos para os parâmetros $\mathrm{C} 1$ e N1 de $1.10^{-8}$ e $1.10^{-3}$, respectivamente.

O método testou as direções de busca ao iniciar a otimização de cada variável com uma estimativa, $e$, igual a $10 \%$ do valor total do passo.

As descargas de rede foram executadas conforme o procedimento padrão entre $3 \mathrm{~h} 22$ e 3 h58 do dia 16 de maio de 2003, com vazões da ordem de 5,0 a 6,0 L/s cada e permanência aproximada de 10 minutos em cada padrão. 
Tabela 5.9 - resultados com calibração sem vazamento pontual

\begin{tabular}{|c|c|c|c|c|c|c|c|c|}
\hline \multirow{2}{*}{ padrão } & \multirow{2}{*}{ nó/trecho } & \multirow{2}{*}{ C1 } & \multirow{2}{*}{ N1 } & \multirow{2}{*}{ FO } & obs & $\operatorname{sim}$ & \multicolumn{2}{|c|}{ desvios } \\
\hline & & & & & \multicolumn{2}{|c|}{$\mathrm{mH}_{2} \mathrm{O}, \mathrm{L} / \mathrm{s}$} & $\mathrm{mH}_{2} \mathrm{O}, \mathrm{L} / \mathrm{s}$ & $\%$ \\
\hline \multirow{5}{*}{ sem descarga } & nó 7 & \multirow{5}{*}{$3.65 \mathrm{E}-05$} & \multirow{5}{*}{0.9370} & \multirow{5}{*}{0.0075} & "55.71 & 52.42 & 3.29 & 5.90 \\
\hline & nó 41 & & & & 31.07 & 30.62 & 0.45 & 1.45 \\
\hline & nó 69 & & & & 53.04 & 52.38 & 0.66 & 1.25 \\
\hline & nó 87 & & & & 71.27 & 68.24 & 3.03 & 4.25 \\
\hline & trecho 141 & & & & 15.72 & 15.60 & 0.12 & 0.78 \\
\hline \multirow{5}{*}{ D22 } & $\begin{array}{ll}\text { nó } 7 \\
\end{array}$ & \multirow{5}{*}{ 3.88E-05 } & \multirow{5}{*}{0.9241} & \multirow{5}{*}{0.0036} & "51.02 & "46.96 & | & $\overline{77.95}$ \\
\hline & nó 41 & & & & 26.28 & 26.72 & -0.44 & -1.66 \\
\hline & nó 69 & & & & 49.16 & 49.37 & -0.21 & -0.43 \\
\hline & nó 87 & & & & 67.19 & 65.40 & 1.79 & 2.66 \\
\hline & trecho 141 & & & & 20.66 & 20.52 & 0.14 & 0.66 \\
\hline \multirow{5}{*}{ D22 + D96 } & nó 7 & \multirow{5}{*}{ 3.36E-05 } & \multirow{5}{*}{0.9564} & \multirow{5}{*}{0.0344} & 45.72 & 44.57 & 1.15 & 2.52 \\
\hline & nó 41 & & & & 21.18 & 22.56 & -1.38 & -6.54 \\
\hline & nó 69 & & & & 43.76 & 44.98 & -1.22 & -2.78 \\
\hline & nó 87 & & & & 60.87 & 53.62 & 7.25 & 11.91 \\
\hline & trecho 141 & & & & 25.71 & 24.25 & 1.46 & 5.69 \\
\hline \multirow{5}{*}{ D96 } & nó 7 & \multirow{5}{*}{ 4.90E-05 } & \multirow{5}{*}{0.9491} & \multirow{5}{*}{0.0134} & 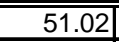 & 48.83 & 2.19 & 4.29 \\
\hline & nó 41 & & & & 26.57 & 26.95 & -0.38 & -1.45 \\
\hline & nó 69 & & & & 48.14 & 48.27 & $\mid-0.13$ & -0.26 \\
\hline & nó 87 & & & & 67.59 & 62.58 & 5.01 & 7.42 \\
\hline & trecho 141 & & & & 21.27 & 20.81 & 0.46 & 2.19 \\
\hline
\end{tabular}

Foram observados desvios considerados aceitáveis entre os valores observados e simulados, diferentemente das calibrações com vazamento.

A simulação sob acionamento da descarga D22 levou a valores melhores da Função Objetivo, em relação à situação sem descargas. Entretanto, houve piora da FO com duas descargas e com a descarga Alvorada.

\subsubsection{Simulações com vazamento pontual}

O modelo de calibração dos parâmetros C1 e N1 sob consumo noturno nulo foi aplicado aos valores observados na madrugada de 09/maio, quando ainda havia influência do vazamento localizado.

A busca direta univariada foi aplicada aos parâmetros com faixas de busca de $1.10^{-6}$ a $1.10^{-4}$ para $\mathrm{C} 1$ e 0,9 e 1,0 para N1. Os valores dos passos iniciais para os parâmetros $\mathrm{C} 1$ e N1 aplicados pelo método foram de $1.10^{-8}$ e $1.10^{-3}$, respectivamente. 
O método testou as direções de busca ao iniciar a otimização de cada variável com uma estimativa, $e$, igual a $10 \%$ do valor total do passo.

As descargas de rede foram executadas conforme o procedimento padrão entre $4 \mathrm{~h} 00$ e 4 h45 do dia 09 de maio de 2003, com vazões da ordem de 5,0 a 6,0 L/s cada e permanência de 15 minutos em cada padrão.

Tabela 5.10 - resultados com calibração com vazamento pontual

\begin{tabular}{|c|c|c|c|c|c|c|c|c|}
\hline \multirow{2}{*}{ padrão } & \multirow{2}{*}{ nó/trecho } & \multirow{2}{*}{ C1 } & \multirow{2}{*}{ N1 } & \multirow{2}{*}{ FO } & obs & sim & \multicolumn{2}{|c|}{ desvios } \\
\hline & & & & & \multicolumn{2}{|c|}{$\mathrm{mH}_{2} \mathrm{O}, \mathrm{L} / \mathrm{s}$} & $\mathrm{mH}_{2} \mathrm{O}, \mathrm{L} / \mathrm{s}$ & $\%$ \\
\hline \multirow{5}{*}{ sem descarga } & nó 7 & \multirow{5}{*}{ 5.06E-05 } & \multirow{5}{*}{0.9526} & \multirow{5}{*}{0.0488} & 48.68 & \begin{tabular}{|l|}
48.17 \\
\end{tabular} & 0.51 & 1.04 \\
\hline & nó 41 & & & & 17.51 & 26.29 & -8.78 & -50.13 \\
\hline & nó 69 & & & & 47.83 & 47.54 & 0.29 & 0.61 \\
\hline & nó 87 & & & & 66.27 & 61.67 & 4.60 & 6.94 \\
\hline & trecho 141 & & & & 21.79 & 21.40 & 0.39 & 1.79 \\
\hline \multirow{5}{*}{ D22 } & nó 7 & \multirow{5}{*}{ 5.06E-05 } & \multirow{5}{*}{0.9530} & \multirow{5}{*}{0.0550} & 42.35 & 43.32 & -0.97 & -2.28 \\
\hline & nó 41 & & & & 12.51 & 21.12 & -8.61 & -68.86 \\
\hline & nó 69 & & & & 43.05 & 43.60 & -0.55 & -1.28 \\
\hline & nó 87 & & & & 61.68 & 58.23 & 3.45 & 5.60 \\
\hline & trecho 141 & & & & 26.17 & 25.89 & 0.28 & 1.08 \\
\hline \multirow{5}{*}{ D22 + D96 } & nó 7 & \multirow{5}{*}{ 4.65E-05 } & \multirow{5}{*}{0.9735} & \multirow{5}{*}{0.1248} & |37.36 & 39.23 & $\mid-1.87$ & 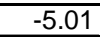 \\
\hline & nó 41 & & & & 9.35 & 17.15 & -7.80 & -83.43 \\
\hline & nó 69 & & & & 37.23 & 39.45 & -2.22 & -5.97 \\
\hline & nó 87 & & & & 54.75 & 46.57 & 8.18 & 14.94 \\
\hline & trecho 141 & & & & 30.61 & 27.71 & 2.90 & 9.48 \\
\hline \multirow{5}{*}{ D96 } & $\begin{array}{ll}\text { nó } 7 \\
\end{array}$ & \multirow{5}{*}{ 7.02E-05 } & \multirow{5}{*}{0.9650} & \multirow{5}{*}{0.0527} & | & | & | 0.10 & (0.24 \\
\hline & nó 41 & & & & 13.43 & 20.70 & -7.27 & -54.10 \\
\hline & nó 69 & & & & 41.31 & 41.34 & -0.03 & -0.07 \\
\hline & nó 87 & & & & 58.93 & 53.86 & 5.07 & 8.61 \\
\hline & trecho 141 & & & & 27.14 & 26.32 & 0.82 & 3.02 \\
\hline
\end{tabular}

Foram observados grandes desvios entre as pressões observadas e simuladas no nó 41, próximo ao vazamento em discussão, com parâmetros calibrados entre 5,0 e 7,0.10 $0^{-5}$ para $\mathrm{C} 1$ e 0,95 a 0,97 para N1.

Novamente, a simulação sob acionamento da descarga D22 levou a valores melhores da Função Objetivo que a situação sem descargas e piores com duas descargas e com a descarga Alvorada. 


\subsection{Simulações sob consumo diurno e vazamento dirigidos pela pressão}

\subsubsection{Simulações com Modelo I de demanda de referência de consumo}

O modelo de calibração dos parâmetros $\mathrm{C} 1$ e N1 sob demanda de consumo e vazamento dirigido pela pressão foi aplicado aos valores registrados durante três instantes do dia 13/maio, quando o vazamento já havia sido reparado.

A busca direta univariada foi aplicada com faixa reduzida aos parâmetros, com valores entre $1.10^{-6}$ a $1.10^{-4}$ para $\mathrm{C} 1$ e expoente $\mathrm{N} 1$ fixo em 0,9 , frente aos valores observados nas simulações noturnas. Os valores dos passos iniciais para os parâmetros C1 e N1 aplicados pelo método foram de $1.10^{-8}$ e $1.10^{-3}$, respectivamente, e a estimativa de passo $e$ permaneceu igual a $10 \%$ do valor total do passo.

No modelo I, as demandas de consumo de referência em cada nó foram obtidas com a média dos consumos hidrometrados no setor, devidamente corrigida pelo índice de submedição do parque de hidrômetros, proporcionalmente à área de influência de cada nó.

As quatro curvas de demanda de consumo dirigida pela pressão foram simuladas considerando uma pressão mínima de abastecimento de $5 \mathrm{mH}_{2} \mathrm{O}$ e uma pressão desejada ou de saturação, igual a $25 \mathrm{mH}_{2} \mathrm{O}$. 
Tabela 5.11 - resultados das calibrações com Modelo I

\begin{tabular}{|c|c|c|c|c|c|}
\hline horário & $\begin{array}{l}\text { valores calibrados } \\
\text { e desvios médios }\end{array}$ & $\begin{array}{l}\text { FUJIWARA } \\
\& \text { LI (1998) }\end{array}$ & $\begin{array}{c}\text { TABESH \& } \\
\text { KARIMZADEH }(2000)\end{array}$ & $\begin{array}{c}\text { EXPONENCIAL } \\
(2003)\end{array}$ & $\begin{array}{l}\text { SENOIDAL } \\
\text { (2003) }\end{array}$ \\
\hline \multirow{9}{*}{ 08h00 } & C $\mathrm{C} 1$ & $2.49 \mathrm{E}-05$ & 2.42E-05 & 3.27E-05 & $2.93 \mathrm{E}-05$ \\
\hline & $\mathrm{N} 1$ & 0.8698 & 0.8820 & 0.8870 & 0.8902 \\
\hline & $\mathrm{FO}$ & 0.0076 & 0.0077 & 0.0079 & 0.0078 \\
\hline & FT & 2.1903 & 2.1858 & 2.0871 & 2.1144 \\
\hline & P7 (\%) & 1.97 & 1.98 & 1.96 & 1.97 \\
\hline & P41 (\%) & -4.54 & -4.54 & -4.69 & -4.64 \\
\hline & P69 (\%) & -4.95 & -4.93 & -4.81 & -4.84 \\
\hline & P87 (\%) & 4.59 & 4.61 & 4.78 & 4.73 \\
\hline & Q141 (\%) & 0.27 & 0.19 & 0.03 & 0.08 \\
\hline \multirow{9}{*}{$12 \mathrm{~h} 00$} & $\mathrm{C} 1$ & 3.30E-05 & 2.92E-05 & 3.41E-05 & $2.75 \mathrm{E}-05$ \\
\hline & N1 & 0.8814 & 0.8870 & 0.8989 & 0.8897 \\
\hline & $\mathrm{FO}$ & 0.0268 & 0.0264 & 0.0286 & 0.0283 \\
\hline & $\mathrm{FT}$ & 2.6980 & 2.7172 & 2.7183 & 2.7778 \\
\hline & P7 (\%) & 3.45 & 3.46 & 3.35 & 3.37 \\
\hline & P41 (\%) & -14.15 & -13.86 & -15.18 & -15.03 \\
\hline & P69 (\%) & -6.35 & -6.39 & -6.07 & -6.24 \\
\hline & P87 (\%) & 9.10 & 9.01 & 9.52 & 9.42 \\
\hline & Q141 (\%) & 0.17 & 0.14 & 0.07 & 0.16 \\
\hline \multirow{9}{*}{$16 \mathrm{~h} 00$} & C1 & 2.30E-05 & 1.95E-05 & 2.97E-05 & 2.46E-05 \\
\hline & N1 & 0.8900 & 0.8890 & 0.8896 & 0.8941 \\
\hline & $\mathrm{FO}$ & 0.0156 & 0.0155 & 0.0160 & 0.0159 \\
\hline & FT & 2.3171 & 2.3507 & 2.2516 & 2.2880 \\
\hline & P7 (\%) & 7.12 & 7.12 & 7.10 & 7.11 \\
\hline & P41 (\%) & -4.49 & -4.47 & -4.74 & -4.63 \\
\hline & P69 (\%) & -2.38 & -2.42 & -2.27 & -2.32 \\
\hline & P87 (\%) & 6.53 & 6.50 & 6.72 & 6.65 \\
\hline & Q141 (\%) & 0.37 & 0.39 & 0.18 & 0.19 \\
\hline
\end{tabular}

O fator temporal de consumo FT calibrado apresentou variações entre os instantes simulados do dia, em analogia ao fator $k_{l}$ empregado na estimativa de vazões máximas da hora de maior consumo do dia.

Os valores dos parâmetros calibrados, $\mathrm{C} 1$ e N1, apresentaram a mesma ordem de grandeza que aqueles simulados sob consumo noturno nulo.

\subsubsection{Simulações com Modelo II de demanda de referência de consumo}

O modelo de calibração dos parâmetros $\mathrm{C} 1$ e N1 sob demanda de consumo e vazamento dirigido pela pressão foi aplicado ao Modelo II de estimativa de demanda de referência de consumo, dentro dos mesmos intervalos de busca e passos que os aplicados ao Modelo I.

As demandas de consumo de referência em cada nó foram obtidas com a média corrigida dos consumos hidrometrados dentro de cada nó. 
As quatro curvas de demanda de consumo dirigida pela pressão foram simuladas considerando uma pressão mínima de abastecimento de $5 \mathrm{mH}_{2} \mathrm{O}$ e uma pressão desejada ou de saturação, igual a $25 \mathrm{mH}_{2} \mathrm{O}$.

Tabela 5.12 - resultados das calibrações com Modelo II

\begin{tabular}{|c|c|c|c|c|c|}
\hline horário & $\begin{array}{l}\text { valores calibrados } \\
\text { e desvios médios }\end{array}$ & $\begin{array}{l}\text { FUJIWARA } \\
\& \text { LI (1998) } \\
\end{array}$ & $\begin{array}{c}\text { TABESH \& } \\
\text { KARIMZADEH (2000) }\end{array}$ & $\begin{array}{c}\text { EXPONENCIAL } \\
(2003)\end{array}$ & $\begin{array}{c}\text { SENOIDAL } \\
(2003) \\
\end{array}$ \\
\hline \multirow{9}{*}{$08 \mathrm{~h} 00$} & $\mathrm{C} 1$ & $2.72 \mathrm{E}-05$ & 2.72E-05 & 2.72E-05 & $2.78 \mathrm{E}-05$ \\
\hline & $\mathrm{N} 1$ & 0.9195 & 0.9211 & 0.9019 & 0.9003 \\
\hline & FO & 0.0159 & 0.0159 & 0.0161 & 0.0161 \\
\hline & $\mathrm{FT}$ & 2.0604 & 2.0549 & 2.1048 & 2.1052 \\
\hline & P7 (\%) & 1.73 & 1.73 & 1.73 & 1.73 \\
\hline & P41 (\%) & -6.29 & -6.29 & -6.26 & -6.26 \\
\hline & P69 (\%) & -4.07 & -4.06 & -4.11 & -4.11 \\
\hline & P87 (\%) & 8.12 & 8.11 & 8.16 & 8.16 \\
\hline & Q141 (\%) & 0.08 & 0.07 & 0.02 & 0.02 \\
\hline \multirow{9}{*}{$12 \mathrm{~h} 00$} & $\mathrm{C} 1$ & $2.95 \mathrm{E}-05$ & $2.75 \mathrm{E}-05$ & 2.80E-05 & $2.75 \mathrm{E}-05$ \\
\hline & $\mathrm{N} 1$ & 0.9507 & 0.9706 & 0.9077 & 0.8981 \\
\hline & $\mathrm{FO}$ & 0.0538 & 0.0534 & 0.0522 & 0.0531 \\
\hline & $\mathrm{FT}$ & 2.6500 & 2.6513 & 2.7607 & 2.7618 \\
\hline & P7 (\%) & 3.09 & 3.10 & 3.06 & 3.07 \\
\hline & P41 (\%) & -17.31 & -17.21 & -17.81 & -17.75 \\
\hline & P69 (\%) & -4.92 & -4.92 & -4.74 & -4.82 \\
\hline & P87 (\%) & 14.50 & 14.44 & 14.22 & 14.36 \\
\hline & Q141 (\%) & 0.07 & 0.04 & 0.18 & 0.16 \\
\hline \multirow{9}{*}{$16 \mathrm{~h} 00$} & C1 & "2.72E-05 & "2.72E-05 & 2.75E-05 & 2.75E-05 \\
\hline & N1 & 0.8974 & 0.9043 & 0.8957 & 0.9133 \\
\hline & $\mathrm{FO}$ & 0.0283 & 0.0283 & 0.0284 & 0.0284 \\
\hline & FT & 2.2407 & 2.2231 & 2.2266 & 2.2109 \\
\hline & P7 (\%) & 6.86 & 6.86 & 6.86 & 6.86 \\
\hline & P41 (\%) & -6.47 & -6.49 & -6.54 & -6.52 \\
\hline & P69 (\%) & -1.46 & -1.45 & -1.44 & -1.43 \\
\hline & P87 (\%) & 10.53 & 10.51 & 10.53 & 10.53 \\
\hline & Q141 (\%) & 0.08 & 0.12 & 0.13 & 0.06 \\
\hline
\end{tabular}

O fator temporal de consumo FT calibrado apresentou variações entre os instantes simulados do dia da mesma forma e proporções que as observadas no Modelo I.

Os desvios resultaram dentro de limites satisfatórios, inclusive os valores entre vazões simuladas sempre menores que simuladas e com desvios menores que $1 \%$.

Da mesma forma que no Modelo I, os desvios cresceram conforme houve incremento de $F T$, mantendo inclusive sinais e proporcionalidade. O mesmo foi observado com o acionamento das descargas de rede durante simulação sob consumo noturno nulo. 
Os pontos de incidência sobre as curvas de demanda definem $\rho$ e, por conseguinte, as vazões de consumo e vazamento. Com a sobreposição das curvas observou-se que os parâmetros variam proporcionalmente com a posição das curvas entre a pressão mínima e a desejada de operação. Assim, pela Equação da Continuidade, se há queda da demanda consumida deve haver crescimento da vazão de vazamento, através do aumento dos valores de $\mathrm{C} 1$ e N1.

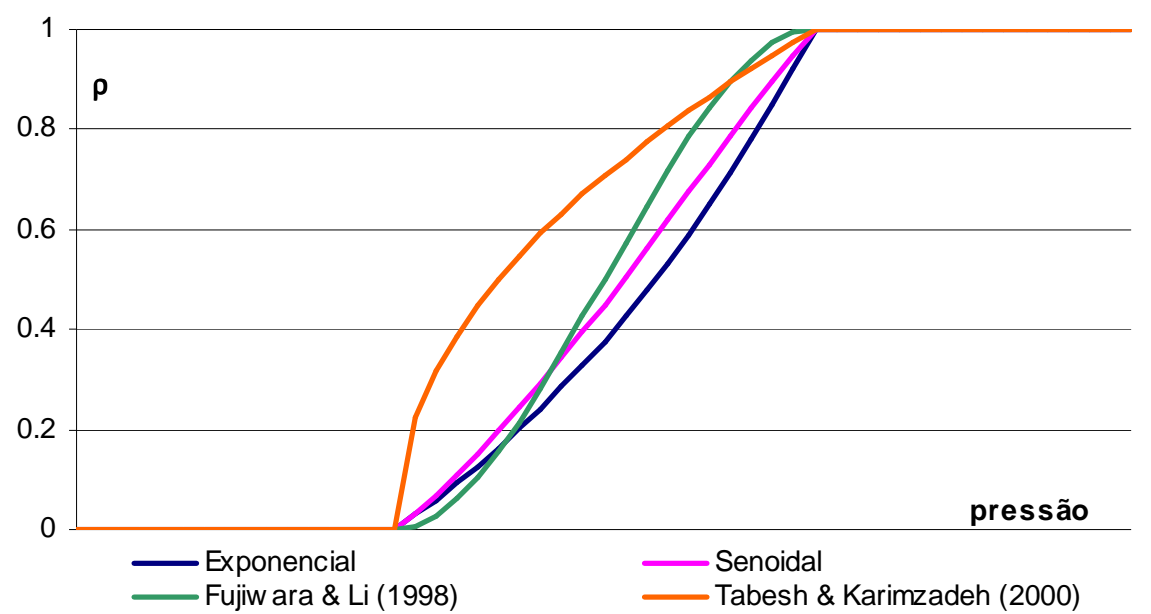

Figura 5.12 - sobreposição das curvas de demanda de consumo dirigida pela pressão

Da sobreposição dos gráficos observa-se que as simulações com a curva Exponencial proposta resultaram em valores mais altos de $\mathrm{C} 1$ e $\mathrm{N} 1$ para a maioria dos horários simulados. O inverso é verdadeiro se considerado que com a curva proposta por TABESH \& KARIMZADEH (2000), com $n=2$, ocorrem os menores valores de C1 e N1 na maioria das simulações.

\subsection{Avaliação das rugosidades adotadas no modelo hidráulico do setor}

Os desvios observados entre os valores simulados e coletados de pressões no setor durante as simulações diurnas sugerem avaliação dos valores das rugosidades absolutas 
adotadas no modelo hidráulico do setor Alvorada. É fato que a modelagem do consumo dirigido pela pressão incorre em erros, pelas suas imprevisíveis variações temporais, espaciais e conforme hábitos de consumo, mas uma avaliação dos valores das rugosidades é razoável já que esta variável não foi calibrada pelo modelo proposto.

Dentre as simulações diurnas realizadas foram observados os desvios mais significativos naquelas realizadas com o Modelo II de consumo de referência.

O horário em que foram observados os maiores desvios (12h00) é exatamente aquele onde foram observadas maiores vazões em função do consumo.

Dentre as curvas experimentadas, a exponencial proposta foi a que indicou valores dos parâmetros calibrados mais próximos daqueles obtidos com ausência de consumo.

Assim, as simulações diante destas condições (modelo II e curva exponencial ao meio-dia) foram repetidas com variações nos valores das rugosidades das tubulações. Em intervalos de $10 \%$, a análise de sensibilidade variou desde $80 \%$ a $120 \%$ dos valores originais adotados, conforme Tabela 5.13.

Tabela 5.13 - resultados obtidos com variação dos valores das rugosidades iniciais

\begin{tabular}{c|c|c|c|c|c}
\hline $\begin{array}{c}\text { valores calibrados } \\
\text { e desvios médios }\end{array}$ & $\mathbf{0 . 8} \boldsymbol{\varepsilon}$ & $\mathbf{0 . 9} \boldsymbol{\varepsilon}$ & $\mathbf{1 . 0} \boldsymbol{\varepsilon}$ & $\mathbf{1 . 1} \boldsymbol{\varepsilon}$ & $\mathbf{1 . 2} \boldsymbol{\varepsilon}$ \\
\hline \hline $\mathrm{C} 1$ & $2.06 \mathrm{E}-05$ & $2.96 \mathrm{E}-05$ & $2.80 \mathrm{E}-05$ & $2.76 \mathrm{E}-05$ & $2.75 \mathrm{E}-05$ \\
\hline $\mathrm{N} 1$ & 0.91 & 0.96 & 0.91 & 0.90 & 0.93 \\
\hline $\mathrm{FO}$ & 0.0484 & 0.0502 & 0.0522 & 0.0543 & 0.0559 \\
\hline $\mathrm{FT}$ & 2.8138 & 2.7140 & 2.7607 & 2.7809 & 2.7733 \\
\hline $\mathrm{P} 7(\%)$ & 3.02 & 3.04 & 3.06 & 3.08 & 3.09 \\
\hline $\mathrm{P} 41(\%)$ & -17.93 & -17.87 & -17.81 & -17.75 & -17.70 \\
\hline $\mathrm{P} 69(\%)$ & -5.03 & -4.75 & -4.74 & -4.66 & -4.55 \\
\hline $\mathrm{P} 87(\%)$ & 13.51 & 13.87 & 14.22 & 14.57 & 14.85 \\
\hline $\mathrm{Q} 141(\%)$ & 0.22 & 0.04 & 0.18 & 0.16 & 0.17 \\
\hline
\end{tabular}


Foram observadas alterações nos valores calibrados da Função Objetivo também, com tímida melhora destes valores com o decréscimo das rugosidades. Para o fator temporal calibrado, FT, não foram observadas tendências de comportamento.

Entretanto, entende-se que as rugosidades devem ser calibradas para o modelo hidráulico juntamente com as variáveis $\mathrm{C} 1$ e $\mathrm{N} 1$, de forma a assegurar simulações e parâmetros do modelo pressão-vazamento mais próximos da realidade. 


\section{CONCLUSÕES}

Os resultados observados em simulações a partir de valores calibrados sob consumo noturno nulo, descargas de rede, patamares de pressão e consumo diurno dirigido pela pressão permitem afirmar que os parâmetros C1 e N1 não são fixos, mas variam conforme o padrão hidráulico de operação da rede.

$\mathrm{O} \operatorname{par}(\mathrm{C} 1 ; \mathrm{N} 1)=\left(3,71 \times 10^{-5} ; 0,9601\right)$, calibrado ao considerar simultaneamente os quatro patamares promovidos, representa a rede estudada de forma mais próxima da realidade, uma vez que sua obtenção se valeu de todos os padrões hidráulicos experimentados com a redução de pressão. Entretanto, nas calibrações que consideraram isoladamente cada patamar promovido, observou-se redução pronunciada do expoente N1 com a redução de pressão, de forma que quanto menores as pressões de distribuição tanto menos dependentes desta variável serão os vazamentos.

O uso de descargas de rede com o objetivo de solicitar a rede de forma conhecida, durante testes sob consumo noturno nulo, pode melhorar os desvios de calibração, mas depende de estudos acerca dos tempos de propagação destas descargas e seus dispositivos de medição.

Desvios entre valores observados e simulados mais pronunciados foram notados em nós nas adjacências de vazamentos localizados. Nestas condições há piora da FO já que o vazamento é contabilizado, mas não é distribuído uniformemente conforme determina o modelo de GERMANOPOULOS \& JOWITT (1989). O modelo distribui os vazamentos e atende a Equação da Continuidade, mas os parâmetros, principalmente C1, devem assumir significado mais matemático que físico.

As simulações com demanda de consumo dirigida pela pressão sofrem influência de fatores como estimativa dos consumos de referência, curva utilizada de demanda 
dirigida pela pressão e do horário do dia. A existência de parâmetros C1 e N1 calibrados sob consumo noturno nulo pode auxiliar na escolha e validação de modelos que melhor se adaptem às condições da rede simulada.

Os desvios entre pressões observadas e simuladas, em calibrações diurnas, resultaram mais acentuados quanto maiores os consumos (valores mais altos do fator temporal FT calibrado), expondo as incertezas que regem a modelagem das demandas de consumo, inclusive para ambos os modelos de demanda de referência.

A redução dos valores da Função Objetivo, com a redução dos valores das rugosidades absolutas no modelo hidráulico do setor, aponta para a possibilidade de que simulações mais precisas podem ser obtidas caso $\mathcal{E}$ seja uma variável calibrada simultaneamente com C1 e N1.

Pode-se afirmar que há desgaste dos hidrômetros domiciliares com a idade e seus efeitos são fortemente sentidos - e nocivos - em vazões próximas à vazão mínima de funcionamento do hidrômetro.

As vazões típicas de consumo residencial implicam em fortes desvios negativos de medição, dado que os reservatórios domiciliares impõem forte amortecimento das vazões de entrada, reduzindo as vazões de trabalho para o limite inferior de medição justamente aquele que admite maiores desvios. Tais vazões também reforçam a hipótese de consumo noturno nulo. 


\section{REFERÊNCIAS BIBLIOGRÁFICAS}

ARREGUÍN-CORTES, F. I.; OCHOA-ALEJO, L. H. (1997). Evaluation of water losses in distribution networks. Journal of Water Resources Planning and Management, ASCE, v.123, n.5, p.284-291, setembro/outubro de 1997.

ASSOCIAÇÃO BRASILEIRA DE NORMAS TÉCNICAS (1996). NBR 8195: Hidrômetro taquimétrico para água fria até 15,0 m3/h de vazão nominal - Método de ensaio. Rio de Janeiro.

(1996). NBR 8009: Hidrômetro taquimétrico para água fria até $15,0 \mathrm{~m} 3 / \mathrm{h}$ de vazão nominal - Terminologia. Rio de Janeiro.

AMERICAN WATER WORKS ASSOCIATION (1990). Water audits and leak detection. AWWA Manual M36, First Edition, Leak Detection Committee - American Water Works Association, Denver, CO, USA.

(1999). Calibration guidelines for water distribuition system modeling. Proceedings of AWWA 1999 ImTech Conference, Engineering Computer Applications Committee - American Water Works Association, Denver, CO, USA.

BAPTISTA, M. B.; COELHO, M. M. L. P. (2002). Fundamentos de Engenharia Hidráulica. Editora UFMG, Coleção Ingenium, 440p. Belo Horizonte.

CALIMAN, R. (2002). Estudo das perdas por vazamento aplicado a setores da rede de abastecimento de água de São Carlos, SP. Dissertação de Mestrado, Escola de Engenharia de São Carlos, Universidade de São Paulo. Orientador: Profa. Dra. Luisa Fernanda Ribeiro Reis. 111p.

CARVALHO FILHO, S. M.; GARCIA, M.; BUONOMANO, V. (2000). Estudo para obtenção do índice de submedição em micromedição e índice de perdas. Artigo não publicado, SANASA Campinas, SP. 
CESARIO, A. L. (1980). Computer modeling programs: tools for model operations. Journal of the American Water Works Association, p.508-513, setembro de 1980.

CHANDAPILLAI, J. (1991). Realistic Simulations of Water Distribution System. Journal of Transportation Engineering, v.117, n.2, p.258-263, março/abril.

EGGENER, C. L.; POLKOWSKI, L. B. (1976). Network models and the impact of the modeling assumptions. Journal of the American Water Works Association, v.68, n.4, p.189-196, abril de 1976.

FOX, R. L. (1971). Optimization methods for engineering design. Capítulo 2. London, Addison.

FUJIWARA, O.; LI, J. (1998). Reliability Analysis of Water Distribution Networks in Consideration of Equity, Redistribution and Pressure-Dependent Demand. Water Resources Research, v.34, n.7, p.1843-1850, julho.

GERMANOPOULOS, G.; JOWITT, P. W. (1989). Leakage reduction by excess pressure minimization in a water supply network. Water Engineering Group, p.195-214, paper 9404, junho de 1989.

GUPTA, R.; BHAVE, P. R. (1996). Comparison of Methods for Predicting Deficient-Networks Performance. Journal of Water Resources Planning and Management, v.122, n.3, p.214-217, maio/julho.

JOWITT, P. W.; XU, C. (1990). Optimal valve control in water-distribution networks. Journal of Water Resources Planning and Management, ASCE, v.116, n.4, p.455-472, julho/agosto de 1990.

KHADAM, M. A.; SHAMMAS, N. K.; AL-FERAIHEEDI, Y. (1991). Water losses from municipal utilities and their impacts. Water International, v.16, p.254-261, agosto de 1991. 
KUROKAWA E.; BORNIA, A. C. (2002). Uma proposta para a utilização do controle estatístico do processo (CEP) através da "carta X" como uma ferramenta gerencial para a avaliação da vazão mínima noturna de um setor. Anais do seminário "Planejamento, projeto e operação de redes de abastecimento de água: estado da arte e questões avançadas”, João Pessoa, PB, junho de 2002.

LAMBERT, A. O. (2001). What do we know about pressure/leakage relationships in distribution systems? IWA Conference on System Approach to Leakage Control and Water Distrbution System Management, Czech Republic, maio de 2001.

LAMBERT, A. O.; BROWN, T. G.; TAKIZAWA, M.; WEIMER, D. (2000). A review of performance indicators for real losses from water supply systems. IWA, $A Q U A$, International Water Association, London, UK.

LAMBERT, A. O.; HIRNER, W. (2000). Losses from water supply systems: standard terminology and recommended performance measures. IWA, AQUA, International Water Association, London, UK, outubro de 2000.

LAMONT, P. A. (1981). Common pipe flow formulas compared with with the theory of roughness. Journal of the American Water Works Association, v.72, n.5, p.274-280, maio de 1981 .

MAGALHÃES, M. N.; LIMA, A. C. P. (2002). Noções de probabilidade e estatística. Editora da Universidade de São Paulo, $5^{\text {a }}$ edição, 391p., São Paulo.

MARTÍNEZ, F.; CONEJOS, P.; VERCHER, J. (1999). Developing an Integrated Model for Water Distribution Systems Considering both Distributed Leakage and Pressure-Dependent Demands. Proceedings of the $26^{\text {th }}$ ASCE Water Resources Planning and Management Division Conference, Tempe, Arizona, julho.

OBRADOVIC, D. (2000). Modeling of Demand and Losses in Real-Life Water Distribution Systems. Urban Water, v.2, n.2, p.131-139, junho. 
ORMSBEE, L. E.; LINGIREDDY, S. (1997). Calibrating hydraulic network models. Journal of the American Water Works Association, v.89, n.2, p.42-50, fevereiro de 1997.

RECH, A. L. (1999). Água, micromedição e perdas. $2^{\mathrm{a}}$ edição. Editora Scortecci, São Paulo, SP, Brasil.

REIS, L. F. R.; PORTO, R. M. (1992). Interpretação hidráulica do modelo Jowitt$\mathrm{Xu}$ de minimização de perdas por vazamento - partes I e II. Memórias do XV Congresso Latinoamericano de Hidráulica, Cartagena, p.449-459.

ROSSMAN, L. A. (2000). EPANET2 users manual. U. S. Environmental Protection Agency, Cincinnati, Ohio.

SANTOS, A. (2000). Estudo das perdas por vazamento aplicado a um setor da rede de abastecimento de água de São Carlos, SP. Dissertação de Mestrado, Escola de Engenharia de São Carlos, Universidade de São Paulo. Orientador: Profa. Dra. Luisa Fernanda Ribeiro Reis. 114p.

SILVA R. T. et al. (1998). Indicadores de perdas nos sistemas de abastecimento de água. PNCDA, Programa Nacional de Controle ao Despercício de Água, Procedimento A2. Ministério do Planejamento e Orçamento, Governo Federal, Brasília.

SILVA, M. N. (2001). Amostragem probabilística. Editora da Universidade de São Paulo, $2^{\mathrm{a}}$. edição, 120p., São Paulo.

SOARES, A. K. (2003). Calibração de modelos de redes de água para abastecimento considerando vazamentos e demandas dirigidas pela pressão. Dissertação de Mestrado, Escola de Engenharia de São Carlos, Universidade de São Paulo. Orientador: Profa. Dra. Luisa Fernanda Ribeiro Reis, 110p.

TABESH, M.; KARIMZADEH, A. (2000). Optimum Design of Reliable Distribution Systems Considering Pressure Dependency of Outflows. In SAVIC, D. A. 
(ed.); WALTERS, G. A. (ed.): Water Network Modeling for Optimal Design and Management, p.211-220, setembro.

TUCCIARELLI, T.; CRIMINISI, A.; TERMINI, D. (1999). Leak analysis in pipeline systems by means of optimal valve control. Journal of Hydraulic Engineering, ASCE, v.125, n.3, p.277-285, março de 1999.

VAIRAVAMOORTHY, K.; LUMBERS, J. (1998). Leakage reduction in water distribution systems: optimal valve control. Journal of Hydraulic Engineering, ASCE, v.124, n.11, p.1146-1154, novembro de 1998.

WAGNER, J. M.; SHAMIR, V.; MARKS, D.H. (1988). Water Distribution Reliability: Simulation Methods. Journal of Water Resources Planning and Management, v.114, n.3, p.276-294, maio de 1988.

WALSKI, T. M. (1984). Technique for calibrating network models. Journal of Water Resources Planning and Management, ASCE, v.109, n.4, p.360-372, outubro de 1983. 
ANEXO I

Setor de distribuição de água "Alvorada”, SEMAE Piracicaba

Malha hidráulica, arruamentos e referências. Escala 1:2000. 


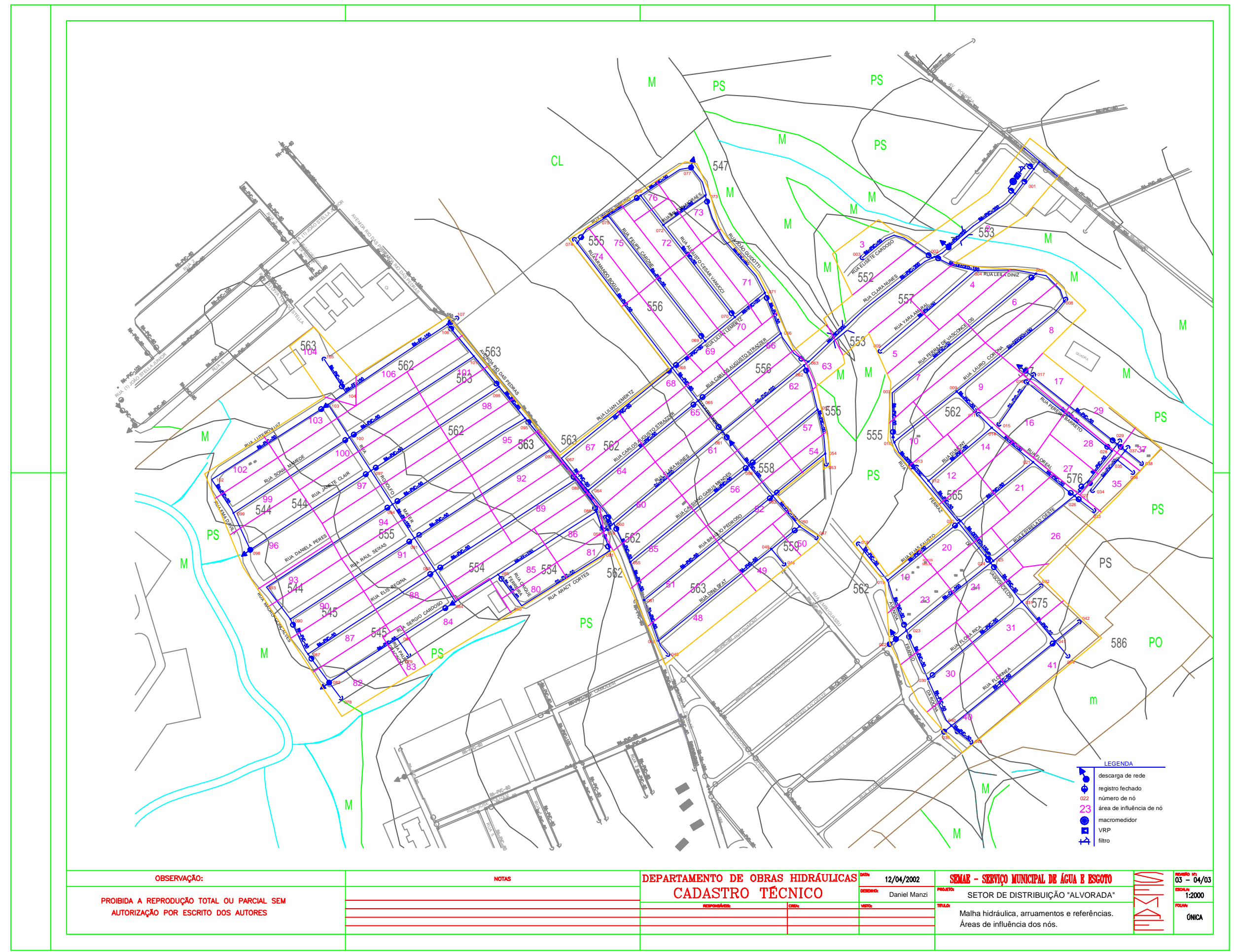

